\title{
PSPBuilder \\ Uma ferramenta de apoio \\ ao Processo de Software Pessoal
}

Djalma Domingos da Silva

Orientação: Prof. Dr. Paulo César Masiero

Dissertação apresentada ao Instituto de Ciências Matemáticas de São Carlos, Universidade de São Paulo, como parte dos requisitos para a obtenção do título de Mestre em Ciências - Área de Ciências de Computação e Matemática Computacional. 
À Eliana, Isadora e Ivan. 
Agradecimentos

Aos amigos da UNIRP pelo incentivo.

À Verdados Tecnologia da Informação por acreditar no meu trabalho.

Aos meus pais, Izolina e Manoel, e à minha familia, Eliana, Isadora e Ivan que, sem medir esforços nem sacrificios, contribuem de forma exemplar para a minha formação.

Ao Prof. Masiero, pela oportunidade, apoio e orientação. 


\section{Índice}

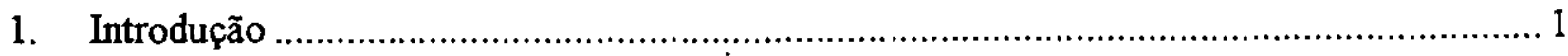

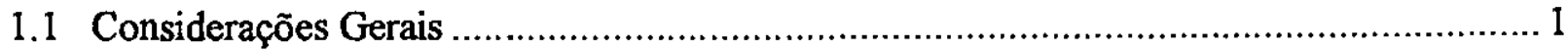

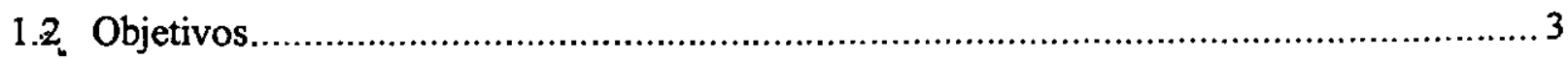

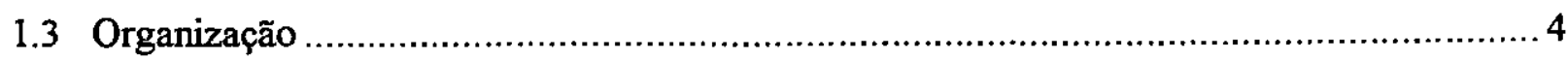

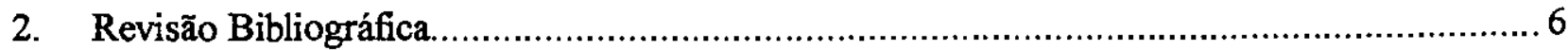

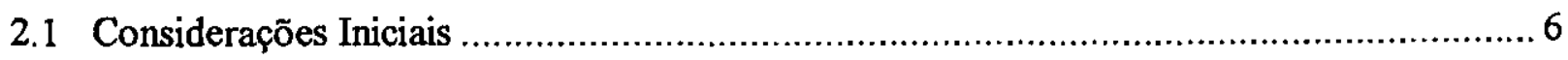

2.2 Introdução à Engenharia de Software ................................................................ 7

2.3 Noções de Qualidade....................................................................................... 7

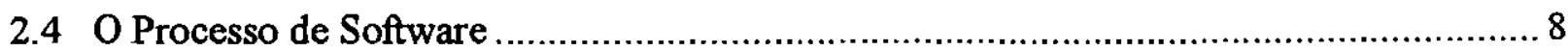

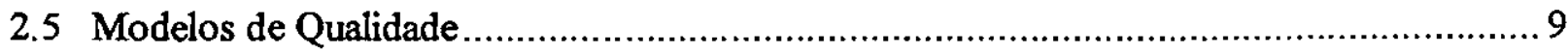

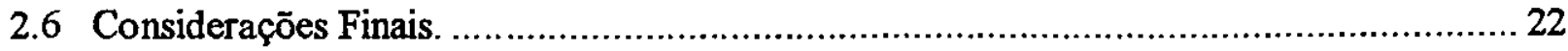

3. 0 Processo de Software Pessoal ...................................................................... 23

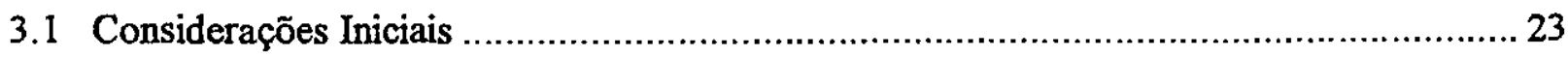

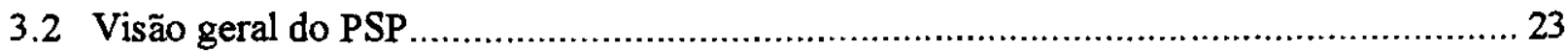

3.3 Relacionamento entre PSP e CMM.............................................................. 27

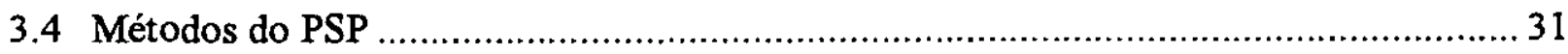

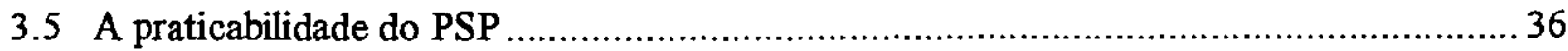

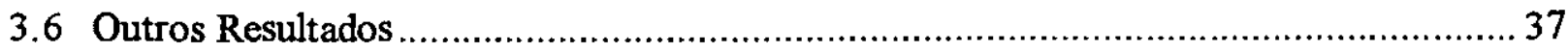

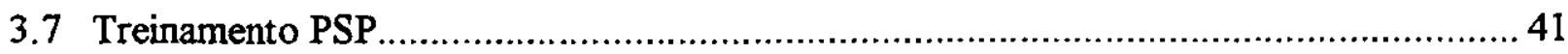

3.8 Adaptação do PSP para a linguagem Java.................................................... 43

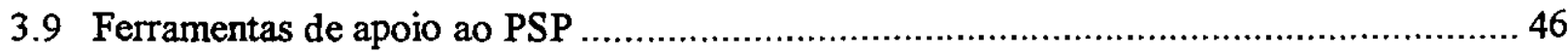

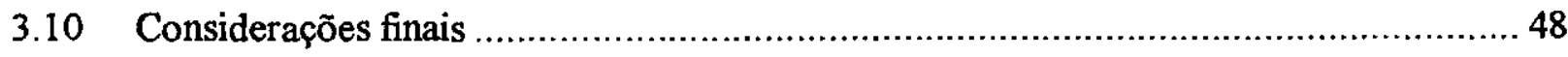

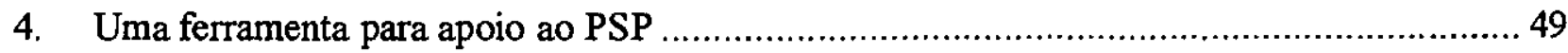

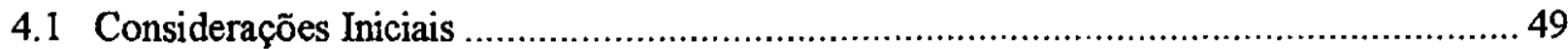

4.2 Especificação de uma Ferramenta Automatizada que apoie o PSP .............................. 50

4.3 Descrição Geral do PSPBuilder ....................................................................... 54

4.4 Modelo Conceitual de Dados do PSPBuilder ...................................................... 56

4.5 Avaliação da Qualidade das Ferramentas PSP mais Completas................................. 59 
4.6 Considerações Finais .

5. Adaptações do PSP para o Domínio de Sistemas de Informação e Exemplo de Uso do PSPBuilder 68

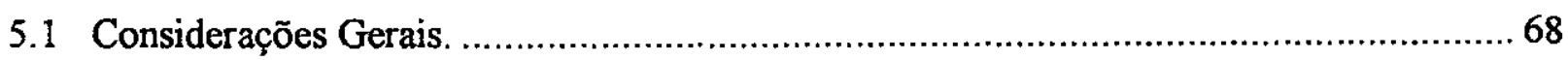

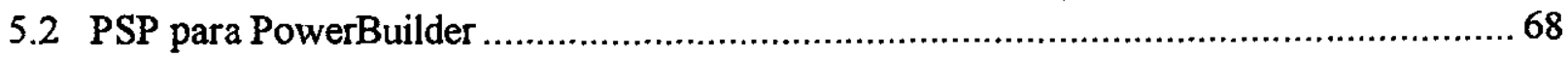

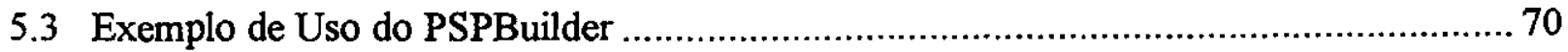

5.4 Implementações das demais etapas PSP no PSPBuilder ........................................78

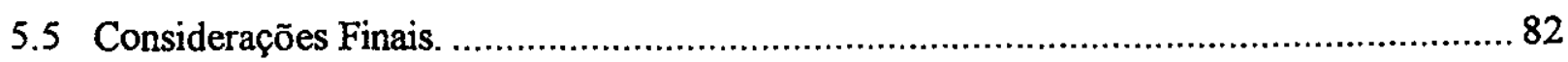

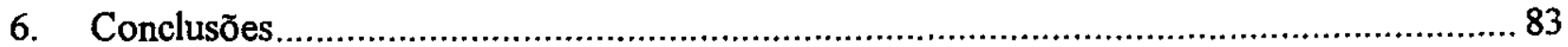

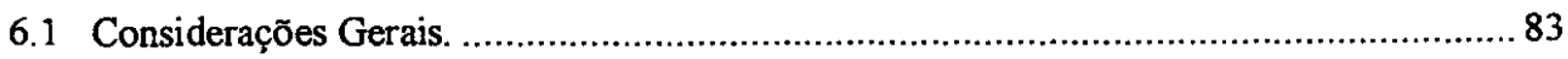

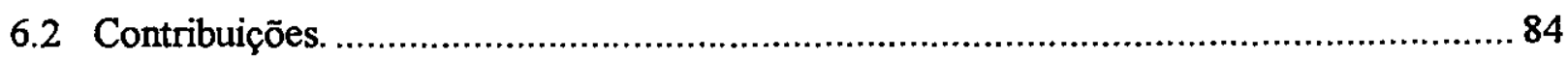

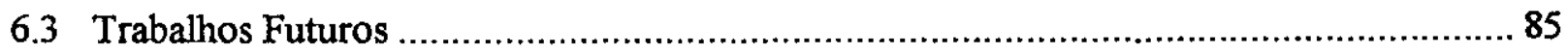

Anexo A - Tabelas da Versão PSP para PowerBuilder................................................89

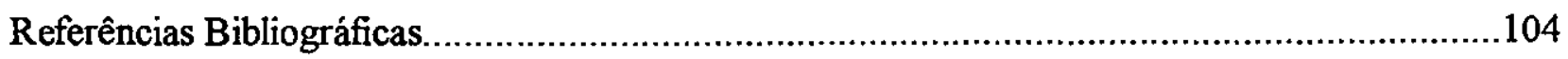

Apêndice 1 - Relatórios Finais dos Programas-Exercícios e Modelo Conceitual de Dados

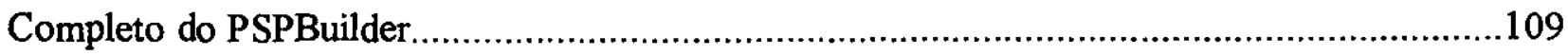




\section{Lista de Figuras}

Figura 1. Níveis de Maturidade do Processo de Software do Modelo SEI-CMM..................... 10

Figura 2. Avaliação do Processo de Software [Lig96] ....................................................... 15

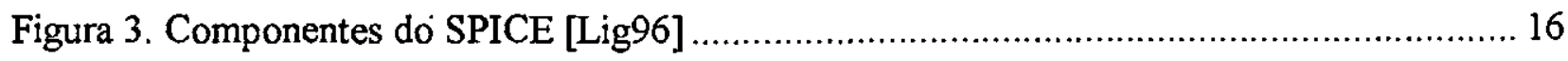

Figura 4. Evolução do P-CMM com as práticas-chave .......................................................... 19

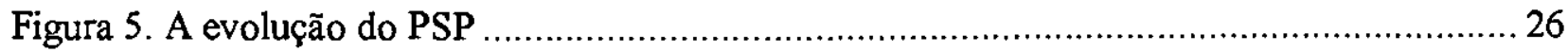

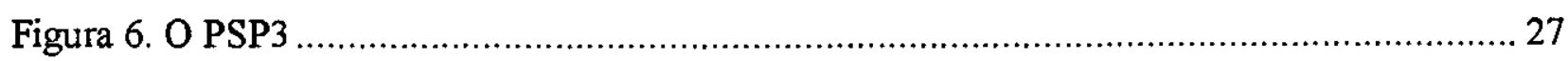

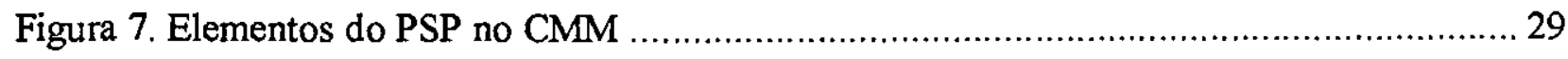

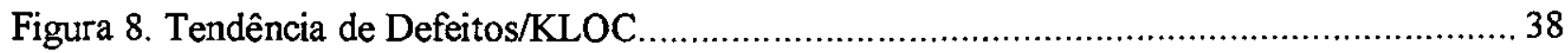

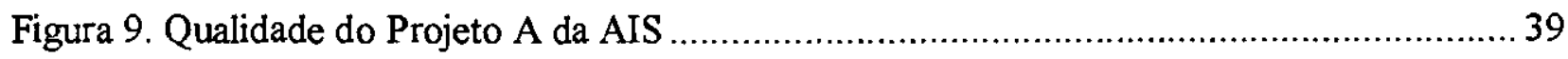

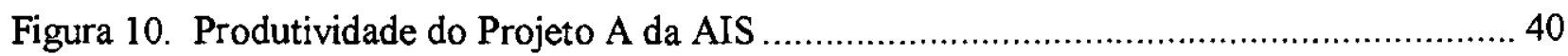

Figura 11. Defeitos dos Projetos da AIS........................................................................... 41

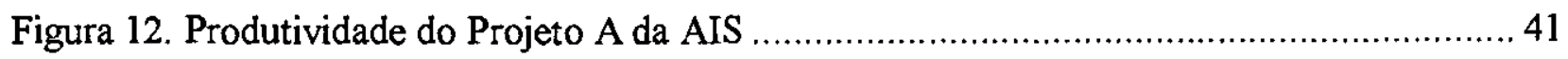

Figura 13. Modelo Conceitual de Dados da etapa PSP0 para o PSPBuilder ................................5 57

Figura 14. Notação do Modelo Conceitual de Dados ............................................................. 58

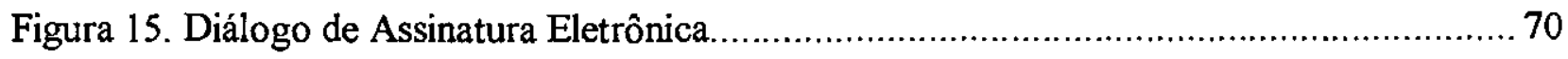

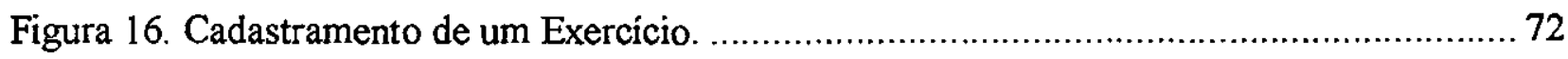

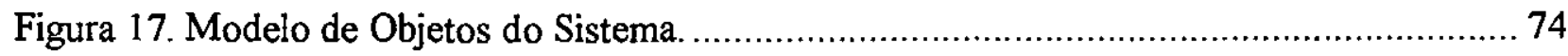

Figura 18. Grafo de Interação entre Objetos da Operação calculo_media_desviopadrao().......... 74

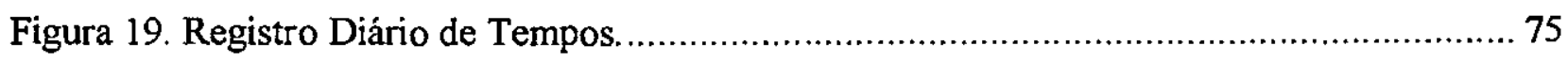

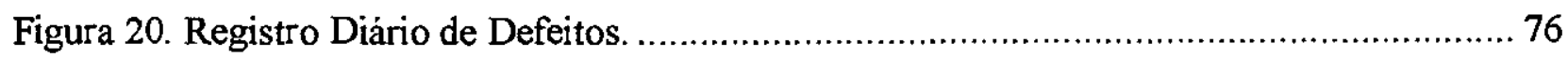

Figura 21. Resultado do Cálculo da Média e do Desvio Padrão do Programa_1A ....................... 77

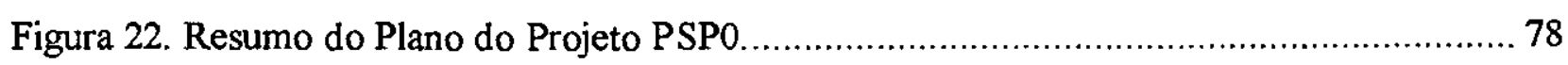

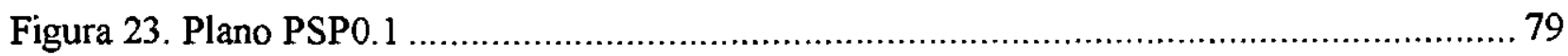

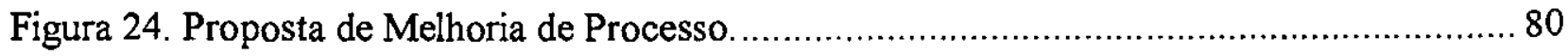

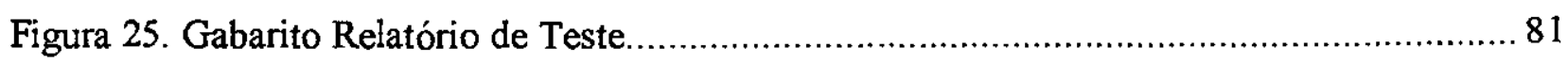

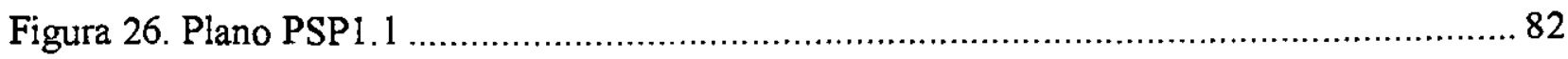




\section{Lista de Tabelas}

Tabela 1. Família ISO 9000 …..........................................................................

Tabela 2. Descrição resumida de cada componente do SPICE................................... 16

Tabela 3. Tipos de Defeito PSP ............................................................................... 33

Tabela 4. Redução de Defeitos.............................................................................. 36

Tabela 5. Melhoria de Produtividade........................................................................ $\quad 37$

Tabela 6. Resumo dos Projetos da AIS................................................................ 40

Tabela 7. Programas-Exercícios PSP Básicos - Série A ………............................. 42

Tabela 8. Relatórios-Exercícios PSP Básicos ........................................................... 42

Tabela 9. Programas-Exercícios PSP - Série B ………………............................... 43

Tabela 10. Avaliação da ferramenta PSPTool0.6 ..................................................... 62

Tabela 11. Avaliação da ferramenta PSP Studio....................................................... 63

Tabela 12. Avaliação da ferramenta PSPBuilder...................................................... 64

Tabela 13. Comparativo entre algumas ferramentas PSP......................................... 65

Tabela 14. Tamanhos de Objetos Pascal e Horas de Desenvolvimento...................... 73 


\section{Resumo}

O Processo de Software Pessoal (PSP), derivado do CMM (Capability Maturity Model), ambos do SEI (Software Engineering Institute), é uma nova abordagem que aplica conceitos importantes de engenharia de software em nivel individual para desenvolver software. O PSP faz uso de um conjunto de sete etapas seqüenciais e progressivas e cada uma dessas etapas possui um conjunto de roteiros, formulários e gabaritos associados, incluindo todos os elementos das etapas anteriores, com a adição de um ou mais elementos novos. O bom uso do PSP depende de treinamento apropriado, da adaptação do próprio processo ao contexto atual de desenvolvimento da organização (métodos e linguagens) e do apoio automatizado às atividades de coleta, manuseio e cálculos sobre os dados do processo, para permitir o aumento da produtividade, a redução de erros, a simplificação das tarefas rotineiras e a liberação dos engenheiros de software para as atividades de maior criatividade. Nesta dissertação faz-se uma revisão bibliográfica deste processo e de alguns importantes modelos de qualidade existentes atualmente; adapta-se o PSP para o Domínio de Sistemas de Informação (com PowerBuilder como linguagem de desenvolvimento); apresenta-se o PSPBuilder, uma ferramenta de apoio ao PSP concebida especialmente para esse mesmo Domínio de Sistemas de Informação e, finalmente, um exemplo de uso dessa ferramenta. A adaptação do PSP consiste principalmente na elaboração de alguns formulários cujos objetivos são: padronizar a codificação para garantir clareza e homogeneidade do código fonte produzido, definir a regra de contagem dessas linhas de código e apresentar um roteiro de revisão de código para garantir qualidade durante as fases de compilação e teste do software. O PSPBuilder apóia o PSP na maioria das etapas (com exceção do PSP3, Desenvolvimento Cíclico), integra-se ao PowerBuilder principalmente para contar objetos de um programa e as linhas de código desses objetos e permite adaptações do processo original, facilitando assim a personalização do processo individual. As características principais do PSPBuilder são: é desenvolvido em três camadas, tem arquitetura Cliente/Servidor (PowerBuilder no Cliente e Sybase SQL Anywhere no Servidor) e é orientado a eventos e também a objetos para o ambiente operacional Windows de 32 bits. No exemplo de uso do PSPBuilder demonstram-se ganhos de tempo e precisão dos resultados nas fases de Planejamento e Autópsia de desenvolvimento de software. 


\section{Abstract}

The Personal Software Process (PSP), derived from the CMM (Capability Maturity Model), both from the SEI (Software Engineering Institute), is a new approach that applies important concepts of software engineering to develop software at the personal level. The PSP uses a set of seven sequential and progressive steps and each step has a set of scripts, forms and templates associated, including all elements of the prior steps with addition of one or more new elements. Good use of PSP depends on suitable training, adaptability of the own process to the current context of the organization development (methods and languages) and of the automation support to the activities of gathering, handling and calculations of the process data, allowing to increase productivity, to decrease errors, to simplify routine tasks and to release software engineers to perform more creative activities. In this dissertation we revise the bibliography about this process and some important quality models existing nowadays; customize the Information Systems Domain (with PowerBuilder as its development language); present the PSPBuilder, a tool that supports the PSP and has been especialiy conceived for the Information Systems Domain, as well as an example of its use. The customization of PSP comprises the elaboration of some forms whose objectives are: to standardize the codification to guarantee clarity and homogeneity of the produced source code; to define rules for counting lines of code; and to present a checklist of code inspection to guarantee quality for the phases of software compilation and test. The PSPBuilder supports the main steps of PSP (with exception of PSP3, Cycled Development); integrates with PowerBuilder mainly to count program objects and the lines of code of these objects, and allows customization of the original process making the customization of the personal process easier. The main characteristics of PSPBuilder are: developed in three tiers, Client/Server architecture (Client with PowerBuilder and Server with Sybase SQL Anywhere), and event and object oriented for the 32 bits Windows operating system. The PSPBuilder example presented demonstrates gain of time and more accuracy of results at the phases of Planning and Postmortem of software development. 


\section{Introdução}

\subsection{Considerações Gerais}

Software é um imenso negócio mundial, que gera uma receita anual estimada em 120 bilhões de dólares e vem crescendo a taxas anuais de dois dígitos durante os últimos 30 anos. Esse fabuloso negócio pode ser desenvolvido por uma pessoa com um clone de PC (Personal Computer) ao custo de mil dólares ou menos, ou seja, é necessário muito pouco capital para começar a desenvolver software. $O$ maior custo desse negócio refere-se à mão-de-obra necessária. As pressões competitivas na indústria de software estão relacionadas a três fatores: salários, produtividade e qualidade [You97].

Fazendo-se uma análise comparativa entre os salários dos profissionais de software do Leste Europeu, América do Sul, África e maior parte da Ásia e dos profissionais de software das partes "avançadas" do planeta, tais como América do Norte, Europa Ocidental, Japão, Singapura, com o objetivo de produzir e exportar software, os primeiros salários são muito menores, em geral 5 a 10 vezes mais baixos, permitindo assim produzir software com um custo também substancialmente muito menor.

Com o uso de novas tecnologias, do tipo linguagens de quarta geração (L4G), que possibilitam às pequenas empresas ou equipes de 3 a 5 pessoas realizarem aquilo que costuma exigir 30 a 50 programadores $\mathrm{COBOL}$ para computadores de grande porte, ganha-se maior produtividade (produtividade 5 a 10 vezes mais elevada), mas isso não é tudo. Outros aspectos precisam ser levados em considerą̧ão: nos grandes projetos e conseqüentemente em grandes empresas desenvolvedoras de software um percentual enorme dos recursos do projeto é dedicado a reuniões, despesas de viagem, documentação e outras atividades que não a codificação em si; em pequenos projetos, pequenas equipes e empresas domésticas, predominam atividades de "puro" desenvolvimento de software. Conclui-se que maior produtividade ou profissionais mais produtivos se traduz em custos mais baixos, reduzindo-se desproporcionalmente o número de pessoas para a mesma quantidade de software a ser desenvolvida em um mesmo periodo de 
tempo, ou reduzindo-se o tempo de ciclo para o mesmo número de pessoas e a mesma quantidade de software a ser produzida.

Por outro lado, um produto de software com niveis de qualidade muito mais elevados (poucos defeitos por ponto por função ou por linha de código), boa documentação e lógica bem organizada certamente será fácil de ser mantido e modificado, criando um impacto substancial sobre o tempo de ciclo das atividades de manutenção.

$\mathrm{Na}$ realidade, ao se desenvolver software muitas dificuldades ainda estão presentes, do tipo: os usuários têm apenas uma vaga e pouco clara idéia de seus requisitos, o ambiente é tão volátil que os requisitos mudam a cada dia, a organização tem um processo de software que beira a anarquia, a aceitação e controle de qualidade são freqüentemente objeto de negociação após o fato, em vez de serem critérios predeterminados antes que o projeto seja iniciado. Esses problemas são de longa data. Há um pouco mais de uma década atrás, Brooks, em seu famoso artigo "No Silver Bullet" [Bro87] advertia sobre a ausência de uma bala de prata, ou seja, a ausência de desenvolvimento, seja em tecnologia ou em técnica gerencial, que por si só possa prometer melhoria de uma ordem de magnitude em produtividade, em confiabilidade e em simplicidade. Essa realidade ainda continua assombrando a área nos dias atuais.

Em resposta a essa advertência, vários autores, institutos e organizações passaram a sugerir algumas prováveis potenciais balas de prata cujo impacto combinado no desenvolvimento de software poderia ser muito significativo. Yourdon, em seu livro "Declínio e Queda dos Analistas e dos Programadores" [You95], faz uma avaliação sombria sobre o posicionamento competitivo da indústria norte-ameriacana de software no mercado mundial, sugere sete soluções mágicas: melhores linguagens de programação, melhores profissionais, ferramentas automatizadas, JAD (Joint Application Development - Desenvolvimento Conjunto de Aplicativos), RAD (Rapid Application Development - Desenvolvimento Rápido de Aplicativos), prototipação, técnicas estruturadas, engenharia de informação, tecnologia orientada a objeto, reutilização e restruturação de software. Harel, em seu artigo "Biting the Silver Bullet" [Har92], também responde ao artigo de Brooks propondo uma abordagem de modelagem "Vanilla", que juntamente com noções fortes de execução e geração de código, poderá ter um profundo impacto na essência do desenvolvimento de sistemas complexos. Em seu livro mais recente, "Ressurreição e Ascensão dos Analistas e dos Programadores", Yourdon apresenta uma visão otimista quanto ao futuro do programador americano e juntamente com essa nova visão, sugere algumas balas de 
prata: novos desenvolvimentos, oportunidades e também problemas na área de peopleware, melhoramento de processo, CASE (Computer Aided Software Engineering - Engenharia de Software Apoiado por Computador), tecnologia de objeto, reutilização de software e métricas[You97].

Dentre esses métodos, modelos e processos, foi selecionado o Personal Software Process (PSP) do Software Engineering Institute (SEI), por ser atualmente uma das grandes promessas em nível pessoal para ganhar produtividade juntamente com melhoria de qualidade. As ferramentas existentes que apoiam esse processo não passam de planilhas eletrônicas. Em recente evento em Curitiba [dTdS97], o instrutor Daniel Roy, professor regular do curso "train the trainer" do SEI para o PSP, recomendou o uso de ferramentas e confirmou a ausência, até aquele momento, de uma ferramenta especialmente desenvolvida que apoiasse os vários níveis de evolução do PSP e a existência de um enorme nicho de mercado em nível nacional (Brasil), 25.000 analistas de sistemas, e em nível internacional, um milhão de engenheiros de software só nos Estados Unidos.

\subsection{Objetivos}

Esta dissertação, que tem a finalidade de apresentar os resultados do trabalho proposto para a conclusão do programa de mestrado, tem como objetivos: fazer uma revisão bibliográfica de métodos, modelos e processos de software que avaliam e/ou melhoram os processos de desenvolvimento e manutenção de software em organizações de TI (Tecnologia de Informação), destacando-se dentre eles o Personal Software Process, proposta recente para melhoria do processo de desenvolvimento de software para individuos e selecionado para ser automatizado; descrever e avaliar, segundo os requisitos sugeridos pelo SEI, algumas ferramentas automatizadas existentes atualmente que apoiam o PSP, inclusive o PSPBuilder, tema principal desta dissertação; adaptar alguns formulários e procedimentos do PSP para atender a um domínio de sistemas de informação que faça uso da linguagem de desenvolvimento PowerBuilder; e aplicação e exemplos de uso do PSPBuilder ao desenvolver alguns dos programas-exercícios que compõem o treinamento PSP. 


\subsection{Organização}

Esta dissertação está organizada em seis capítulos. Os temas estão dispostos de forma a compor incrementalmente um contexto minimo para o perfeito entendimento do PSP, descrevendo assim os requisitos funcionais que a ferramenta PSPBuilder contempla.

O capítulo 2 apresenta uma introdução à Engenharia de Software, noções de qualidade de software, qualidade de processo e qualidade individual, noção de processo de software e uma descrição geral dos principais modelos de gerenciamento de processo de software mais comumente utilizados. Alguns dos modelos descritos são SEI-CMM - Capability Maturity Model, ISO9000 - International Organization for Standardization, SPICE - Software Process Improvement and Capability dEtermination e P-CMM - People-Capability Maturity Model. Esse capítulo contém considerações sobre como a maioria dos modelos apresentados estão voltados à organização e não ao indivíduo. Estas considerações são a motivação para o desenvolvimento do processo apresentado no capítulo 3.

O capítulo 3 descreve com algum detalhe o PSP - Personal Software Process, para gerenciamento individual de software, e algumas ferramentas automatizadas existentes atualmente que apoiam o PSP. Nesse capítulo também são apontados alguns pontos críticos encontrados no processo. Um estudo sobre o PSP foi realizado e algumas restrições são apresentadas, as quais são as motivações para a elaboração do PSPBuilder.

O capitulo 4 descreve em detalhes o PSPBuilder, uma versão definida inicialmente aọ processo de softwares desenvolvidos utilizando a ferramenta de desenvolvimento orientada a objetos PowerBuilder, os requisitos mais relevantes que uma ferramenta que automatize o PSP deve contemplar e a avaliação de qualidade dessas ferramentas apresentadas, inclusive o PSPBuilder.

As adaptações do PSP para atender um domínio de sistemas de informação e exemplos de uso do PSPBuilder ao implementar alguns dos programas-exercícios que fazem parte do treinamento PSP são apresentados no capítulo 5.

E, por último, o capítulo 6 sugere alguns trabalhos futuros e apresenta as conclusões deste trabalho. 
O Anexo A no final desta dissertação apresenta as tabelas adaptadas do PSP para o ambiente de desenvolvimento proposto anteriormente, um roteiro que atende a todas as etapas do processo PSP e o Apêndice 1, os relatórios produzidos durante a realização do programaexercício lA que compõe o treinamento PSP.

É importante notar que, por se tratar de um assunto muito recente, praticamente divulgado a partir da publicação do livro "A Discipline for Software Engineering" em 1995 [Hum95a], não existem muitas referências bibliográficas a respeito e a maioria é de autoria do próprio autor do processo, Humphrey. 


\section{Revisão Bibliográfica}

\subsection{Considerações Iniciais}

Após duas décadas de promessas não cumpridas sobre ganhos de produtividade e qualidade em aplicar novos métodos e tecnologias de software, as organizações industriais e governamentais estão percebendo que seus problemas fundamentais estão na incapacidade de gerenciar o processo de software [DoD87]. Os beneficios dos melhores métodos e ferramentas não podem ser percebidos na grande confusão de um projeto indisciplinado, caótico e desorganizado. Em muitas organizações os projetos estão muitas vezes excessivamente atrasados e excedendo em mais do que o dobro do orçamento previamente planejado [Sie90]. Em tais casos, a organização não está fornecendo a infra-estrutura e suporte necessários para ajudar os projetos a evitar tais problemas.

Pode ocorrer também que alguns projetos de software produzam excelentes resultados em organizações indisciplinadas. Geralmente isso deve-se mais aos esforços heróicos de uma equipe dedicada, do que à repetição de métodos comprovados adotados por uma organização com um processo de software maduro. $\mathrm{Na}$ ausência de um processo de software para toda a organização, repetir resultados depende totalmente de ter os mesmos indivíduos disponiveis para o próximo projeto. Sucesso que se apóia somente na disponibilidade dos mesmos indivíduos não fornece base para produtividade a longo prazo e melhoria de qualidade para toda uma organização. Melhoria contínua pode ocorrer somente por meio de esforço focado e contínuo para a construção de uma infra-estrutura de processo de práticas efetivas de engenharia e gerenciamento de software [PCCW93].

Dentro desse contexto, são apresentadas a seguir uma introdução à Engenharia de Software, noções de qualidade, uma definição de processo de software e uma descrição dos principais modelos de qualidade existentes atualmente. 


\subsection{Introdução à Engenharia de Software}

Com a evolução do software, os problemas associados ao desenvolvimento e à manutenção intensificaram-se e tornaram-se mais complexos. Podem ser citados como fatores que contribuíram para esse aumento de complexidade a falta de métodos para a construção de software, a capacitação inadequada dos desenvolvedores, a manutenção dos programas ameaçada por projetos ruins e recursos inadequados, a construção de hardware mais poderoso exigindo do software extrair todo o seu potencial, estimativas de prazos e custos imprecisas, baixa produtividade dos profissionais desenvolvedores de softwares e qualidade inadequada de software. Em resposta a esses problemas, a Engenharia de Software se propõe a fornecer métodos e práticas para resolvê-los [Pre95a].

A Engenharia de Software abrange um conjunto de três elementos fundamentais: métodos, ferramentas e procedimentos [Pre95a]. Os métodos são os modelos para a construção de software, as ferramentas fornecem apoio automatizado ou semi-automatizado aos métodos e os procedimentos definem a seqüência de métodos a serem aplicados, os produtos a serem entregues, os controles que ajudam a assegurar a qualidade e a coordenar mudanças e os marcos de referência que possibilitam aos gerentes de software avaliar o progresso durante a construção do software. Esses três componentes fornecem ao desenvolvedor uma estrutura básica para controlar e gerenciar o processo de desenvolvimento do software e para construir software de qualidade de forma eficiente.

\subsection{Noções de Qualidade}

A qualidade na Engenharia de Software é composta de três aspectos: qualidade do produto, qualidade do processo de desenvolvimento e qualidade do time de desenvolvimento.

A qualidade de software consiste num conjunto mínimo de requisitos exigidos do software, que correspondem a fatores internos e externos ao software. Com os requisitos definidos, o desenvolvedor de software conhece quantitativamente que nível de qualidade deseja alcançar no seu software e precisa estruturar métodos e técnicas para garantir e controlar esta qualidade desejada [And96,NBR94,ISO94]. 
A tarefa de desenvolver software com um certo grau de complexidade, com determinada quantidade de recursos envolvidos, exigindo altos padrões de qualidade e um prazo e orçamento a cumprir exige um processo muito bem definido, sem o qual corre-se o risco de provocar um completo caos. Os processos de software não são fixos nem rotineiros; variam de organização para organização, e até mesmo de projeto para projeto dentro de uma mesma organização. Por essa razão não é simples defini-los a contento. Contudo, modelos bastante abstratos estão disponíveis na literatura [PCCW93,ISO96a,ISO96b,Lig96] e fornecem uma estrutura básica para, a partir deles, definir o próprio processo de software. Uma vez definido o processo, há a necessidade de garantir que este seja seguido e executado por toda a organização. Para isso é necessário disciplina do time de desenvolvimento para seguir os padrões de qualidade em cada fase, na supervisão e no acompanhamento do processo. Somente assim a qualidade de todo processo de software é garantida.

Inúmeros fatores influenciam a qualidade individual e a qualidade do serviço oferecido por um indivíduo, tornando assim a sua avaliação muito complexa. Podem ser citados alguns desses fatores: de ordem psicológica, financeira, emocional, estado de saúde, satisfação profissional, formaçăo profissional, etc. Selecionando apenas alguns fatores tais como erros cometidos, tempo efetivamente consumido de programação, consumo de homens/hora e outros fatores mensuráveis, pode-se avaliar o código desenvolvido pelo indivíduo e assim avaliar a qualidade do software produzido. Todos esses fatores são úteis quando se deseja avaliar a relação custo versus beneficio do processo de desenvolvimento de software.

\subsection{O Processo de Software}

O desenvolvimento de software alcançou um nível tal de complexidade que os métodos artesanais de construção não mais satisfazem os requisitos organizacionais e operacionais exigidos. Para ter um perfeito controle e uma gerência eficaz do desenvolvimento de software é preciso ter um processo de software muito bem definido.

O processo de software corresponde a todas as atividades realizadas durante as fases do ciclo de vida do software. É por intermédio do controle de cada uma dessas atividades que se 
obtém um completo domínio, uma gerência eficaz e um planejamento adequado das ações a serem tomadas durante todo o processo de desenvolvimento.

\subsection{Modelos de Qualidade}

A crise da qualidade do software, caracterizada pela falta de planejamento e de recursos para controle e garantia da qualidade dos softwares, obrigou as organizações desenvolvedoras de software a priorizarem investimentos em mecanismos de qualidade.

Com o surgimento de grupos de pesquisa, institutos e organizações voltadas exclusivamente para o estudo dos processos de qualidade, surgiram vários modelos e técnicas fornecendo um apoio à engenharia de software nesta direção. Alguns destes modelos são descritos a seguir.

\subsubsection{SEI-CMM}

O modelo de maturidade do processo de software proposto pelo Software Engineering Institute (SEI), também chamado de modelo de maturidade de capacidade CMM (Capability Maturity Model) é um processo que mede a evolução baseado em níveis de maturidade com metas a serem alcançadas a cada nível [PCCW93]. Esse modelo é ilustrado na Figura 1.

Cada um dos cinco níveis de maturidade possui um conjunto bem definido de objetivos que, quando satisfeitos, estabilizam um dos componentes do processo de desenvolvimento do software. Alcançando cada nível de maturidade estabelecido no processo de desenvolvimento do software, está-se melhorando o processo de capacitação da organização como um todo. As características da organização que se enquadram em cada um desses níveis de maturidade e as ações-chave para avançar para o próximo nivel são: 


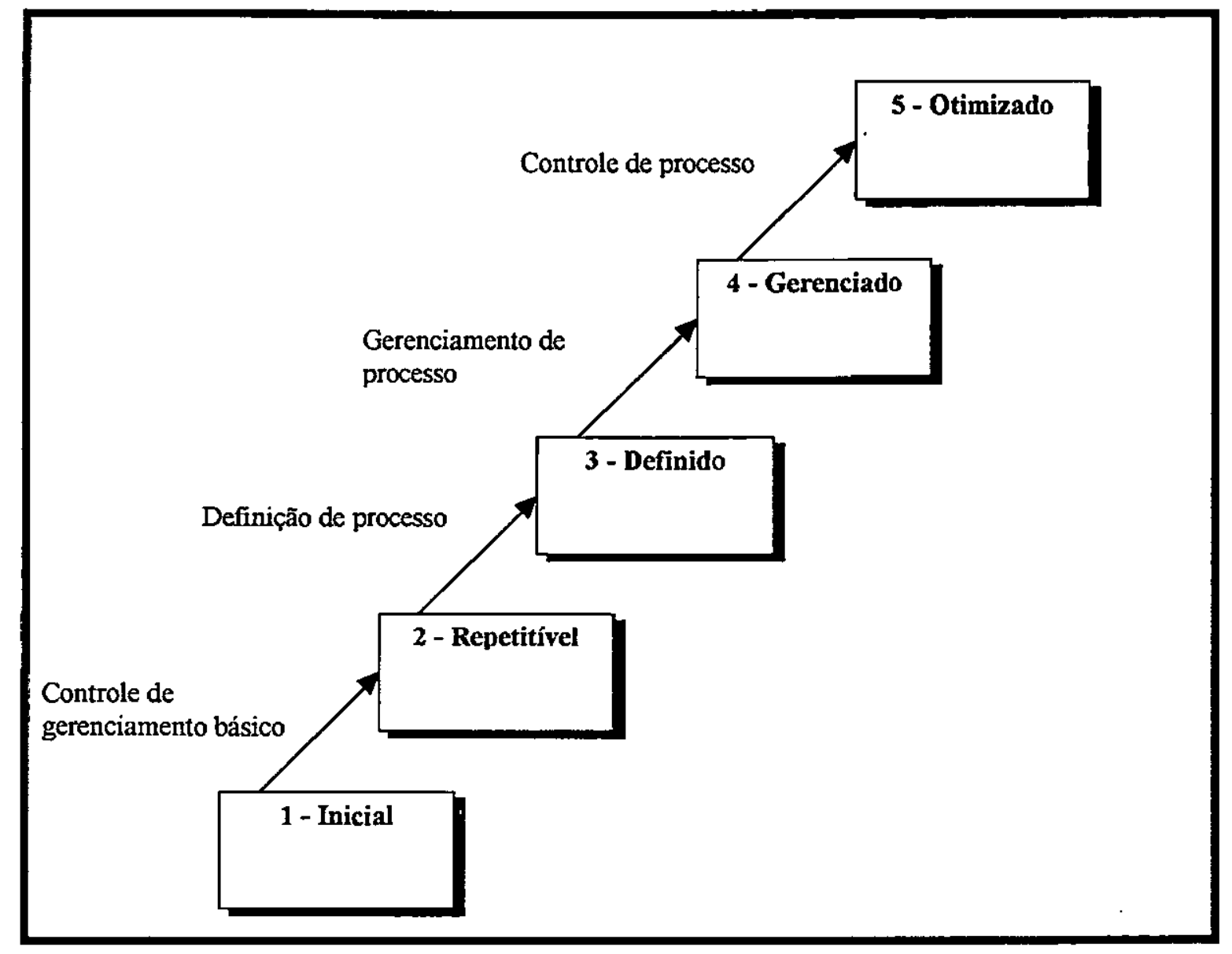

Figura 1. Níveis de Maturidade do Processo de Software do Modelo SEI-CMM

Inicial. O processo de software é caracterizado como "ad hoc" ou desorganizado ou também, ocasionalmente, caótico. Poucos processos são definidos e o sucesso depende do esforço individual dos membros da equipe de desenvolvimento. Há pouca formalização e ferramentas são informalmente aplicadas no processo. Neste nível, quando a organização apresenta um processo, ele é instável e imprevisivel, pois muda constantemente com a urgência dos prazos de entrega do software. Em tempos de crise, as fases do projeto de desenvolvimento e o planejamento são abandonados e o ciclo de vida do software se resume na implementação e teste. As ações-chave para avançar o nível Repetitível consistem em iniciar rigoroso gerenciamento do projeto, rigorosa supervisão do gerenciamento e controle de qualidade.

Repetitível. Processos básicos para gerenciamento de projeto para rastrear custo, escalonamento e funcionalidade estão implementados. A necessária disciplina de processo está presente para repetir sucessos anteriores em projetos com aplicações similares. Um processo 
estável é alcançado com nivel de repetição controlado estatisticamente. Dessa maneira, o processo está disciplinado. As ações-chave para avançar para o nível Definido são: estabelecer um grupo de processo, estabelecer uma arquitetura de processo de desenvolvimento de software e introduzir métodos e tecnologias de engenharia de software.

Definido. O processo de software para as atividades de gerenciamento e engenharia é documentado, padronizado e integrado em um processo de software padrão para a organização. Todos os projetos usam um processo padrão da organização aprovado e moldado para desenvolvimento e manutenção de software. É estabelecida a base para um progresso maior e continuado. Apesar de seguir o CMM, a organização é capaz de identificar o seu próprio processo de software, o qual possui características próprias do projeto que está sendo desenvolvido. As ações-chave são: estabelecer um conjunto básico de gerenciamentos de processo para identificar os parâmetros de qualidade e custo, estabelecer um banco de dados de processo, coletar e manter dados de processos, avaliar a qualidade relativa de cada produto e informar a supervisão.

Gerenciado. Medições detalhadas e abrangentes do processo de software e qualidade do produto são coletadas. Há melhorias substanciais da qualidade do produto. Ambos, o processo de software e os produtos, são quantitativamente compreendidos e controlados. Assim, a organização pode definir qualitativamente quais objetivos pretende alcançar, tanto do processo quanto do produto. $\mathrm{O}$ processo, nesse nivel, pode ser considerado previsível, pois a organização consegue medir os seus limites e, com isto, melhor estimar e planejar suas ações. Apoio para coletar automaticamente os dados do processo e usá-los para analisar e modificar o processo são algumas das ações-chave para avançar para o próximo nível de maturidade, o Otimizado.

Otimizado. Melhorias significativas e contínuas em termos de qualidade e quantidade no processo de desenvolvimento do software estão sendo realizadas. De posse dos dados obtidos durante os seus projetos e o uso de idéias inovadoras e tecnologias emergentes, a organização pode melhorar e ampliar os seus limites, otimizando seus objetivos em relação às suas potencialidades. A ação-chave consiste em buscar continuamente a melhoria e a otimização do processo.

Cada nivel de maturidade, exceto o primeiro, o Inicial, é composto por Áreas-Chave do Processo ACP (Key Process Areas) que indicam as áreas na organização que devem ter seus processos melhorados. Cada ACP é descrita por meio de práticas-chave (Key Practices), que 
descrevem especificamente quais atividades devem ser melhoradas. Algumas dessas ACPs com as suas respectivas práticas-chave, são descritas detalhadamente no capítulo 3 , o Processo de Software Pessoal.

$\mathrm{Na}$ reapresentação do curso "Introduction to the Capability Maturity Model" ministrado no próprio SEI da Universidade de Carnegie Mellon, em Pittsburgh, USA, com o título Gestão da Qualidade no Desenvolvimento de Software: O Modelo CMM/SEI, realizado durante o X Simpósio Brasileiro de Engenharia de Software na Universidade Federal de São Carlos, SP, no período de 15 a 18 de outubro de 1996 [dTdS96], a conclusão do instrutor é que o CMM não resolve todos os problemas de engenharia de software, além de que está totalmente focado no processo e não nas pessoas envolvidas no desenvolvimento de software, o peopleware. O CMM também não cobre quais técnicas utilizar em cada fase ou em cada nível de maturidade. Ele define - as metas a alcançar, mas nada diz a respeito de como alcançá-las. Fornece apenas uma estrutura conceitual.

\subsubsection{ISO 9000}

A série de padrões ISO9000 foi desenvolvida pelo International Organization for Standardization (ISO), federação mundial de grupos de padrões nacionais de aproximadamente cem países, um de cada país. A ISO é uma entidade não-governamental fundada em 1947, cuja missão é promover o desenvolvimento da padronização e das atividades relacionadas no mundo com a criação de padrões. A sua visão é facilitar a troca internacional de produtos e serviços, e desenvolver cooperação nas esferas das atividades intelectual, científica, tecnológica e econômica. O trabalho da ISO resulta em acordos internacionais que são publicados como Padrões Internacionais. O escopo da ISO não está limitado a qualquer ramo em particular; cobrindo todos os campos de padronização, exceto o de engenharia elétrica e eletrônica, que é de responsabilidade do IEC, International Electrotechnical Commission, criada em 1906. O trabalho no campo da tecnologia da informação é cumprido pelo comitê técnico ISO/IEC [ISO96a].

Os padrões ISO 9000 especificam os requisitos de qualidade de sistemas para serem usados quando um contrato entre duas partes requer a demonstração da capacidade do formecedor para projetar e fornecer um produto. As duas partes poderiam ser um cliente externo $\mathrm{e}$ 
um fornecedor, ou ambos poderiam ser internos, tal como os grupos de marketing e de engenharia de uma mesma companhia.

O padrão ISO 9001, padrão da série ISO 9000 que trata do desenvolvimento e manutenção de software, identifica os requisitos mínimos para garantia de qualidade de sistemas. As organizações utilizam esse padrão quando elas precisam garantir que o fornecimento está em conformidade com os requisitos especificados durante os diversos estágios do desenvolvimento do software. O padrão ISO 9000-3 fornece orientações para a aplicação do ISO 9001 ao software, ou seja, define um padrão para desenvolvimento, fornecimento e manutenção de software. A Tabela 1 a seguir possui a descrição resumida de alguns padrōes que constituem a família ISO 9000 [ISO96b].

A premissa fundamental do ISO 9001 é que as organizações deveriam documentar todos os processos importantes e verificar a qualidade em todas as atividades, seja na entrega do produto ou no controle de qualidade. O ISO 9001 requer uma documentação que contém instruções ou orientações sobre o que deveria ser feito ou como deveria ser feito.

A maior diferença entre os modelos CMM e ISO 9001 é: o ISO 9001 determina somente o conjunto mínimo de requisitos para um sistema de qualidade, enquanto que o modelo CMM visa a melhoria contínua da qualidade do processo. Outra diferença é que o CMM se concentra especificamente no software enquanto que ISO 9001 tem um escopo muito mais abrangente que compreende hardware, software, materiais e serviços.

Uma organização com o certificado ISO 9001 deveria ser classificada no modelo CMM como nível 3 ou até mesmo nível 4, mas existem casos que foram avaliadas como nível 1. 0 maior motivo para esta discrepância é o alto nível de abstração com que é definido o padrão ISO 9001, causando diferentes interpretações por parte dos auditores [Pau95].

A conversão CMM para ISO 9001 não é bidirecional. CMM, apesar de conceitual, utiliza dados mais concretos que as definições abstratas do ISO 9001 , possibilitando que uma organização no nível 3 do CMM obtenha com certeza o certificado ISO 9001, mas o contrário nem sempre é verdadeiro [Pau95]. 
Tabela 1. Família ISO 9000.

\begin{tabular}{|c|c|c|}
\hline Padrão & Ano & Descrição \\
\hline ISO $9000-1$ & 1994 & $\begin{array}{l}\text { Padrão para garantia e gerenciamento da qualidade - Parte 1: uso } \\
\text { e seleção. }\end{array}$ \\
\hline ISO $9000-2$ & 1993 & $\begin{array}{l}\text { Padrão para garantia e gerenciamento da qualidade - Parte 2: } \\
\text { linhas gerais para aplicação de ISO } 9001 \text {, ISO } 9002 \text { e ISO } 9003 \text {. }\end{array}$ \\
\hline ISO $9000-3$ & 1991 & $\begin{array}{l}\text { Padrão para garantia e gerenciamento da qualidade - Parte 3: } \\
\text { aplicação de ISO } 9001 \text { ao desenvolvimento, fornecimento e } \\
\text { manutenção de software. }\end{array}$ \\
\hline ISO $9000-4$ & 1993 & $\begin{array}{l}\text { Padrão para garantia e gerenciamento da qualidade - Parte 4: } \\
\text { confiabilidade do gerenciamento. }\end{array}$ \\
\hline ISO 900I & 1994 & $\begin{array}{l}\text { Modelo para garantia de qualidade em projeto, desenvolvimento, } \\
\text { produção, instalação e prestação de serviço. }\end{array}$ \\
\hline ISO 9002 & 1994 & $\begin{array}{l}\text { Modelo para garantia de qualidade em produção, instalação e } \\
\text { prestação de serviço. }\end{array}$ \\
\hline ISO 9003 & 1993 & Modelo para garantia de qualidade em inspeção final e teste. \\
\hline ISO 10011-1 & 1990 & $\begin{array}{l}\text { Guia de orientação para auditoria em sistemas de qualidade, } \\
\text { Parte 1: auditoria. }\end{array}$ \\
\hline ISO $10011-2$ & 1991 & $\begin{array}{l}\text { Guia de orientação para auditoria em sistemas de qualidade. Parte } \\
\text { 2: critérios de qualificação para auditores de sistemas de qualidade. }\end{array}$ \\
\hline ISO $10011-3$ & 1991 & $\begin{array}{l}\text { Guia de orientação para auditoria em sistemas de qualidade. } \\
\text { Parte 3: gerenciamento de programas de auditoria. }\end{array}$ \\
\hline ISO 10012-1 & 1992 & $\begin{array}{l}\text { Requisitos de garantia de qualidade para equipamentos de } \\
\text { medição. Parte 1: sistema de confirmação de medidas para } \\
\text { equipamentos de medição. }\end{array}$ \\
\hline ISO 10013 & - & $\begin{array}{l}\text { Guia de orientação para desenvolvimento de manuais de } \\
\text { qualidade. }\end{array}$ \\
\hline ISO/TR 13425 & - & $\begin{array}{l}\text { Guia de orientação para seleção de métodos estatísticos na } \\
\text { padronização e especificação. }\end{array}$ \\
\hline ISO 8402 & 1994 & Vocabulário para gerenciamento e garantia de qualidade. \\
\hline
\end{tabular}

\subsubsection{SPICE}

O SPICE - Software Process Improvement \& Capability dEtermination, é um projeto da ISO/IEC JTC1/SC7/WG10 (International Organization for Standardisation / International Electrotechnical Comission Joint Technical Commitee / Software Engineering / Process Assessment) e desenvolve um padrão internacional para avaliação do processo de software visando à melhoria contínua deste processo e determinação de capacitação, baseado principalmente nos projetos CMM, TRILLIUM, BOOTSTRAP, COMPITA, STD e 
BELLCORE. Este projeto tem como objetivo apoiar o planejamento, gerenciamento, execução, controle e melhoria da aquisição, fornecimento, desenvolvimento, operação, mamutenção e suporte de software [Lig96].

O projeto SPICE surgiu da investigação das necessidades e dos requisitos para uma avaliação padrão do processo de software e concluiu-se que havia um consenso internacional dessa necessidade, em Junho de 1992. Em Junho de 1993 a organização desse projeto foi estabelecida com sua coordenação em centros de desenvolvimento na Europa, América do Norte e Ásia (Pacífico).

O projeto SPICE, após dois anos de estudos, foi definido como sendo composto de três etapas: produzir diretrizes de trabalho para a padronização, com vistas à avaliação do processo de software, encarregar-se de definir o padrão completo para avaliação de processo de software a partir de resultados coletados com testes de usuários com o uso dos guias e formar uma consciência no mercado sobre a padronização da avaliação de processo de software, consolidando assim a aceitação desse padrão. A Figura 2 ilustra a dinâmica da avaliação do processo de software.

O projeto já possui um conjunto de diretrizes definidas que estão sendo utilizadas provisoriamente para obter informações e experiência de seu uso prático. Esse conjunto de diretrizes é composto de nove partes, descritas a seguir na Tabela 2 e ilustradas na Figura 3.

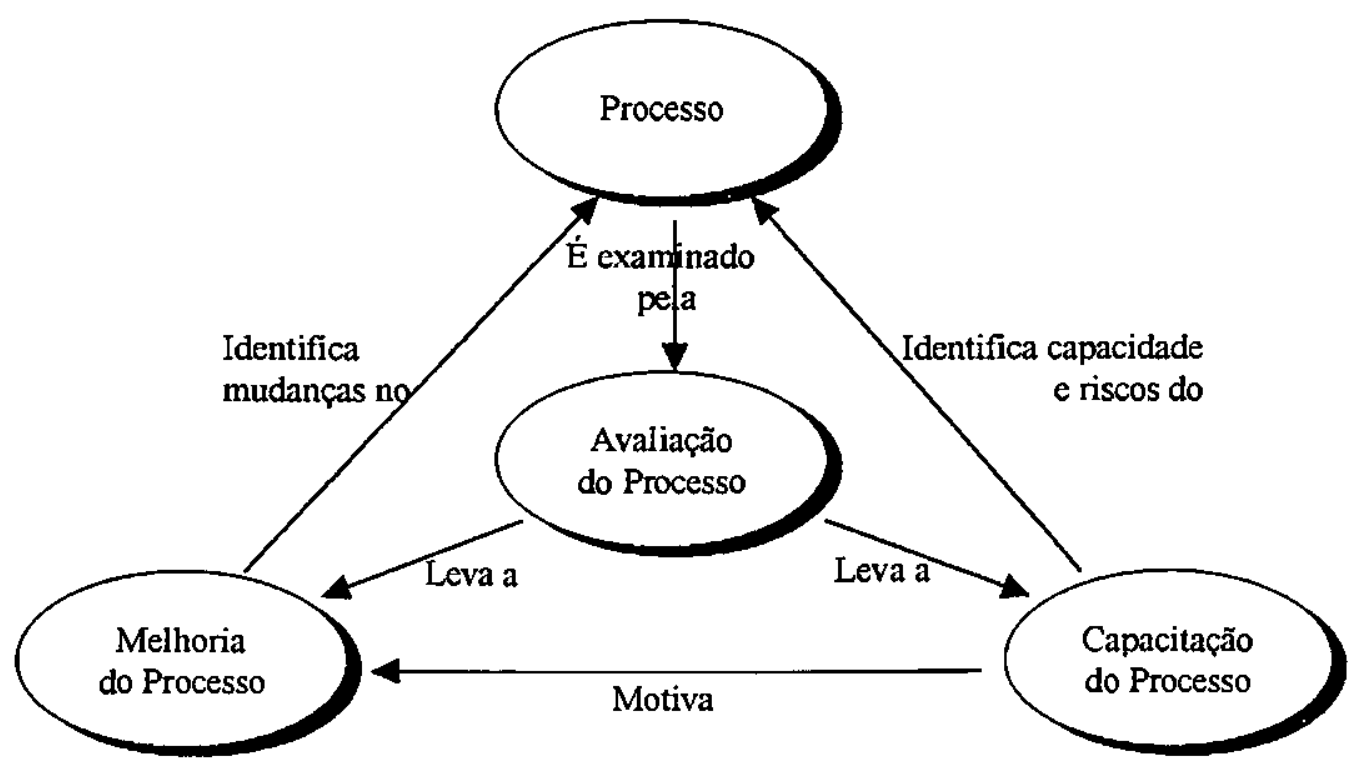

Figura 2. Avaliação do Processo de Software [Lig96] 


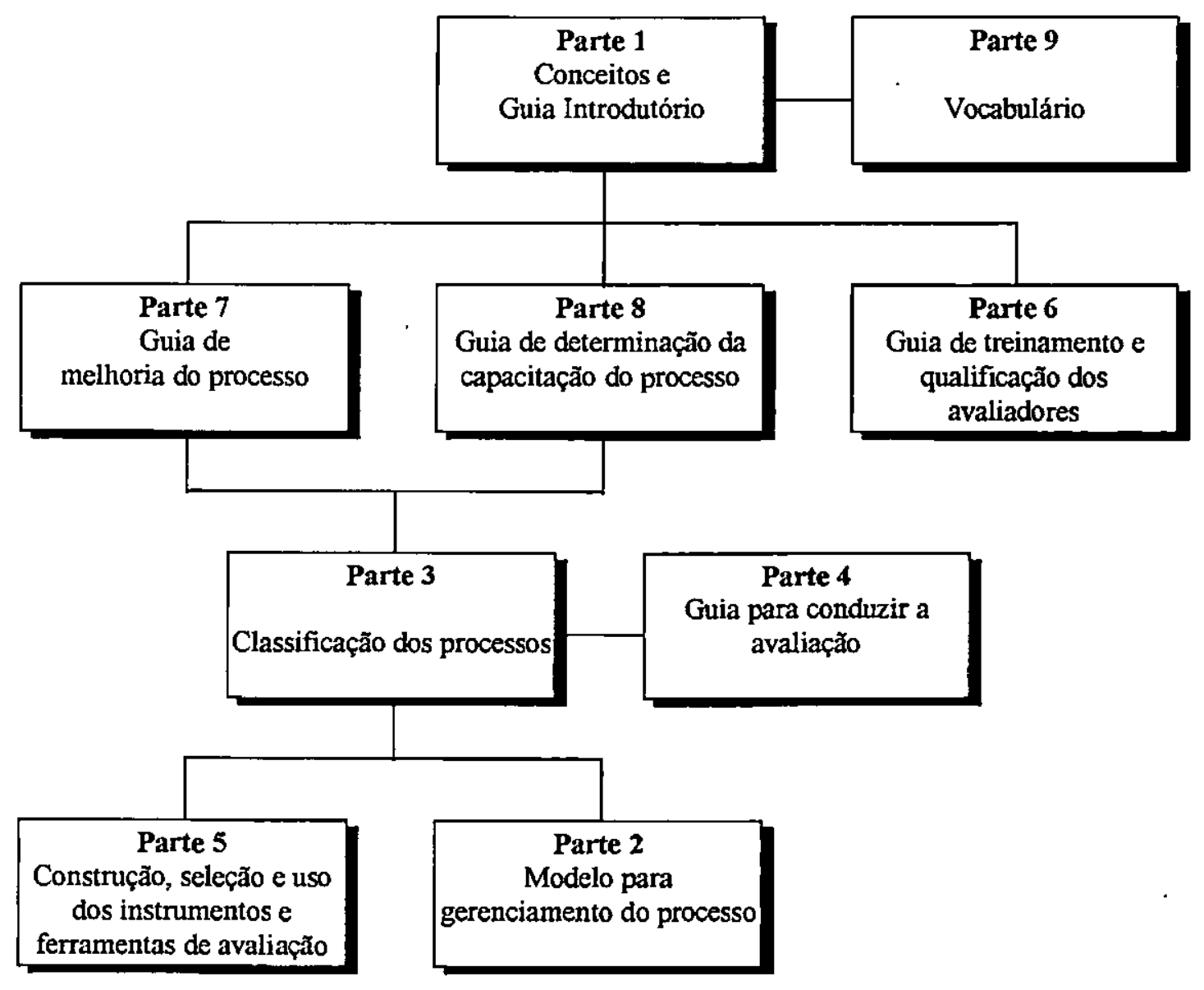

Figura 3. Componentes do SPICE [Lig96]

Tabela 2. Descrição resumida de cada componente do SPICE.

\begin{tabular}{|l|lr|l|}
\hline Parte & Título & Comentário \\
\hline $\mathbf{1}$ & $\begin{array}{l}\text { Conceitos e Guia } \\
\text { Introdutório }\end{array}$ & $\begin{array}{l}\text { É descrito como as demais partes se relacionam e são fornecidas } \\
\text { sugestões para seleção e uso de cada uma delas. Contém também } \\
\text { uma explicação dos requisitos contidos no padrão . e sua } \\
\text { aplicabilidade na avaliação. }\end{array}$ \\
\hline $\mathbf{2}$ & $\begin{array}{l}\text { Modelo para } \\
\text { Gerenciamento do } \\
\text { Processo }\end{array}$ & $\begin{array}{l}\text { Define em linhas gerais as atividades essenciais para a engenharia } \\
\text { de software. É estruturada seguindo o modelo de níveis de } \\
\text { maturidade do processo do CMM. }\end{array}$ \\
\hline $\mathbf{3}$ & $\begin{array}{l}\text { Classificação dos } \\
\text { Processos }\end{array}$ & $\begin{array}{l}\text { Contempla a definição de uma estrutura para a realização de uma } \\
\text { avaliação mais concreta, fornecendo uma base para taxas, valores } \\
\text { e medições de maturidade do processo. }\end{array}$ \\
\hline $\mathbf{4}$ & $\begin{array}{l}\text { Guia para Conduzir a a gua é bastante genérico e pode ser utilizado em diversas } \\
\text { Avaliação }\end{array}$ & $\begin{array}{l}\text { O guia } \\
\text { organizações, não apenas nas de software. O guia utiliza as mais } \\
\text { variadas técnicas e métodos. }\end{array}$ \\
\hline
\end{tabular}


Tabela 2. Descrição resumida de cada componente do SPICE (continuação).

\begin{tabular}{|c|c|c|}
\hline Parte & Título & \\
\hline 5 & $\begin{array}{lr}\text { Construção, } & \text { Seleção } \\
\text { e Uso } & \text { dos } \\
\text { Instrumentos } & \mathrm{e} \\
\text { Ferramentas } & \text { de } \\
\text { Avaliação } & \end{array}$ & $\begin{array}{l}\text { Define elementos numa estrutura para construção de } \\
\text { instrumentos e ferramentas para auxiliar o avaliador durante a } \\
\text { avaliação de processo, além de fornecer também um guia para } \\
\text { seleçâo e utilização de aspectos desejados nos vários tipos de } \\
\text { ferramentas e instrumentos. }\end{array}$ \\
\hline 6 & $\begin{array}{l}\text { Guia de Treinamento } \\
\text { e Qualificação dos } \\
\text { Avaliadores }\end{array}$ & $\begin{array}{l}\text { Esta parte fornece mecanismos que podem ser utilizados para } \\
\text { demonstrar a competência, a qualificação e o conhecimento do } \\
\text { avaliador. }\end{array}$ \\
\hline 7 & $\begin{array}{l}\text { Guia de Melhoria do } \\
\text { Processo }\end{array}$ & Itados de uma \\
\hline 8 & \begin{tabular}{ll|} 
Guia & de \\
Determinação & da \\
Capacitação & do \\
Processo &
\end{tabular} & $\begin{array}{l}\text { É descrito como definir a entrada e o uso dos resultados de uma } \\
\text { avaliação para a determinação da maturidade do processo. Esse } \\
\text { guia se propõe a fornecer uma estrutura para determinar tanto a } \\
\text { maturidade da organização que está sendo avaliada quanto a de } \\
\text { seus fornecedores. }\end{array}$ \\
\hline 9 & & \\
\hline
\end{tabular}

Esses guias estão em constante evolução na medida em que mais resultados são obtidos e novos parâmetros detectados.

\subsubsection{P-CMM}

O P-CMM, People Capability Maturity Model, também do SEI, é complementar ao modelo CMM, pois tem como objetivo gerenciar e desenvolver a força de trabalho da organização, suprindo assim deficiências em relação ao gerenciamento e melhoria do processo pessoal nas organizações que implantam programas de melhoria e otimização de processo de software seguindo o modelo CMM para software [CHM95a].

Com a implantação de modelos de gerenciamento de processo, as organizações precisam também avaliar e capacitar seu pessoal. O objetivo do P-CMM é melhorar a capacidade das organizações desenvolvedoras de software para atrair, desenvolver, motivar, organizar e reter o talento necessário para o melhoramento contínuo da capacidade de desenvolvimento de software. O P-CMM é projetado para permitir às organizações de software integrar a melhoria da força de trabalho com os programas de melhoria do processo de software conduzidos pelo CMM. 
O P-CMM auxilia as organizações desenvolvedoras de software a caracterizar o nível de maturidade das práticas de sua força de trabalho, orienta um programa de desenvolvimento contínuo da força de trabalho, prioriza ações imediatas, integra o desenvolvimento da força de trabalho com a melhoria do processo de software e estabelece uma cultura de excelência em engenharia de software.

O P-CMM é estruturado também em cinco níveis de maturidade, cada um deles com as suas práticas-chave para o gerenciamento e desenvolvimento de pessoal de uma organização, semelhantemente ao proposto pelo CMM, como mostra a Figura 4 abaixo [CHM95b]. Esses niveis de maturidade descrevem um caminho de evolução que vai desde um estado caótico com práticas inconsistentes a um estado maduro com práticas organizadas, técnicas bem definidas e motivações para o desenvolvimento pessoal. A maturidade no P-CMM representa a capacidade da organização em melhorar as técnicas e o conhecimento dos recursos humanos e associar isso com os objetivos da organização.

No Nível 1, Inicial, a organização não possui um conjunto de técnicas nem de métodos que forneça recursos para um gerenciamento disciplinado de pessoal.

Quando a organização se encontra no Nível 2, Repetitível, políticas são adotadas e implantadas para que as práticas relacionadas com pessoal estejam completamente estabelecidas.

No Nivel 3, Definido, a organização começa a alcançar maturidade para adaptar as práticas definidas para os funcionários no nível repetitível para a sua realidade, direcionando o processo pessoal especificamente para sua atividade fim.

A organização que se encontra no Nível 4 , Gerenciado, possui formação de times de trabalho, forte orientação resultante da experiência adquirida nos outros níveis e práticas relacionadas a pessoal direcionadas ao desenvolvimento desses times. 


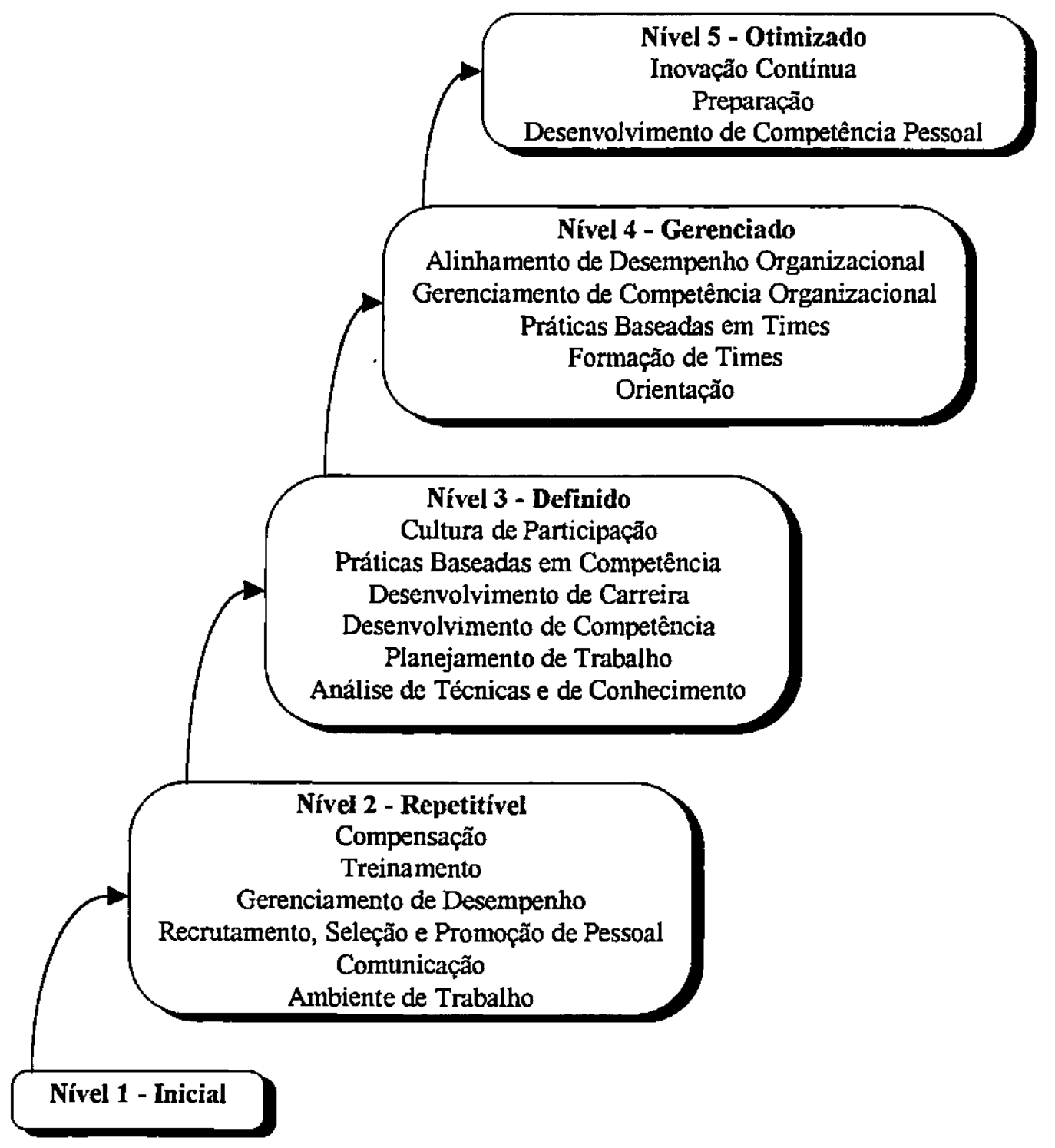

Figura 4. Evolução do P-CMM com as práticas-chave

No Nivel 5, Otimizado, todos os niveis da organização são alvos para a melhoria contínua de desempenho.

A orientação fornecida pelos cinco níveis de maturidade oferece à organização uma estrutura linear, ou seja, as práticas de um nivel só são exigidas depois que todas as práticas do nível anterior estão consolidadas na organização. Essa estrutura linear é importante para a melhoria gradativa da forma de trabalho de engenheiros de software e de outros profissionais. 


\subsubsection{Outros Modelos de Qualidade}

\subsubsection{Trillium}

Trillium é um modelo de domínio público, também baseado em niveis de maturidade e utilizado pela Bell Canada para avaliar principalmente o desenvolvimento de produtos de telecomunicações e produtos baseados em tecnologia de informação [Tri95].

Trillium é utilizado de quatro diferentes maneiras: na Avaliação de Maturidade do produto em desenvolvimento, dos fornecedores e dos riscos associados, monitorando o programa de melhoria de maturidade e qualidade; na Avaliação Conjunta de Maturidade durante o desenvolvimento do produto em consenso com os fornecedores, trocando experiências e informações úteis às duas partes; na Auto-avaliação de Maturidade por um comitê sério, capacitado e respeitado por todos os membros da organização; e na Melhoria Contínua, tornando a filosofia de melhoria contínua uma cultura na organização, garantindo processos e mecanismos apropriados para encorajar essa cultura, definindo e otimizando os processos para alcançar os requisitos desejados.

A estrutura e as práticas são baseadas principalmente no SEI/CMM V1.1 e também nos padrões ISO 9001 e ISO 9000-3.

As principais diferenças entre Trillium e CMM são as seguintes: no Trillium, a arquitetura é baseada em guias ao invés de áreas-chave no $\mathrm{CMM}$, e no primeiro a perspectiva é voltada mais ao produto, ao passo que no segundo é voltada totalmente ao processo.

\subsubsection{Bootstrap}

Bootstrap é um serviço oferecido pela empresa internacional de consultoria de software Etnoteam, certificada em ISO 9001, especializada em melhoria da qualidade e produtividade de software. O serviço Bootstrap e seu método associado são derivados do ISO 9000 e do SEI/CMM [Boo95]. 
O método Bootstrap propõe-se a garantir altos níveis de imparcialidade, precisão e confidencialidade. Cada avaliação resulta em um relatório de diagnóstico, completo e preciso, que também dispõe em ordem as ações necessárias para a organização evoluir para um nível maior de qualidade e produtividade. A avaliação consiste em duas etapas, sendo a primeira um diagnóstico do ambiente de desenvolvimento do software, tais como organização, métodos de desenvolvimento de manutenção, ferramentas de apoio do tipo CASE (Computer Aided Software Engineering) e plataformas de desenvolvimento, e a segunda o desenvolvimento de um plano de ação que ordena as etapas necessárias para a melhoria da qualidade e da produtividade, evoluindo assim para um maior nível de maturidade de processo.

\subsubsection{Kaizen}

Kaizen tem o significado de Melhoria. É uma estratégia japonesa para melhoria contínua [QTt96]. Organizacionalmente falando, seu conceito corresponde a uma política, ou a um conjunto de valores definidos como verdade, que servirão de orientação para o comportamento de um determinado grupo de pessoas, e também a uma cultura, ou a um conjunto de valores já incorporados pelo grupo e que pode ser observado pelo comportamento natural do mesmo.

Seus princípios são: recursos humanos são os bens mais importantes da organização; processos devem sofrer melhorias contínuas e progressivas e não mudanças bruscas e radicais; e a melhoria de processo deve ser baseada na avaliação estatística e quantitativa do desempenho do processo.

\subsubsection{QIP}

QIP, Quality Improvement Paradigm, é um modelo iterativo para melhoria contínua do desenvolvimento de software. O QIP é um processo cíclico que inclui etapas de Entendimento, Avaliação e Empacotamento de melhorias para os ambientes de desenvolvimento de software, assim como para incorporar experiências adquiridas de esforços de melhoria em futuros desenvolvimentos [QIP96]. 
$\mathrm{Na}$ fase de Entendimento tem como objetivo melhorar o processo de software e seus produtos, caracterizando o ambiente de produção. Isso implica em caracterizar tipos de desenvolvimento de software, definição de problemas e características de processo e de produto. $\mathrm{Na}$ fase de Avaliação é medido o impacto das tecnologias disponiveis e das mudanças de processo na geração do produto. Também determina quais tecnologias são benéficas e apropriadas para um determinado ambiente e, ainda, como tecnologias ou processos devem ser refinados para melhor se adaptarem. Uma vez identificadas as melhorias de processo, segue-se a etapa de Empacotamento, que consiste em organizar o pacote formado pela tecnologia que será utilizada na organização. Isto inclui desenvolvimento e melhoria de padrões e políticas de treinamento e desenvolvimento.

\subsection{Consideraçōes Finais.}

Seguindo um modelo de gerenciamento de processo de software, as organizações têm alcançado melhorias significativas nos seus processos e modos de trabalho [HCR+94] e muitas dessas organizações perceberam que a obtenção de índices melhores dependem do talento individual de seus funcionários. Por essa razão, estudos e pesquisas foram direcionados para a capacitação e melhoria do processo pessoal e individual.

Com exceção do P-CMM, os demais modelos de qualidade de software apresentados cobrem apenas aspectos de qualidade do processo e do produto de software, desconsiderando aspectos de qualidade de pessoal ou individual. Ao observar esta lacuna, o SEI desenvolveu o P-CMM e o PSP - Personal Software Process como recursos para melhoria e otimização do processo de pessoal e processo individual de trabalho, respectivamente. Essas considerações motivaram a escolha do assunto principal deste trabalho e por esse motivo o PSP é apresentado mais detalhadamente no próximo capítulo. 


\section{O Processo de Software Pessoal}

\subsection{Considerações Iniciais}

O PSP sugere práticas e métodos para que o próprio indivíduo consiga identificar e corrigir seus pontos fracos. Entretanto, o mérito do talento individual jamais será superado por tais técnicas. A criatividade e a capacidade de iniciativa necessárias e presentes nos bons funcionários não são inibidas por esse processo [Hum95b]. O PSP é uma sugestão para organizar e disciplinar os processos individuais e não diminui, nem restringe, a capacidade criativa dos indivíduos. Este capitulo apresenta O PSP, com suas descrições, caracteristicas, principais objetivos, o relacionamento entre PSP e CMM, seus métodos, praticabilidade e resultados, o treinamento PSP, um trabalho de pesquisa realizado sobre o assunto e uma descrição geral de algumas ferramentas de apoio ao PSP existentes.

\subsection{Visão geral do PSP}

O modelo SEI-CMM (Software Engineering Institute - Capability Maturity Model) tem tido notável impacto em muitas grandes organizações de software à medida que focaliza sua atenção no conceito de "processos-chave" para obtenção de melhoramentos em produtividade e qualidade. $\mathrm{O}$ modelo CMM tende a ser usado principalmente pelas empresas de TI (Tecnologia de Informação) de maior porte, cuja cultura sente-se confortável com métodos e processos formais, e tende a não ser usado por empresas menores de consultoria e produtoras de software, que alegam agir com mais ênfase sobre a individualidade e criatividade do que sobre alguma disciplina de processo imposta externamente. Estas últimas estão muito conscientes da importância de cumprir prazos e orçamentos, e por razões competitivas, elas querem muitíssimo melhorar sua produtividade e qualidade. $O$ problema é que elas não possuem recursos para investir em tempo adicional, pessoal e planejamento exigidos pela abordagem do SEI para 
melhoramento de processo. $\mathrm{O}$ investimento inicial em termos de tempo e esforço provavelmente não será apreciado pelo usuário final, e um exame superficial dos processos SEI formais freqüentemente acaba revelando a existência de processos que são relevantes apenas se toda a empresa de TI vier a praticá-los.

A questão principal que deu origem ao PSP, ou Processo de Software Pessoal, foi: como o CMM poderia ser aplicado no trabalho individual ou em pequenas equipes de projeto? Em resposta a esta pergunta o SEI começou um projeto de pesquisa em processo de software para examinar maneiras pelas quais profissionais de software pudessem individualmente aplicar princípios do nível 5 do CMM, o nível máximo de capacidade e maturidade almejado. Após anos de pesquisa, foram criados meios para adaptar 12 das 18 áreas-chave de processo CMM ao trabalho individual de profissionais de software. Esta nova abordagem é uma grande oportunidade para aplicar conceitos importantes de engenharia de software em nível individual para desenvolver software, e não apenas para codificar programas.

Assim como um processo de software (Software Process) é uma seqüência de etapas necessárias para se desenvolver ou fazer manutenções em software, o PSP faz uso de um conjunto de sete etapas seqüenciais e progressivas, feitas sob medida para se desenvolver programas de tamanho modular entre 50 a 5.000 linhas de código (LOC). Cada uma dessas etapas possui um conjunto de roteiros, formulários e gabaritos associados.

O PSP é apoiado por um livro texto e um curso introdutório oferecido por esse mesmo livro [Hum95a]. À medida que os profissionais de desenvolvimento de software aprendem a medir os seus trabalhos, a analisar essas medidas e a definir e atingir metas de melhoria, eles passam a enxergar os beneficios de usar o processo definido e são motivados constantemente a utilizá-lo. Durante esse curso introdutório, os profissionais utilizam as etapas do PSP para completar os exercícios de programação e relatórios. O principal veículo de aprendizado é a experiência que os alunos adquirem em fazer os exercícios.

O PSP tem por objetivo demonstrar os princípios do processo pessoal, determinar a situação do processo atual de software pessoal, desenvolver um processo de planejamento para desenvolvimento de software, medir o tamanho do software como parte do processo de planejamento, fazer uma estimativa antecipada do tamanho do software, fazer uma estimativa do cronograma e dos recursos necessários para o software, realizar medições apropriadas do processo pessoal, fazer revisões significativas de projeto e código, executar gerenciamento da 
qualidade do software, executar projeto de software de modo mais formal, verificar o projeto usando métodos como máquinas de estados finitos e rastreamento de programa, aumentar a escala de PSP para problemas maiores, ajudar a elaborar planos mais precisos, determinar as etapas necessárias para melhorar a qualidade do produto, estabelecer um padrão de referência para se medir as melhorias do processo pessoal e determinar o impacto das mudanças sobre a eficiência profissional.

O PSP introduz os conceitos de processo de software no nível pessoal, numa série de sete etapas, como descrito anteriormente. Cada uma das etapas do PSP, apresentadas na Figura 5 , inclui todos os elementos das etapas anteriores com a adição de um ou mais elementos novos. Ao introduzir os conceitos, um a um, ajuda os profissionais de software a aprender disciplinadamente os métodos pessoais.

A Medição Pessoal ou PSP0 é onde o PSP inicia. Nesta etapa os profissionais de software aprendem a aplicar os formulários e roteiros do PSP aos seus trabalhos pessoais, medindo tempos e defeitos de desenvolvimento, defeitos estes injetados ou removidos. Isso faz com que os engenheiros de software reunam informações reais e práticas que servirão como um ponto de referência contra o qual será medido o progresso enquanto aprendem a praticar o PSP. O PSP0 possui três fases: planejamento, desenvolvimento e autópsia, sendo o desenvolvimento composto de projeto, código, compilação e teste. O PSP0.1 adiciona um padrão de codificação, medição de tamanho e o formulário de Proposta de Melhoramento do Processo (PMP). Os profissionais de software registram no PMP os problemas, os tópicos importantes para discussão e argumentação e as idéias a serem usadas futuramente, aperfeiçoando assim os seus processos pessoais.

O Planejamento Pessoal (PSP1) introduz o método PROBE (Proxy-based estimating method). Os profissionais de software usam esse método para estimar tamanhos e tempos de desenvolvimento para novos programas, com base nos seus próprios dados pessoais. O PROBE utiliza regressão linear para calcular parâmetros de estimativa e gera intervalos de confiança para indicar a qualidade da estimativa de tamanhos e tempos. $O$ escalonamento e planejamento de tarefas são adicionadas ao PSP1.1.

A Qualidade Pessoal (PSP2) introduz o gerenciamento de defeitos. Com os dados de defeitos reunidos previamente, os profissionais de software constróem e usam listas de verificação para revisão de projeto e código. No treinamento é salientada a importância de focar qualidade desde o início e como revisar eficientemente os programas. O PSP2.1 introduz as técnicas de 
especificação de projeto e análise, em adição à prevenção de defeitos, análise e comparação de processos. Medindo os tempos das tarefas realizadas e o número de defeitos injetados ou removidos em cada fase do processo, os profissionais de software aprendem a avaliar e melhorar a eficiência pessoal.

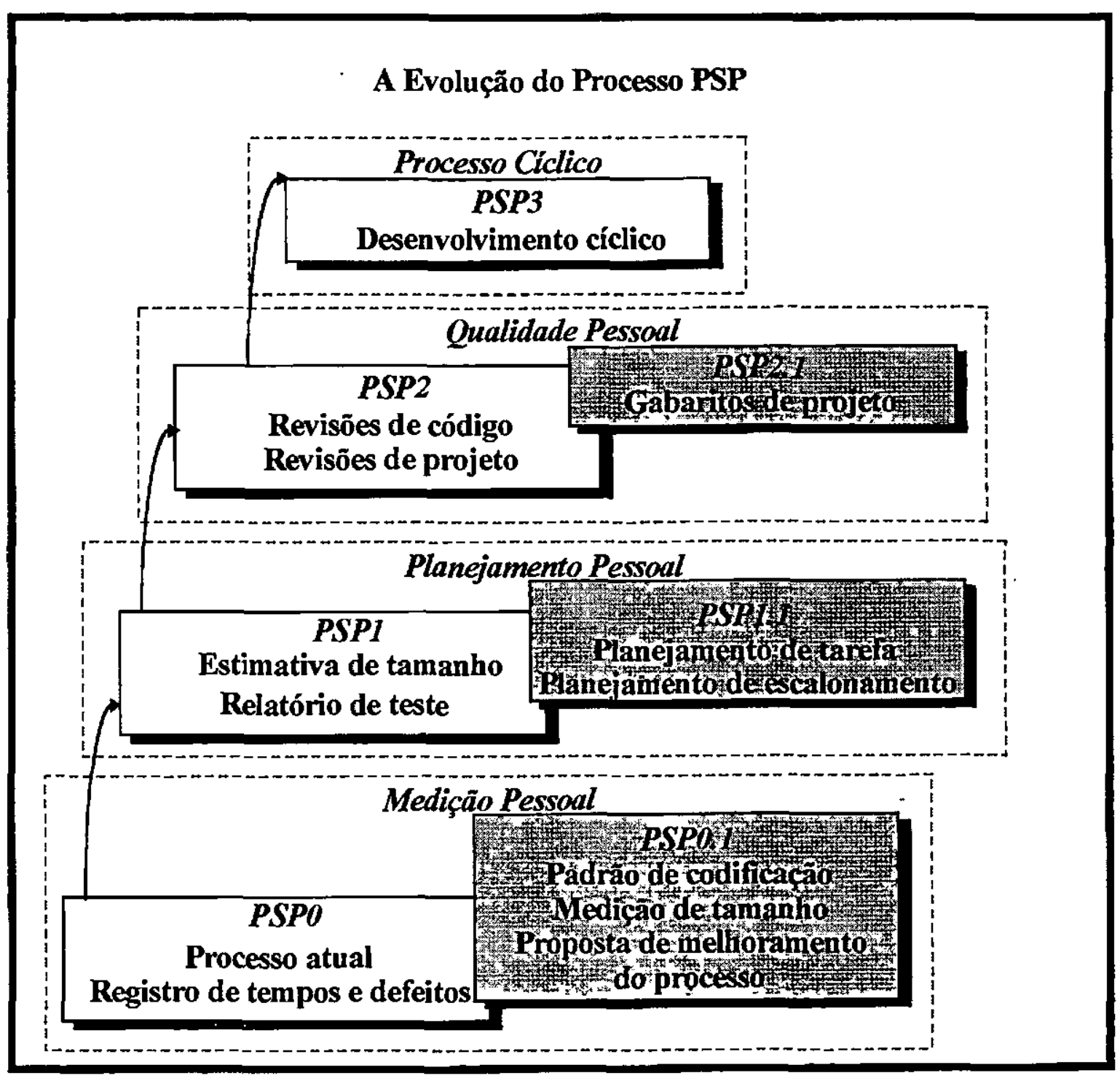

Figura 5. A evolução do PSP

O Processo Ciclico (PSP3) é a etapa final do PSP. A Figura 6 ilustra como os profissionais de software combinam múltiplos PSP2.1 de uma forma cíclica para construir 
módulos com milhares de linhas de código (KLOC). Neste nivel, os profissionais exploram os métodos de verificação de projeto, assim como os princípios e métodos de definição de processo.

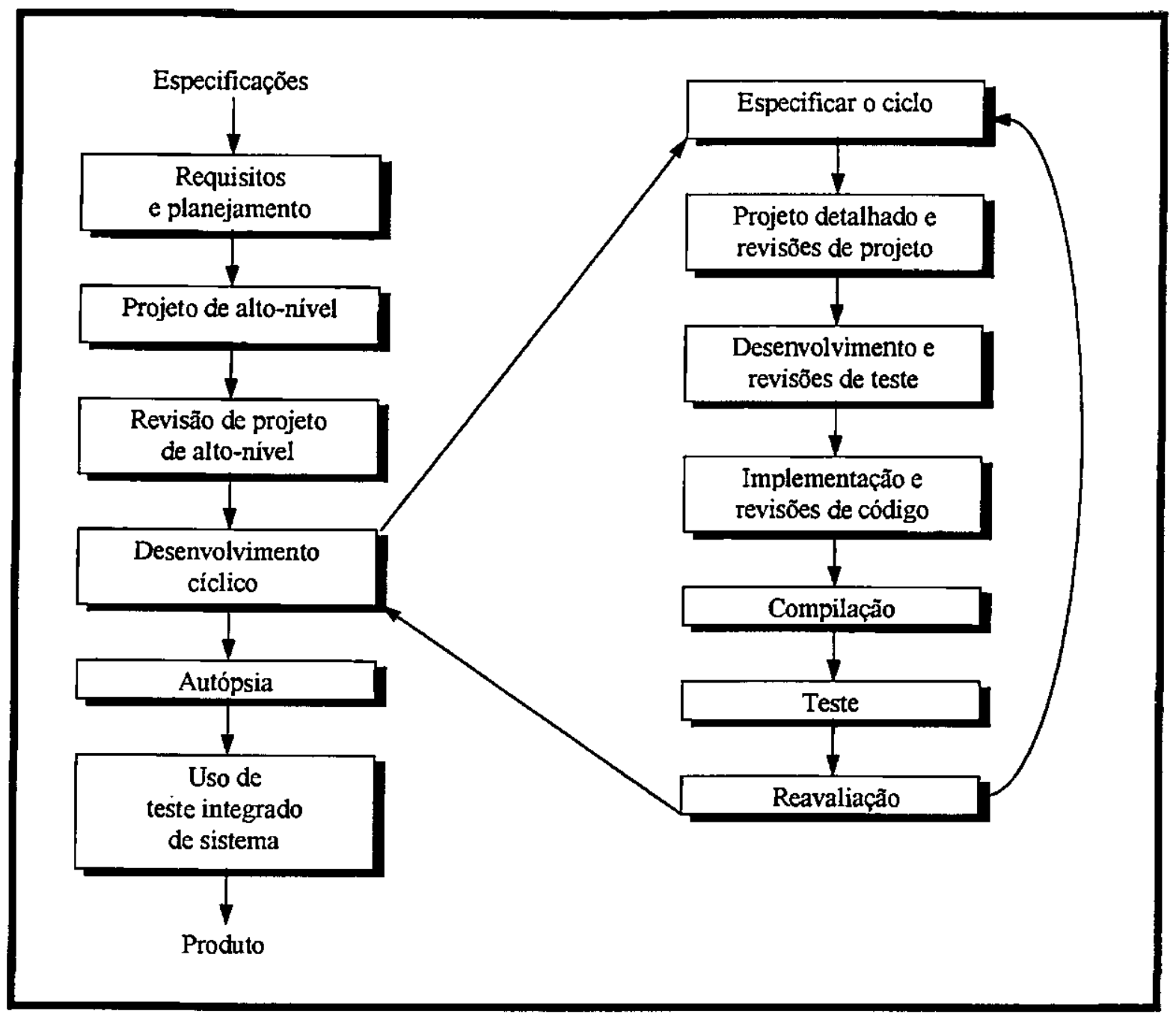

Figura 6. O PSP3

\subsection{Relacionamento entre PSP e CMM}

O SEI-CMM é uma estrutura que dá forma e apóia o processo de melhoramento de software focado na organização. Apesar do CMM permitir e facilitar um bom trabalho, não o garante. Os profissionais de software devem também usar práticas pessoais efetivas, complementando assim o modelo. São ações convergentes. O CMM é uma abordagem de cima 
para baixo, ao passo que a proposta do PSP é o inverso, de baixo para cima, para o melhoramento do processo. Por ser uma abordagem de baixo para cima, tem-se mostrado uma excelente prática, ou seja, reflete aquilo que os trabalhadores estão fazendo, em vez daquilo que os seus superiores pensam que eles deveriam estar fazendo. Esta prática que se origina nas bases da empresa é coerente com as tendências predominantes de downsizing, eliminação de camadas intermediárias de gerência e delegação de poderes para o pessoal que trabalha nas camadas inferiores da empresa. Para serem totalmente eficazes, os profissionais necessitariam de um ambiente disciplinado e eficiente, o que significa que o PSP será mais efetivo em uma organização de software que esteja próxima do Nível 2 do $\mathrm{CMM}$, ou acima, de preferência.

Ambos, o PSP e o CMM, se apoiam mutuamente. O CMM fornece um ambiente organizado que os profissionais necessitam para fazer um trabalho de grandes proporções, e o PSP equipa os profissionais para fazerem tal trabalho de alta qualidade e participar ativamente no melhoramento do processo da organização. A Figura 7 mostra os cinco estágios do SEI-CMM original com as 18 áreas-chave de processo, e o PSP adapta 12 das 18 áreas-chave de processo do CMM ao trabalho individual de profissionais de software. As demais áreas-chave de processo estão além da capacidade dos profissionais de software individualmente. Essas atividades simplesmente existem e são apenas executadas de modo repetitivo, se a empresa definir os processos e indicar pessoas e recursos para executá-los.

O Planejamento e o Rastreamento/supervisão do projeto de software, dois dos processos do nível "Repetitível", ou 2, indicados na Figura 7, são áreas em que os processos pessoais são significativos, tanto para o projeto de uma pessoa como para as atividades de uma pessoa dentro de um projeto maior. Sendo igualmente importantes dentro da estrutura do PSP, elas podem ser definidas, formalizadas, padronizadas, medidas e monitoradas do ponto de vista matemático e estatístico, e melhoradas, tudo em base pessoal. Esse tipo de medição e monitoração cuidadosa dos próprios processos individuais transforma-se na base do aperfeiçoamento. 
Nivel 5 - Otimizado

Gerenciamento de mudança de processo

Gerenciamento de mudança de tecnologia

Prevençāo de defeitos

Nivel 4-Gerenciado

Gerenciamento da qualidade de software

Gerenciamento quantitativo de processo

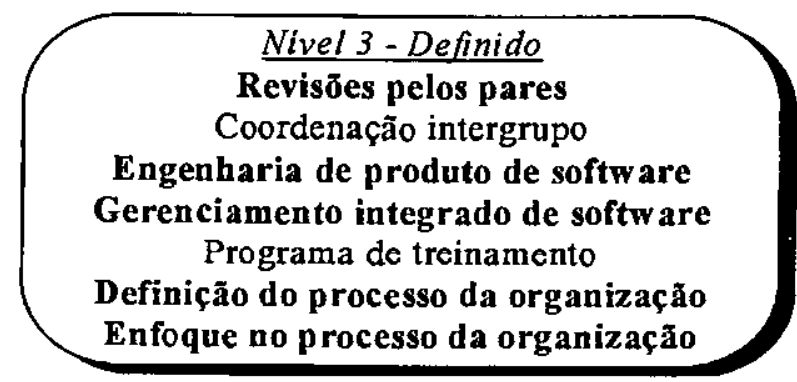

Nivel 2-Repetitivel

Gerenciamento de configuração de software

Controle de qualidade de software

Gerenciamento do subcontrato de software

Rastreamento/supervisão do projeto de software

Planejamento do processo de software

Gerenciamento dos requisitos

Nivel 1-Inicial

Figura 7. Elementos do PSP no CMM ${ }^{1}$.

As Revisões pelos Pares (nivel 3) poderão ser preparadas e organizadas informalmente e posteriormente poderão ser padronizadas como parte da atividade para todos que trabalham numa pequena equipe de projeto, constituindo assim uma excelente prática.

$O$ Gerenciamento Integrado e a Engenharia de Produto de Software têm como propósitos integrar as atividades de engenharia e gerência de software em nivel do processo de

1 Os itens em negrito correspondem às áreas-chave do processo do SEI-CMM original que foram adaptadas para o PSP. 
software pessoal, e consistentemente executar um processo de engenharia bem definido que integra todas as atividades de engenharia de software para produzir produtos de software consistentes e corretos, de uma maneira efetiva e eficiente. Deve ser moldado ao ambiente do projeto e descreve as atividades técnicas do projeto, tais como análise de requisitos, projeto, código e teste.

O Enfoque e Definição do Processo da Organização (nível 3) consiste em definir e documentar o próprio processo que está sendo seguido. $O$ ponto-chave aqui é que a ênfase e o enfoque do desenvolvedor de software deslocam-se do produto para o processo. O processo que está sendo seguido não precisa necessariamente ser um método bem conceituado, de última geração, na sua íntegra. $O$ método pode ser uma combinação de vários conceitos bem difundidos do que existe de melhor na área, ou algo inteiramente inédito. $O$ importante é que seja um procedimento organizado e seguido sistematicamente, cujas atividades sejam medidas e submetidas a constantes aperfeiçoamentos.

O Gerenciamento da Qualidade de Software e Gerenciamento Quantitativo de Processo (nível 4) consiste em documentar, medir e acompanhar o custo de qualidade (COQ - Cost Of Quality), como base para os melhoramentos. O COQ possui três componentes: custos de falhas, custos de avaliação e custos de prevenção. Os custos de falhas correspondem aos custos do diagnóstico da falha, da execução dos reparos, da recompilação, do reteste do software e de voltar ao processo. Os custos de avaliação correspondem aos custos para determinar o nivel de qualidade do produto, inclusive revisões de projeto/código e inspeções. Já os custos de prevenção correspondem aos custos associados com procedimentos de identificação das causas dos defeitos e ações para evitar que voltem a ocorrer no futuro.

O Gerenciamento de Mudança de Processo (nivel 5) é a estratégia organizada para usar realimentação do gerenciamento do nível 4, a fim de realizar mudanças e melhoramentos nos próprios processos pessoais, seja na forma de melhoramentos incrementais de processo, ou por meio da execução de mudanças substanciais na abordagem metodológica usada individualmente.

o Gerenciamento de Mudança de Tecnologia (nível 5) é a estratégia organizada para determinar quando e como uma nova tecnologia deverá ser introduzida no processo de desenvolvimento de software pessoal.

E por último, a Prevenção de Defeitos (nível 5) é o esforço medido e controlado, visando a modificar o processo de desenvolvimento de software praticado para evitar a ocorrência de 
erros, ao invés de investir mais esforço em testes de software para descobrir erros após sua ocorrência.

\subsection{Métodos do PSP}

\subsubsection{Coleta de Dados}

As medidas básicas do PSP são o tempo que os profissionais despendem em cada fase do processo, os defeitos introduzidos e encontrados em cada uma das fases e os tamanhos dos produtos produzidos em linhas de código (LOC). Esses dados são coletados em todas as fases do processo e são resumidos na conclusão de cada uma das fases, assim como do projeto como um todo.

\subsubsection{Estimativa e Planejamento}

Foi desenvolvido para o PSP um método que permite que os profissionais de software utilizem seus dados pessoais acima coletados para estimar tamanhos e recursos necessários. Este método é denominado PROBE, PROxy-Based Estimating, que estima o tamanho e o tempo de desenvolvimento requerido para o desenvolvimento de um novo programa. O PROBE utiliza unidades de medida de tamanho, tais como objetos e funções, podendo também utilizar pontos por função, capítulos de um livro, telas e relatórios.

\subsubsection{Gerenciamento de Defeitos}

No PSP todos os defeitos são registrados, seja durante a compilação, o teste do software, o teste de mesa ou as inspeções. O processo de remoção deve ser projetado para encontrar cada tipo de defeito. Os engenheiros de software devem compreender os defeitos injetados antes que eles possam efetivamente ajustar os seus processos para encontrá-los eficientemente. 
Um dos princípios fundamentais do PSP é que o gerenciamento de defeitos é de responsabilidade pessoal de cada engenheiro de software, ou seja, desde que cada defeito seja introduzido por um engenheiro de software, é de sua total responsabilidade encontrá-lo e corrigilo. Se os defeitos não são gerenciados pelos próprios profissionais nas fases iniciais do processo de software, ficarão mais caros para serem encontrados e corrigidos futuramente.

$O$ gerenciamento de defeitos consiste em rastrear e analisar os defeitos. São coletados dados sobre as fases nas quais os defeitos foram injetados e removidos, os tipos de defeitos, os tempos de correção ${ }^{2}$ e as descrições dos defeitos. As fases propostas inicialmente para o PSP são planejamento, projeto, revisão de projeto, codificação, revisão de código, compilação e teste. Os tipos de defeitos sugeridos são os propostos pelo trabalho de Chillarege e apresentados na Tabela 3 abaixo [Chi92].

O PSP utiliza revisões individuais de projeto e código para identificar e corrigir defeitos tão logo seja possível no processo. Estas revisões são apoiadas por listas de verificação que os próprios engenheiros de software desenvolvem a partir de seus dados pessoais de defeito. Concentrando a atenção nos defeitos que causaram problemas, as listas de verificação auxiliam os engenheiros de software a conduzir revisões mais eficientes. Medições de defeitos são também utilizadas para desenvolver um perfil histórico e projetar o número de defeitos a serem injetados e encontrados em cada fase do projeto.

Localizar e corrigir defeitos, tipicamente, consome parte substancial do tempo de desenvolvimento, encarecendo assim um projeto. Estatísticas demonstram que os engenheiros de software despendem cerca de $30 \%$ de seus tempos compilando e testando seus programas (teste de módulo) e outros $30 \%$ a $50 \%$ do tempo de desenvolvimento nos testes de integração e de sistema. Esse esforço é qquase qque exclusivamente devotado a localizar e corrigir defeitos. Dessa maneira, embora outros aspectos de qualidade de software sejam igualmente importantes, gerenciamento de defeito deve ser a maior preocupação, a menos que os custos de deteç̧ão de defeitos e reparação possam ser reduzidos a níveis mais gerenciáveis. Portanto, o foco principal do PSP é detectar e prevenir defeitos.

\footnotetext{
2 O tempo de correção é o tempo total desde o inicio da deteç̧ão do defeito até que o defeito seja corrigido e a correção vcrificada.
} 
Tabela 3. Tipos de Defeito PSP.

\begin{tabular}{|c|c|c|}
\hline \multicolumn{3}{|c|}{ TIPOS DE DEFEITO PSP } \\
\hline Número & Nome & Descrição \\
\hline 10 & Documentação & comentários, mensagens \\
\hline 20 & Sintaxe & $\begin{array}{l}\text { ortografia, pontuação, digitação, formatos de } \\
\text { instrução }\end{array}$ \\
\hline 30 & $\begin{array}{l}\text { Estrutura, } \\
\text { pacote }\end{array}$ & gerência de mudança, biblioteca, controle de versão \\
\hline 40 & Atribuição & declaração, nomes duplicados, escopo, limites \\
\hline 50 & Interface & $\begin{array}{l}\text { procedimentos de chamadas e referências, } \mathrm{I} / \mathrm{O} \text {, } \\
\text { formatos de usuário }\end{array}$ \\
\hline 60 & Verificação & mensagens de erro, verificações inadequadas \\
\hline 70 & Dado & estrutura, conteúdo \\
\hline 80 & Função & $\begin{array}{l}\text { lógica, ponteiros, laços, recursividade, cálculo, } \\
\text { defeitos de função }\end{array}$ \\
\hline 90 & Sistema & configuração, sincronização, memória \\
\hline 100 & Ambiente & $\begin{array}{l}\text { projeto, compilação, teste ou outros problemas de } \\
\text { suporte de sistema }\end{array}$ \\
\hline
\end{tabular}

Se os engenheiros de software desejam reduzir o número de defeitos que eles encontram no teste, eles devem revisar seus códigos para encontrá-los, antes mesmo da compilação. Dessa maneira economizarão tempo na compilação e esta será uma verificação da qualidade das revisões de código. Uma outra razão para revisar o código antes de compilá-lo é o sentimento de satisfação ao se fazer um trabalho de qualidade. Humphrey afirma que projetos cujos produtos apresentam muitos defeitos no teste tendem a atrasar e a extrapolar o orçamento. Há também uma forte evidência de que quanto mais defeitos são encontrados na compilação, mais defeitos surgirão no teste. Números reduzidos de defeitos de teste implicam numa maior qualidade do produto acabado [Hen94]. 
A principal medida de qualidade do PSP é o número de defeitos removidos que é definido como o percentual de defeitos que foram encontrados e corrigidos antes da compilação e teste do programa.

\subsubsection{Controle do Custo da Qualidade}

O PSP utiliza as medidas de Custo-da-Qualidade (COQ) para auxiliar o gerenciamento da qualidade do processo. As principais medidas COQ são: custo de avaliação (COQ de avaliação), custo de falha (COQ de falha) e custo de prevenção (COQ de prevenção), como mencionado no tópico Relacionamento entre PSP e CMM. O COQ de avaliação é o percentual do tempo de desenvolvimento gasto nas revisões de projeto e código; o COQ de falha é o percentual do tempo gasto na compilação e teste; e o COQ de prevenção é o percentual do tempo gasto prevenindo defeitos antes que surjam, considerando inclusive atividades de prototipação e especificação formal.

Uma outra medida COQ é a razão entre o COQ de avaliação e o COQ de falha, chamada Razão-Avaliação-Falha, ou A/FR, ou seja, a razão entre o tempo gasto na revisão de projeto e código e o tempo gasto na compilação e teste. O A/FR pode ser visto como uma medida do esforço relativo gasto na remoção de defeitos iniciais. Enquanto o objetivo do número de defeitos removidos é reduzir o número de defeitos encontrados na compilação e teste, o $\mathrm{A} / \mathrm{FR}$ tem 0 objetivo de aumentar o número de defeitos removidos.

A estratégia sugerida pelo PSP é que os engenheiros de software inicialmente esforcem-se por obter valores de A/FR superior a 2. Quanto mais defeitos são encontrados no teste, tanto maior deveria ter sido a dedicação nas revisões de projeto e código (maiores valores para $\mathrm{A} / \mathrm{FR}$ ). Quanto menos ou nenhum defeito encontrado no teste, trabalha-se no sentido de reduzir o A/FR. A razão de aumentar o A/FR é atingir alta qualidade do produto, reduzindo assim o número de defeitos encontrados no teste, e ao mesmo tempo, diminuindo o tempo de compilação e teste. Uma vez que o objetivo da qualidade foi atingido, reduções do A/FR aumentarão a produtividade. 


\subsubsection{Compreensão da Produtividade}

Quando engenheiros de software saem às pressas produzindo código demasiadamente infestado de erros, os projetos que utilizam esse código despenderão muitas horas no teste de integração e de sistema. Contrariamente, se esses mesmos profissionais produzissem programas livre de defeitos ou próximos disso, seus projetos seriam mais produtivos.

O PSP adiciona várias tarefas que muitos engenheiros de software não executam normalmente. Quando tais tarefas adicionais são executadas pode ser que alguns engenheiros de software finalizem suas atividades com baixa média de linhas de código (LOC) por hora. Mas experimentos PSP demonstram o contrário, como será discutido no tópico Praticabilidade do $P S P$. Nesses experimentos observa-se não só ganhos de produtividade, mas também de qualidade. Embora os métodos de gerenciamento e de planejamento do PSP consumam tempo adicional, estes são os métodos que fazem os engenheiros de software tornarem-se mais eficazes.

\subsubsection{Princípios do Projeto de Software}

O principal foco do PSP é a prevenção de defeitos no projeto. O PSP não adota um método de projeto específico. O PSP sugere utilizar um critério de conclusão do projeto. Pesquisas sobre o uso do PSP têm mostrado que poucos defeitos de projeto são resultados de alguma lógica sofisticada. As principais causas são descuidos, equivocos e simples deslizes. Muitos desses defeitos são causados por representação imprópria de projetos, por projetos incompletos, ou até mesmo pela ausência de projeto. Má representação de projeto faz com que os engenheiros de software projetem durante a implementação, o que, e por sua vez, pode ser também uma fonte de erro significativa. Estabelecendo um critério de conclusão de projeto, o PSP auxilia os profissionais a produzirem projetos suscetiveis a revisão, que podem ser implementados com um mínimo de erros. 


\subsubsection{Princípios do Processo de Software}

Um objetivo do PSP é ajudar os engenheiros de software a entender como aplicar os princípios do processo aos seus trabalhos. Isto mostra aos profissionais como definir novos processos, como planejar uma tarefa do processo e quanto tempo tal trabalho tipicamente leva.

\subsection{A praticabilidade do PSP}

São apresentadas a seguir, nas Tabelas 4 e 5 , algumas estatísticas de melhoramentos baseados em experimentos PSP de Humphrey, com grupos de profissionais de software, aprendizes e veteranos, justificando não só a praticabilidade, mas também a funcionalidade do processo [Hum95d]. Um curso sobre PSP com duração de 15 semanas contou com a participação de 4, 12, 6 e 19 engenheiros de software para os grupos A, B, C e D, respectivamente. Os participantes dos grupos $\mathrm{A}, \mathrm{B}$ e $\mathrm{C}$ eram profissionais moderadamente experientes, enquanto a maioria dos participantes da turma $\mathrm{D}$ era composto de estudantes de pós-graduação com pouca experiência profissional.

Os percentuais de melhoria no número médio de defeitos por mil linhas de código (KLOC) foram coletados no início (exercícios 1A e 2A) e no fim dos cursos (exercícios $9 \mathrm{~A}$ e $10 \mathrm{~A})^{3}$.

Tabela 4. Redução de Defeitos.

\begin{tabular}{lrrrr}
\hline Redução de Defeitos & Grupo A & Grupo B & Grupo C & Grupo D \\
\hline Na Compilação & $68,8 \%$ & $76,6 \%$ & $75,7 \%$ & $88,1 \%$ \\
No Teste & $68,8 \%$ & $81,7 \%$ & $64,2 \%$ & $83,2 \%$ \\
\hline Total & $53,4 \%$ & $45,8 \%$ & $55,1 \%$ & $80,1 \%$ \\
\hline
\end{tabular}

A produtividade é medida como sendo a média de linhas de código (LOC) por hora. Nos cursos, as linguagens utilizadas foram $\mathrm{C}$ e Pascal e para se medir tal produtividade, além dos

\footnotetext{
${ }^{3}$ Maiores informações sobre os exercícios se encontram no tópico Treinamento PSP.
} 
registros de tempos e defeitos, houve a necessidade de definir um padrão de codificação e uma medição de tamanho, que neste caso foi o LOC (nível PSP0.1).

Tabela 5. Melhoria de Produtividade

\begin{tabular}{lrrrr}
\hline Produtividade & Grupo A & Grupo B & Grupo C & Grupo D \\
\hline Exercicios 1A e 2A & 19,9 & 31,4 & 11,4 & 13,8 \\
Exercícios 9A e 10A & 36,3 & 38,6 & 26,9 & 22,3 \\
\hline Melhoria de produtividade & $82,4 \%$ & $22,9 \%$ & $136,0 \%$ & $61,6 \%$ \\
\hline
\end{tabular}

Outros experimentos demonstram também que o PSP tem mais chance de sucesso numa empresa que já tenha alcançado nível 2 na escala SEI do que naquelas de nível 1 [Hum96].

\subsection{Outros Resultados}

A seguir são mostrados alguns outros resultados provenientes dos treinamentos PSP de 104 engenheiros de software [CMU97] e de um grupo industrial de software que usa o PSP [Fer97].

\subsubsection{Resultados dos Treinamentos PSP}

Dados do SEI de 104 engenheiros mostram que na média o treinamento PSP reduz erros de estimativa de tamanho em $25,8 \%$ e erros de estimativa de tempo em $40 \%$. Linhas de código escritas por hora aumentam na média de $20,8 \%$ e a parte do tempo de desenvolvimento dos engenheiros gasto na compilação é reduzido em $81,7 \%$. O tempo de teste é reduzido em $43,3 \%$, defeitos totais em $59,8 \%$ e defeitos de teste em $73,2 \%$.

O gráfico Total de Defeitos/KLOC Vs. Número do Programa da Figura 8 abaixo apresenta a média total do número de defeitos encontrados em cada um dos dez exercícios de programação. Para o programa 1, a média é de 116,4 defeitos por KLOC com um desvio padrão 
de 76,9 . Já para o programa 10 , a média de defeitos declinou para 48,9 e o desvio padrão ficou próximo de 35,5 .

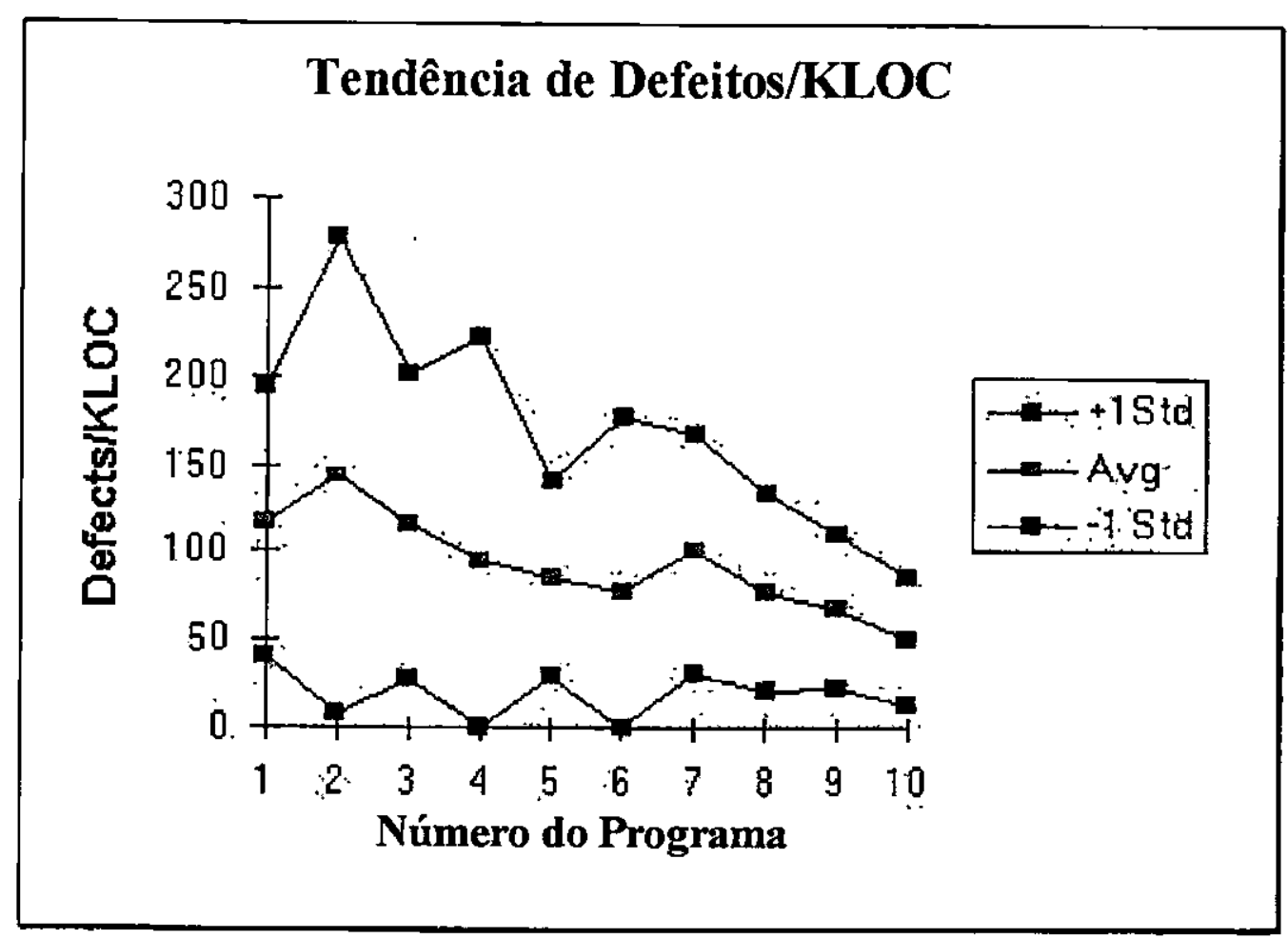

Figura 8. Tendência de Defeitos/KLOC

\subsubsection{Resultados de Um Grupo industrial de Software}

Advanced Information Services Inc. (AIS), Motorola Paging Products Group e Union Switch \& Signal Inc. (US\&S) foram os três grupos industriais de software pesquisados [Fer97]. Cada um treinou vários grupos de engenheiros de software e mediu os resultados de vários projetos que utilizaram os métodos PSP. Em todos os casos, os projetos faziam parte das operações normais das companhias e não foram projetados especialmente para esse estudo.

Os projetos da Motorola e da US\&S envolveram manutenções corretivas e evolutivas de software, enquanto os da AIS envolveram o desenvolvimento de um novo produto e manutenções evolutivas. Entre essas companhias, as áreas de aplicação incluem processamento de dados 
comercial, apoio industrial interno, apoio a produtos de comunicação e controle de processo em tempo-real. As linguagens de programação empregadas foram $\mathrm{C} \mathrm{e} \mathrm{C}+$.

$\mathrm{O}$ porte das companhias varia desde menos de cem a milhares de funcionários em uma grande corporação internacional. A maioria dos projetos envolveu de um a três engenheiros de software, mas um dos projetos da AIS usou dois grupos, um nos E.U.A. e outro na Índia, de três a cinco engenheiros. Enquanto a maioria dos projetos foram para clientes comerciais, um foi desenvolvido para uma agência do governo americano.

Um dos projetos da AIS (Projeto A) possuia nove componentes que variavam de 500 a 2200 linhas de código aproximadamente. Os primeiros três componentes, que totalizavam 15.800 LOC, foram desenvolvidos antes do treinamento PSP e não finalizaram na data prevista. $O$ percentual médio de erro de estimativa de escalonamento desses três primeiros componentes foi de $394 \%$, ou seja, o realizado foi 4,94 vezes superior ao estimado. Os demais componentes foram desenvolvidos após o treinamento PSP e totalizavam 11.700 LOC. O percentual médio de erro de estimativa de escalonamento desses seis últimos componentes foi de $-10,4 \%$, isto é, o realizado foi bem próximo do estimado e ligeiramente inferior. Os tempos de testes de sistema de ambas as partes levaram 1,5 meses cada uma porque a nova parte do projeto desenvolvida após o treinamento teve de ser testada junto com a outra parte desenvolvida anteriormente ao treinamento PSP. As Figuras 9 e 10 ilustram os aspectos de qualidade e produtividade do Projeto A da AIS.

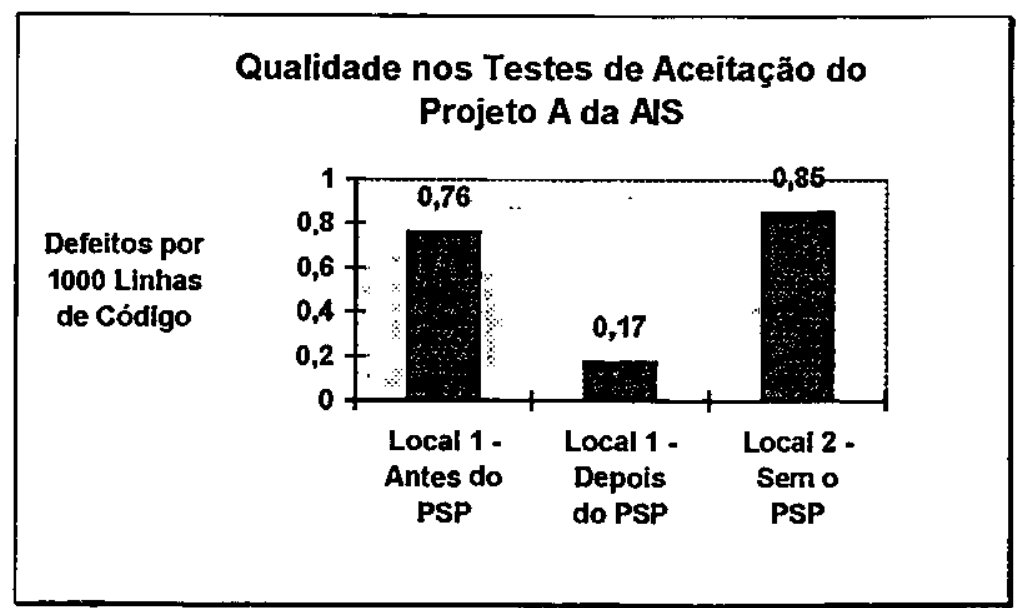

Figura 9. Qualidade do Projeto A da AIS
Como se pode observar, após o treinamento PSP houve um grande ganho de qualidade em relação à mesma localidade antes do treinamento e à outra localidade que não foi treinada. $O$ ganho de melhoria de qualidade foi de $78 \%$ em relação à mesma localidade anterior ao treinamento. 
Também houve ganho de produtividade na mesma localidade que foi treinada. Esta melhoria foi de $7,4 \%$ em relação à situação anterior ao treinamento.

\section{Produtividade do Projeto A da AIS}

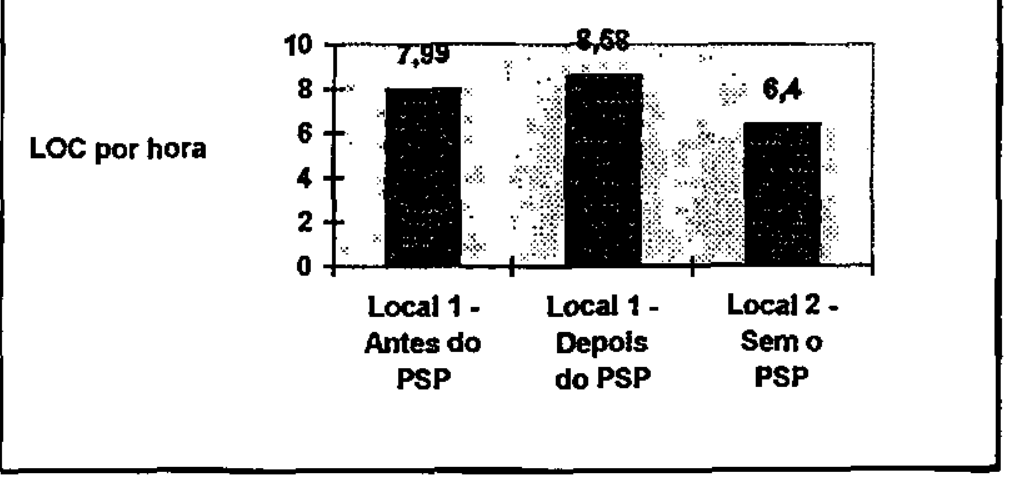

Figura 10. Produtividade do Projeto A da AIS

A seguir são apresentados na Tabela 6 o resumo dos dados de alguns projetos da AIS, e na Figura 11 o aspecto de qualidade de cada um desses projetos, mostrando assim a eficácia do PSP. Os Projeto B, C e D eram muito semelhantes. Semelhantes no tipo de manutenção, tamanhos aproximados, mesma plataforma, linguagem e banco de dados e o Projeto $C$ possuía os mais experientes engenheiros de software. O Projeto $E$ é da área governamental e finalizou substancialmente abaixo do orçamento, além de terminar conforme previsto.

Tabela 6. Resumo dos Projetos da AIS.

\begin{tabular}{|c|c|c|c|c|c|c|}
\hline Projeto & $\begin{array}{c}\text { Pessoal } \\
\text { PSP }\end{array}$ & $\begin{array}{c}\text { Pessoal } \\
\text { Não } \\
\text { PSP }\end{array}$ & $\begin{array}{c}\text { Tamanho } \\
\text { do Produto }\end{array}$ & $\begin{array}{c}\text { Entrega: } \\
\text { Planejado / } \\
\text { Realizado } \\
\text { (meses) }\end{array}$ & $\begin{array}{c}\text { Defeitos no } \\
\text { Teste de } \\
\text { Aceitação }\end{array}$ & $\begin{array}{c}\text { Defeitos } \\
\text { Durante o } \\
\text { Uso }\end{array}$ \\
\hline B & 3 & 0 & 24 requisitos & $7 / 5$ & 1 & 0 \\
C & 0 & 3 & 19 requisitos & $2 / 5$ & 11 & 1 \\
D & 0 & 3 & 30 requisitos & $10 / 19$ & 6 & 14 \\
E & 1 & 0 & 2.255 LOC & $6 / 6$ & 0 & 0 \\
F & 1 & 0 & 1.400 LOC & $2 / 2$ & 0 & 0 \\
G & 2 & 1 & 6.196 LOC & $2 / 2$ & 0 & 3 \\
\hline
\end{tabular}




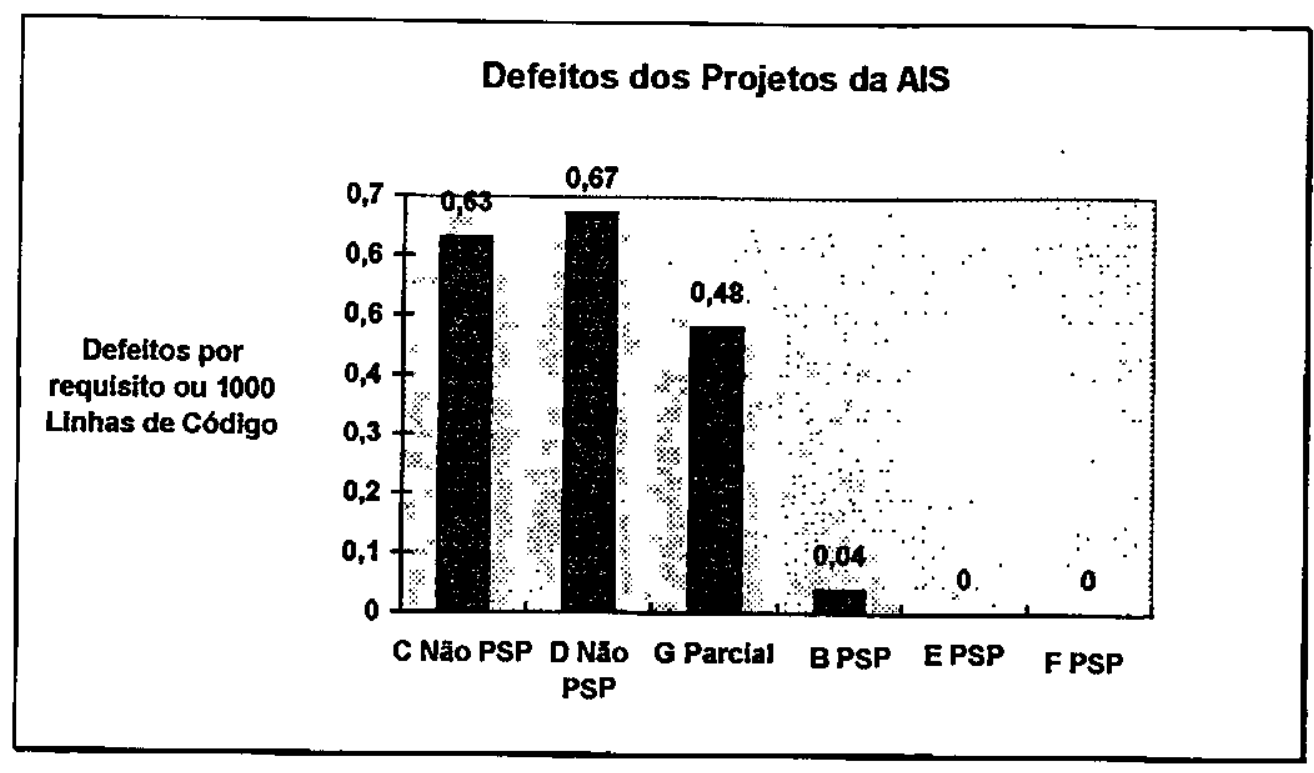

Figura 11. Defeitos dos Projetos da ArS

\subsection{Treinamento PSP}

No meio acadêmico, o treinamento PSP já se tornou uma disciplina de extensão para alunos recém-graduados ou prestes a graduar-se (último-anistas) dos cursos de graduação em engenharia de software de algumas universidades. Os únicos pré-requisitos necessários são proficiência em uma linguagem de programação e competência em desenvolver software.

A duração do curso é de um semestre (15 semanas, aulas de 90 minutos por semana). O curso PSP padrão corresponde aos dez programas exercícios da série $\mathrm{A}$ e aos cinco relatórios programas apresentados nas Tabelas 7 e 8, respectivamente; a série B é opcional (Tabela 9). A dedicação individual de cada estudante a todos os exercícios da série A durante o curso é de aproximadamente 150 a 200 horas, ou seja, de $10 \mathrm{~h}$ a $13 \mathrm{~h} 20 \mathrm{~min}$ por semana.

O mecanismo de aprendizagem consiste no ganho de experiência ao completar os exercícios. Discussões freqüentes sobre os resultados de todo o grupo são aconselhadas e necessárias, mas nenhum resultado ou dado individual pode ser apresentado aos demais participantes, apenas ao próprio estudante. 
Tabela 7. Programas-Exercícios PSP Básicos - Série A.

\begin{tabular}{|c|c|}
\hline \multicolumn{2}{|r|}{ Programas-Exercícios PSP Básicos - Série A } \\
\hline Número & Especificação \\
\hline$\overline{\mathbf{1 A}}$ & $\begin{array}{l}\text { Usando uma lista encadeada, escreva um programa para calcular a média e o desvio padrão } \\
\text { de um conjunto de dados. }\end{array}$ \\
\hline $\mathbf{2 A}$ & Escreva um programa para contar LOC de programas. \\
\hline $\mathbf{3 A}$ & Melhore o programa 2A para contar LOC total de programas e LOC de funções e objetos. \\
\hline $4 \mathrm{~A}$ & Usando uma lista encadeada, escreva um programa para calcular os parâmetros de regressĩo linear. \\
\hline $\mathbf{5 A}$ & Escreva um programa para executar uma integração numérica. \\
\hline 6A & Melhore o programa 4A para calcular os parâmetros de regressấo linear e o intervalo de confiança. \\
\hline $7 \mathbf{A}$ & $\begin{array}{l}\text { Usando uma lista encadeada, escreva um programa para calcular a correlação de dois } \\
\text { conjuntos de dados. }\end{array}$ \\
\hline $8 \mathbf{A}$ & Escreva um programa para classificar uma lista encadeada. \\
\hline 9A & $\begin{array}{l}\text { Usando uma lista encadeada, escreva um programa para fazer um teste } \chi^{2} \text { para uma } \\
\text { distribuição normal. }\end{array}$ \\
\hline $10 \mathrm{~A}$ & $\begin{array}{l}\text { Usando uma lista encadeada, escreva um programa para calcular as três variáveis dos } \\
\text { parâmetros de estimativa de regressão múltipla e os intervalos de confiança. }\end{array}$ \\
\hline
\end{tabular}

Tabela 8. Relatórios-Exercícios PSP Básicos.

\begin{tabular}{|c|l|}
\hline \multicolumn{2}{|c|}{ Relatórios-Exercícios PSP Básicos } \\
\hline Número & Especificação \\
\hline R1 & $\begin{array}{l}\text { Padrão de contagem de LOC: Conte LOC lógicas na linguagem que você usa para } \\
\text { desenvolver os exercícios PSP. }\end{array}$ \\
\hline R2 & Padrão de codificação: Forneça uma LOC fisica para cada LOC lógica. \\
\hline R3 & Relatório de análise de defeitos: Analise os defeitos dos programas IA ao 3A \\
\hline R4 & Relatório intermediário de análise de melhoria do processo. \\
\hline R5 & Relatório final de melhoria do processo e da qualidade e liçðes aprendidas. \\
\hline
\end{tabular}

Devido ao sucesso alcançado pelo treinamento nas universidades, algumas instituições já incorporaram uma disciplina na grade curricular dos cursos de graduação em engenharia de software e ciência da computação com o título de "Introdução ao PSP", que já conta com um livro texto para esta finalidade [Hum97]. 
Tabela 9. Programas-Exercícios PSP - Série B.

\begin{tabular}{|c|l|}
\hline \multicolumn{2}{|c|}{ Programas-Exercícios PSP - Série B } \\
\hline Número & Especificação \\
\hline 1B & Escreva um programa que armazene e recupere números em um arquivo. \\
\hline 2B & Melhore o programa 1B para modificar registros em um arquivo. \\
\hline 3B & Melhore o programa 2B para manusear erros comuns de usuários. \\
\hline 4B & Melhore o programa 3B para manusear mais tipos de erros de usuários. \\
\hline 5B & Melhore o programa 4B para manusear matrizes de números reais. \\
\hline 6B & Melhore o programa 5B para calcular os parâmetros de regressão linear de um arquivo. \\
\hline 7B & Melhore o programa 6B para calcular os paràmetros de regressão linear e o intervalo de confiança. \\
\hline 8B & Melhore o programa 5B para classificar um arquivo. \\
\hline 9B & $\begin{array}{l}\text { Escreva um programa para fazer um teste } \chi^{2} \text { para uma distribuição normal de dados } \\
\text { armazenados em um arquivo. }\end{array}$ \\
\hline
\end{tabular}

No meio empresarial é recomendável aplicar um curso específico de PSP. Levantamentos mostram que apenas um dentre cinco a dez profissionais de software que iniciam o auto-estudo finaliza o treinamento.

Uma outra abordagem de sucesso tem sido introduzir o PSP de uma maneira de cima para baixo nas organizações industriais de software, ou seja, atingindo inicialmente o corpo gerencial da empresa.

\subsection{Adaptação do PSP para a linguagem Java}

O PSP-JOA é uma abordagem do processo de software pessoal orientado a Java (Personal Software Process - A Java Oriented Approach) desenvolvida por Albuquerque em sua dissertação de mestrado na Universidade Federal de Pernambuco em Fevereiro de 1997 [Alb97].

É uma versão definida única e exclusivamente para o processo individual de softwares desenvolvidos utilizando a linguagem orientada a objetos Java. São apresentadas as tabelas e os roteiros modificados de PSP e uma descrição geral da linguagem de programação Java. 
O PSP-JOA é a adaptação de PSP para Java, ilustrando o procedimento sugerido de adaptar o curso para melhor aproveitamento do PSP.

Foi desenvolvido também um editor (mini-ambiente de programação) para apoiar a implementação de programas na linguagem Java, o JavaEdit. O JavaEdit é um editor de propósito geral com formatação de texto Java e um contador de linhas de código (LOC) para Java.

$O$ produto final desse trabalho se resume em redefinir algumas das tabelas propostas por Humphrey em seu livro "A Discipline for Software Engineering" [Hum95a], criando assim a versão Java para PSP. Para isso, foram implementados alguns dos programas-exercícios propostos no curso PSP do mesmo livro (exercícios $1 \mathrm{~A}, 2 \mathrm{~A}$ e $3 \mathrm{~A}$ ) em duas linguagens de programação orientadas a objetos, o Smalltalk e a Java.

Nesse trabalho, mais uma vez, ficou evidente que o PSP depende da linguagem, do paradigma e dos recursos oferecidos pelo ambiente de programação que é utilizado para a implementação dos programas.

Como sugestões para trabalhos futuros são apresentadas uma proposta de construção de um ambiente de programação Java com coleta de dados automática e o esboço de uma disciplina para ser lecionada nos centros de formação de engenheiros de software e de profissionais de computação em geral.

Os principais resultados positivos apresentados e observados nesse trabalho sobre o PSP são: há realmente uma melhoria da qualidade do código desenvolvido; a capacidade de estimar tempo e esforço é consideravelmente melhorada com os dados fornecidos no decorrer do curso; um melhor gerenciamento de dados, por exemplo, facilidade de recuperação de informações, é conseguido por meio dos relatórios gerados e das tabelas preenchidas e armazenadas; um histórico da eficiência do programador é fornecido; e o processo pessoal de desenvolvimento de software é mais disciplinado.

A melhoria alcançada com o PSP é indiscutível, segundo Albuquerque, porém, esses resultados ainda não são completos e a eficácia do processo pode ser questionada se utilizada em situações reais. A aplicação do curso a indivíduos que utilizem outras linguagens de programação ao invés de $\mathrm{C}++$ e Object-Pascal propostas pelo autor do processo, deverá ser cautelosa e sofrer revisões quanto à forma de avaliação e medição dos dados.

Quanto ao curso PSP, foram apontados como pontos críticos a dependência entre as tabelas do curso com relação ao paradigma de programação que se está utilizando para 
implementar os exercicios, por exemplo, procedimental versus orientado a objetos; a forte dependência dos exercícios do curso em relação à linguagem e ao ambiente de programação utilizados, por exemplo, Smalltalk versus Java; o PSP proposto originalmente por Humphrey é fortemente concentrado em codificação e teste e pouco se refere à análise de requisitos, especificação, projeto ou garantia de corretitude e de qualidade; o preenchimento de tabelas é ineficiente no desenvolvimento de um sistema na prática; a cronometragem manual de tempo não é realista; e para implantação do PSP, as empresas têm que reservar regularmente um intervalo de tempo necessário para o treinamento seguindo o curso PSP, curso este moldado especificamente ao ambiente de trabalho da organização.

O trabalho sugere ao PSP uma adaptação do curso para contornar as diferenças quanto a linguagem, ambiente e paradigma de programação, incluindo avaliação e modificação dos exercícios, tabelas e roteiros. Para aplicação real do processo, um sistema de gerenciamento de dados automático e tomada de tempo independentemente do usuário devem ser implementados e utilizados em conjunto com a implantação do processo de trabalho individual. Sugere também criar nos níveis mais baixos de PSP (antes de PSP2.1), roteiros e tabelas para análise de requisitos e especificação do sistema, mesmo que não seja formal a especificação, mas que introduza na disciplina de desenvolver software essas fases. Finalmente, sugere a inclusão do PSP durante a formação profissional do engenheiro de software.

Vários foram os motivos da escolha da linguagem de programação Java no PSP-JOA. Dentre os motivos pode-se citar que Java é uma linguagem amplamente utilizada pelos profissionais de computação, é carente de fontes literárias contendo métodos e processos para desenvolvimento de software utilizando-a e é semelhante ao $\mathrm{C}++$, permitindo a adaptação do PSP para Java de uma forma mais natural e suave.

As principais mudanças realizadas nos roteiros e tabelas PSP-JOA foram devidas às várias tabelas de Instruções Resumo do Plano de Projeto propostas por Humphrey não ressaltarem a necessidade de computar o tempo necessário para classificar uma nova classe a ser desenvolvida, a não distinção entre o código reusado da API (Application Program Interface) de Java e o de outras fontes, e por não estar ainda completamente definido um padrão de codificação para Java.

As tabelas originais propostas por Humphrey em seu livro "A Discipline for Software Engineering" [Hum95a] e modificadas para o PSP-JOA são: Roteiro de Planejamento PSP (C11, C22, C31, C42, C52, C60 e C75), Roteiro de Desenvolvimento PSP (C12, C23, C32, C43, C53, 
C61 e C78), Instruções e Resumo do Plano de Projeto (C26, C35, C46, C56, C64 e C81), Diário de Registro de Defeito (C18), Padrão de Codificação (C29) e Gabarito de Planejamento de Tarefa (C48).

\subsection{Ferramentas de apoio ao PSP}

\section{PSPTool0.6}

O PSPTool0.6 [Wor97] é codificado em TCL-TK, linguagem independente de plataforma, escrito por Andrew Worsley e implementa o nivel PSP 2.1. Possui um painel principal que controla o resumo do plano do projeto, permite registrar os defeitos e os tempos de acompanhamento. A ferramenta implementa um cronômetro utilizando botões de início e parada e esses tempos são medidos em segundos. O tempo acumulado na fase atual é apresentado e pode ser editado.

A ferramenta apresenta os tipos de defeito padrão e permite que os usuários criem seus próprios tipos de defeito. O diálogo Resumo do Plano pode ser apresentado a qualquer momento. A edição dos campos no diálogo depende da fase em que se encontra: os diálogos de planejamento são editáveis na fase de planejamento, o tamanho de software final é editável na fase de autópsia e lido apenas nas demais fases. O diálogo é automaticamente atualizado assim que os tempos e defeitos são informados. Permite ser executado nos ambientes X/Unix, MS Windows, $\operatorname{Mac}$ OS e OS $/ 2$.

\section{TimeLog}

TimeLog [Lah97] é uma aplicação que registra e analisa os tempos de um projeto. É uma implementação em Java do Diário de Registro de Tempos do PSP, escrito por Christoph Clemens Lahme. TimeLog combina todos os componentes padrão do Diário de Registro de Tempos do PSP com o componente "Tempos nas Fases" do Resumo do Plano do Projeto PSP. Assim que os tempos são informados, o resumo do plano é atualizado automaticamente. O TimeLog também permite a personalização das fases. $\mathrm{O}$ usuário poderá manter diferentes processos em seu perfil 
(PSP0, PSP3 ou um PSP personalizado). Todos os processos são editáveis e novos processos podem ser acrescentados.

Timelog também apresenta um diálogo de Pausa que paralisa o cronômetro durante a interrupção de um trabalho. Um formulário resumo apresenta o tempo gasto nas diferentes fases do dia atual, da última semana e de todo o projeto. Os dados são armazenados em arquivos ASCШ e podem ser facilmente importados por outros programas, tais como planilhas eletrônicas. Os ambientes operacionais que permitem a sua execução são Windows 95/NT, Solaris e Linux (com $\mathrm{KDE}$ ) e exige o Java runtime JDK 1.1.3 ou superior. A versão atual é a 5.15, liberada desde Março de 1998.

\section{Timmie}

Timmie [IPD97] é uma ferramenta de acompanhamento de tempo e registro de defeitos desenvolvida pelo Grupo de Engenharia de Software do IPD (Institute for Program Structures and Data Organization) da Universidade de Karlsruhe. É um aplicativo implementado em Java que lida com diferentes projetos. Timmie fornece um diálogo que lista os vários projetos. Quando selecionado (pressionado) um projeto, o tempo é contabilizado para aquele projeto e projetos podem ser adicionados ou removidos quando necessário. Quando o diálogo está ativo, todos os projetos são apresentados e o tempo é acumulado automaticamente para o projeto que está em destaque.

\section{PSP Studio}

PSP Studio [ETS97] é um projeto da equipe Design Studio da East Tennesse State University para as plataformas Windows 95 e Windows NT. Fornece apoio a todos os sete niveis e formulários do PSP, inclusive os relatórios de teste, modelos de projeto, proposta de melhoria do processo e registro de problemas. PSP Studio mede os tempos de desenvolvimento, permite registrar também os defeitos e tamanhos de programa e armazena estas informações no banco de dados relacional SQL Anywhere. Faz os cálculos estatísticos necessários utilizando os dados históricos armazenados. Fornece também os roteiros de cada etapa do PSP, ajuda on-line e manual do usuário, auxiliando assim a condução do processo. 


\subsection{Considerações finais}

Embora muitos métodos eficientes de desenvolvimento de software sejam conhecidos, poucos são praticados [Hum89] e não é usualmente ensinado aos engenheiros de software como planejar, medir e acompanhar seus próprios trabalhos. Por essas razões, esses profissionais desconhecem seus desempenhos, talentos e habilidades.

O PSP surgiu não só da necessidade de melhoria do processo de software em pequenas organizações e pequenas equipes de projeto mas também da oportunidade de se colocar em prática importantes conceitos e técnicas de Engenharia de Software, antes só utilizados em grandes organizações com processo de software maduro [Hum95c]. É um processo pessoal melhorado e disciplinado que ajuda a aumentar a eficácia individual dos engenheiros de software e demais profissionais de software, justificado pelos resultados apresentados anteriormente. Conseqüentemente, se o desempenho individual dos engenheiros melhora, o desempenho de suas equipes e projetos também melhorará [Hum94].

Pressman salienta que o mais importante componente que se precisa ter em mente ao tentar fazer melhoria de processos de software são as pessoas, o que é fundamentalmente o proposto pelo PSP ao desenvolver uma estratégia abrangente para a melhoria pessoal em Engenharia de Software, combinando melhorias incrementais do tipo práticas de Engenharia de Software, medições e um maior foco em qualidade, todos em nivel individual. É uma abordagem bottom-up (de baixo para cima) para a melhoria do processo de software, oposto à pesada estratégia top-down (de cima para baixo) dos demais modelos apresentados, que ajuda os engenheiros de software a fazer melhores estimativas de tempo, a inserir poucos defeitos a a melhorar as suas produtividades ao construir software [Pre95b]. 


\section{Uma ferramenta para apoio ao PSP}

\subsection{Considerações Iniciais}

O Processo de Software Pessoal envolve um número considerável de tarefas não triviais, dados de processo para serem coletados e manuseados e cálculos para serem feitos. Por essas razões, o apoio automatizado a essas atividades traria significativa ajuda para os engenheiros de software. As maiores vantagens desse apoio seriam: simplificar a coleta de dados de tempos e defeitos, fazer os cálculos que o PSP necessita, garantir a consistência e integridade dos dados (removendo assim a necessidade de copiar ou transferir os dados manualmente), fornecer pronto acesso aos formulários de dados, armazenar automaticamente os dados para propósitos de análise histórica, fornecer orientações do processo (sobre a seqüência de tarefas PSP) e fornecer indicadores dinâmicos do desempenho do processo atual e projeções da conclusão do trabalho.

Os métodos e o conjunto de dados relacionados ao PSP podem ser executados com caneta, papel e a ajuda de uma calculadora. Entretanto, este tipo de execução é maçante e consome uma substancial quantidade de tempo, está sujeito a erros humanos freqüentes e gera dados inconsistentes. Existe também o risco de perder esses dados. $O$ acompanhamento preciso de tempo, manualmente, é dificil. Este cenário poderá ser agravado se o PSP tiver que ser personalizado ao processo pessoal de alguém, requerendo assim mudanças trabalhosas nos formulários.

Por outro lado, existe uma forte demanda por ferramentas automatizadas que apoiam o PSP [dTdS97]. Entretanto, essas ferramentas não poderiam ser um inconveniente para os seus usuários e uma ferramenta que apoia o PSP deve ser transparente com relação à tarefa em execução, permitindo assim aos desenvolvedores focar suas atenções nos produtos ao invés do processo. Atualmente estão disponiveis, além do PSPBuilder [Sil98], ferramenta tema deste trabalho, as ferramentas PSPTool0.6 [Wor97], TimeLog [Lah97], Timmie [IPD97] e PSP Studio [ETS97], todas ferramentas que apoiam o PSP. 
Neste capitulo apresentam-se inicialmente os requisitos ideais que uma ferramenta automatizada que apoie o PSP deveria conter. Em seguida é apresentada a descrição geral da ferramenta PSPBuilder, as avaliações de qualidade de algumas das ferramentas que apoiam o PSP descritas anteriormente em relação às orientações mínimas do SEI para a automação do PSP [CMU96] e, finalmente, é feita uma análise comparativa destas ferramentas de software seguindo parcialmente os critérios da Norma ISO/IEC 12119 [ISO94] em relação às mesmas orientações mínimas do SEI (Software Engineering Institute).

\subsection{Especificação de uma Ferramenta Automatizada que apoie o PSP}

Os requisitos ideais que uma ferramenta automatizada que apoie o PSP deve contemplar estão agrupados a seguir em seis categorias, que correspondem às seis características básicas de qualidade que um produto de software deve ter segundo a Norma NBR ISO/IEC 9126 [NBR94]. As categorias são: Funcionalidade, Confiabilidade, Usabilidade, Eficiência, Manutenibilidade e Portabilidade.

\section{Funcionalidade.}

Os dados básicos ao longo do processo são classificados em três subcategorias, a saber: tempos por fase, tamanho de programa e defeitos.

Tempos por Fase: A ferramenta deve registrar os tempos gastos em cada uma das dez fases PSP propostas originalmente. Em cada registro de tempo deverão ser informados os instantes inicial e final ou sua duração em minutos e a fase ou ciclo em que se encontra. $O$ produto deve permitir que os formulários Diário de Registro de Tempo, Diário de Registro de Defeito, Proposta de Melhoria do Processo e o Diário de Temas para Debate estejam disponiveis aos usuários a todo instante durante o processo de desenvolvimento e devem ser preenchidos automaticamente pela ferramenta ou editados manualmente. A ferramenta deve garantir também que nenhum controle evidente seja imposto, ou seja, usuários podem operar em qualquer fase que eles acharem apropriado. Entretanto, a disponibilidade de formulários completos e dados gerados impõe uma ordenação parcial sobre a seqüência de atividades. A ferramenta deve funcionar mesmo que alguns registros históricos estejam indisponiveis para 
prever produtividade, médias de defeitos injetados e removidos e tamanho de código. Se tais registros históricos estiverem indisponíveis, isto é, se o sistema de apoio ao PSP automatizado não estivesse previamente sendo usado, assim mesmo o sistema deveria ser capaz de funcionar. Isso inicialmente afeta as atividades associadas com os formulários de Estimativa de Tamanho e Resumo do Plano do Projeto.

Tamanho de Programa: A ferramenta deve permitir que o usuário informe manualmente o tamanho do software quando necessário. Alternativamente, a ferramenta deve permitir também medir automaticamente o tamanho do software diretamente com o auxílio de ferramentas ou utilitários externos.

Defeitos: Um defeito é um problema que evita que o software funcione corretamente. A ferramenta deve permitir fazer as adaptações necessárias para acomodar novas interpretações de defeitos. Assim como um defeito pode ser encontrado a qualquer momento, este também poderá ser registrado a qualquer momento.

Os tempos, tamanhos de programa e defeitos se combinam e a ferramenta deve produzir as seguintes métricas calculadas: Tempo total por fase e geral; Defeitos injetados por fase; Defeitos removidos por fase e geral; LOC (Line Of Code - Linhas de Código) por hora; Índice de Desempenho de Custo; Esforço de Revisão de Projeto e Código (1 menos o percentual de total de defeitos por KLOC (1000 LOC) que foi encontrado na fase de teste); Razão entre a Avaliação e Falha do Custo de Qualidade (razão entre o tempo das fases de revisão e o tempo das fases de compilação e teste); Defeitos por hora e por fase; e, Média de remoção de defeito.

Para o propósito de autópsia, a ferramenta deve apresentar e permitir a impressão dos Resumos do Plano do Projeto para todas as sete etapas do PSP (PSP0, PSP0.1, PSP1, PSP1.1, PSP2, PSP2.1 e PSP3) no final do desenvolvimento.

A ferramenta deve também inserir automaticamente os dados de cabeçalhos de todos os formulários com base nas informações fornecidas desde a assinatura eletrônica ao iniciar uma nova atividade de desenvolvimento, de tal maneira que o desenvolvedor não precise informar um dado mais que uma vez. Essas informações são o nome do desenvolvedor, o nome do programa, a identificação do programa, a linguagem utilizada e a data atual.

Para propósitos de revisões, o sistema deve manter uma lista de itens checados e permitir a impressão dessa lista quando necessária. Cada item de verificação deve ser classificado quando estiver sendo aplicado, ou seja, de revisão de código, revisão de projeto ou de requisitos. 
A ferramenta deve apoiar o usuário em estimar os tempos e tamanhos de um projeto com base no seu desempenho histórico. Para propósitos de planejamento, os dados históricos de um desenvolvedor devem ser preservados.

Desempenho Histórico: $O$ produto deve armazenar os pares tamanhos estimado e realizado para todos os programas de um desenvolvedor. Esse é o propósito do método PROBE de estimativa baseada em regressão.

Acúmulos: As métricas tempos por fase, tempo total, defeitos injetados por fase, defeitos removidos por fase, defeitos totais, LOC novas e alteradas totais e tamanho total em LOC devem ser acumuladas para todos os projetos de um mesmo desenvolvedor.

Para o processo de Planejamento, o Modelo de Estimativa de Tamanho é utilizado para estimar tamanhos de programas. Uma instância desse formulário deve ser empregada para cada módulo e cada um desses módulos constitui um Ciclo PSP. Os desenvolvedores devem desenvolver suas próprias categorias de tamanho de software, tais como: Tamanho de um programa base (zero se nenhum programa base está sendo alterado); Exclusões de um programa base; Instruções modificadas em um programa base; Tamanhos totais de novas instruções e novos objetos; e Tamanho total de itens reutilizados.

Uma das categorias deve ser selecionada como base da estimativa de tempo. É recomendado que a estimativa de tempo leve em consideração o tamanho de LOC novas e alteradas do software. O PSP não tem a necessidade de ser praticado em ciclos. Se o desenvolvimento cíclico não é necessário, este é tratado como um projeto de um único ciclo. Caso contrário, o Resumo do Plano do Projeto Final é um acúmulo dos diversos ciclos utilizados e neste caso, o usuário registra os tempos selecionando o ciclo que está sendo praticado.

Assim que o Plano do Projeto e o Plano Cíclico são finalizados, o Modelo de Planejamento de Tarefas é desenvolvido. Cada tarefa pertence a uma fase especifica de um particular ciclo e seus tempos planejados são informados. O usuário poderá então informar uma data final pretendida para cada uma das tarefas.

Apoio à estimativa é altamente necessário. '́ uma estimativa realista de tempo, considerando o desempenho histórico e fórmulas matemáticas.

O produto deve permitir que a qualquer momento possam ser emitidos relatórios de todos os principais formulários PSP, divulgando assim os resultados. 
O Diário de Temas para Debate consiste em número, data e descrição das questões. Estas questões são de problemas relacionados ao programa ou exercício e não ao processo. Este formulário deverá estar disponivel a todo instante. Futuramente o sistema poderá permitir que este formulário possa ter a sua capacidade melhorada. $O$ formulário atual fornece quatro elementos de informação: Número do Tema, Data, Fase e Descrição. Um quinto elemento poderá ser incorporado: a Fase de Solução, que indica quando o tema foi resolvido. Com a adição desse novo elemento, a Fase proposta inicialmente deverá ser renomeada para Fase de Inserção.

A Proposta de Melhoria do Processo consiste de problemas relacionados ao processo e suas soluções propostas. Um programa ou exercício poderá estar relacionado a vários destes problemas e soluções. Também este formulário deve estar disponivel a todo instante.

\section{Confiabilidade.}

A ferramenta deve garantir que nenhum dado seja informado mais que uma vez, garantindo assim a sua integridade.

A ferramenta deve garantir também a privacidade dos dados, de tal maneira que somente os desenvolvedores têm acesso aos seus próprios dados pessoais. Entretanto, funcionalidade também deve ser fornecida para que os dados médios de projeto possam ser divulgados publicamente e o desenvolvedor possa ter acesso público autorizado a selecionar os diversos grupos de formulários de seus dados pessoais.

\section{Usabilidade.}

A ferramenta deve oferecer menus suspensos e em cascata, assim como uma barra de ferramentas das principais funções utilizadas para uma maior agilidade na operação do sistema. $O$ produto deve fornecer também ajuda on-line adequada e sensível ao contexto, orientando como executar cada uma das atividades, desenvolvendo assim o cenário operacional, e como completar cada um dos formulários.

A ferramenta deve também permitir que algumas adaptações do processo original proposto para o usuário final possam ser consideradas, tais como: os tipos de defeitos possam ser alterados ou subdivididos, as fases possam ser adicionadas ou eliminadas e os seus nomes alterados, adaptando assim a ferramenta ao seu próprio processo de software pessoal. 


\section{Eficiência.}

A ferramenta deverá proporcionar um ganho de no mínimo $8 \%$ de tempo em relação ao procedimento manual.

\section{Manutenibilidade.}

Uma funcionalidade futura poderia ser a adaptação da ferramenta a usar outras unidades de medidas de tamanho de software, tal como Pontos por Função, por exemplo.

\section{Portabilidade.}

A ferramenta deve atender às plataformas Windows 3.XX, 9X e NT, e também UNIX (Linux e Solaris).

\subsection{Descrição Geral do PSPBuilder}

A decisão de implementar uma ferramenta que apoiasse o PSP foi tomada em Junho de 1997. Até aquele momento não havia divulgação alguma de desenvolvimentos semelhantes a este, muito menos de produtos já disponíveis. Independente da razoável quantidade de produtos que atualmente apoiam o PSP, nota-se que uns são mais específicos que outros, mas de uma maneira geral não atendem por completo todos os requisitos ideais do PSP e as particularidades de cada ambiente de desenvolvimento, tais como a contagem de linhas de código para uma linguagem de programação específica.

Algumas características da ferramenta automatizada PSPBuilder 1.0 são: gráfica e de interface amigável (GUI - Graphical User Interfaces), lógica distribuida em camadas (ClienteServidor), orientada a objetos e ao ambiente operacional de 32 bits (Windows 9X ou NT), com coleta de dados automática. Os recursos gráficos e interação amigável são explorados para facilitar o uso e operação da ferramenta; a orientação a objetos e a lógica distribuída em camadas torna a ferramenta simples, modular e integra, permitindo assim uma grande escalabilidade; a orientação aos sistemas operacionais de 32 bits deve-se à grande aceitação e popularidade destes ambientes operacionais atualmente; e por fim, a coleta automática de dados visa a facilitar e precisar ao máximo as tomadas de tempo, independentemente do usuário. 
A ferramenta é codificada na linguagem visual RAD (Rapid Application Development) de desenvolvimento de sistemas PowerBuilder 5.0 e armazena as informações no Banco de Dados Relacional SQL Anywhere 5.0, ambos da Sybase. As opções do menu suspenso principal da ferramenta PSPTool são os relatórios Resumos do Plano do Projeto, os principais Cadastros de um projeto ou treinamento, as estimativas ou Planos para cada etapa do PSP, os diversos Apontamentos e as principais Consultas do PSP.

A opção Cadastros é constituida de Instrutor, Projeto, Programa, Estudante, Exercicio, Teste, Processo, Fase e Tipos de Defeito Padrão. A op̧̧ão de Apontamentos é de Inicio de Atividade, Interrupção Imediata ou Histórica, Defeito e de Término de Atividade. Para a medição de tamanhos (LOC) são utilizados os itens $A P U$ (utilitário do PowerBuilder que associa os diversos objetos a uma aplicação), a Contagem de LOC e Métodos de objetos e o registro das LOC codificadas durante o desenvolvimento. A PMP (Proposta de Melhoria do Processo) é também fornecida nesta opção, assim como os cálculos dos Parâmetros de Regressão Linear e Tamanhos Relativos utilizados no método PROBE. A opção Consultas é fornecida pelos itens Registro Diário de Tempos, Registro Diário de Defeitos e os relatórios Densidades de Defeito, Defeitos de Compilação e Teste e Tempos de Correção de Defeito. E por última, a opção Resumos é constituida por todos os niveis PSP, de 0 a 3 .

Além deste menu suspenso, a ferramenta também apresenta uma barra de icones com as principais e mais utilizadas funções, tais como os Cadastros de Instrutor, Projeto, Programa, Estudante, Exercicio, Processo, Fase e Tipos de Defeito Padrão, os Apontamentos de Inicio de Atividade, Interrupção Imediata, Interrupção Histórica, Defeito e Término de Atividade, além da Ajuda On-line e Finalização. Para essas funçōes, basta pressionar uma vez o ícone (um clique do mouse). Um clique apenas para interromper uma atividade em andamento e uma declaração da interrupção e/ou novamente um clique do mouse para dar continuidade à mesma atividade.

O estágio atual da ferramenta implementa o nivel 2.1 do PSP. Permite registrar os tempos das atividades e interrupções com precisão de segundos; as quantidades de defeitos localizados, removidos e injetados, assim como detalhes sobre estes defeitos e o tempo gasto em corrigi-los; automatiza muitos dos cálculos necessários com base nos dados fornecidos (dados históricos), tais como a contagem de linhas de código (LOC), estimativas de LOC a partir das linhas de código contadas e estimativas de tempo e defeitos a partir das linhas estimadas; e, apóia as revisões de código e de projeto, calculando muitas das métricas, tais como Yield (Esforço da 
Revisão de Projeto), médias de defeitos removidos, de tal maneira que seja possível quantificar o esforço nas revisões e se está beneficiando ou não o processo. Possibilita também o preenchimento dos Relatórios de Teste, os Modelos de Projèto, as Propostas de Melhoria do Processo e o Registro de Problemas durante o desenvolvimento.

O PSPBuilder permite também personalizar os tipos de defeitos, os processos e as fases de uma maneira ilimitada, refinando em mais categorias e subcategorias. Todas as informações fornecidas são editáveis. Todos os formulários podem ser apresentados a qualquer momento e permitem a impressão. Toda informação é fornecida apenas uma vez e apresentada sempre da mesma forma onde for necessário. A instalação é feita apenas com a execução de uma simples instrução: SETUP. Os runtimes do PowerBuilder e do Banco de Dados Relacional SQL Anywhere acompanham a mídia de instalação. $O$ espaço em disco necessário para a sua instalação é de aproximadamente $20 \mathrm{Mb}$ (Hard Disk). A versão atual é a 1.0 e estará liberada a partir da conclusão desta dissertação.

\subsection{Modelo Conceitual de Dados do PSPBuilder}

A seguir são apresentados o Modelo Conceitual de Dados da etapa PSP0 para a ferramenta PSPBuilder (Figura 13), sua notação (Figura 14) e a definição de cada entidade ou objeto que compõem esse modelo:

- Instrutor: pessoa responsável pelo treinamento PSP. Este papel poderia ser desempenhado pelo gerente de projeto de uma equipe de desenvolvimento de sistemas em uma empresa. Alguns de seus atributos são: nome completo, identificação e senha;

- Projeto: é o próprio treinamento PSP ou o desenvolvimento e manutenção de um sistema em uma empresa desenvolvedora de software. Um projeto tipicamente produz um ou vários produtos (programas). Alguns de seus atributos são: descrição e identificação;

- Programa: especificação de cada programa-exercício componente do treinamento PSP ou aplicação de um software. Definição do futuro exercício ou aplicação que fará parte integrante de um software. Seus principais atributos também são descrição e identificação; 


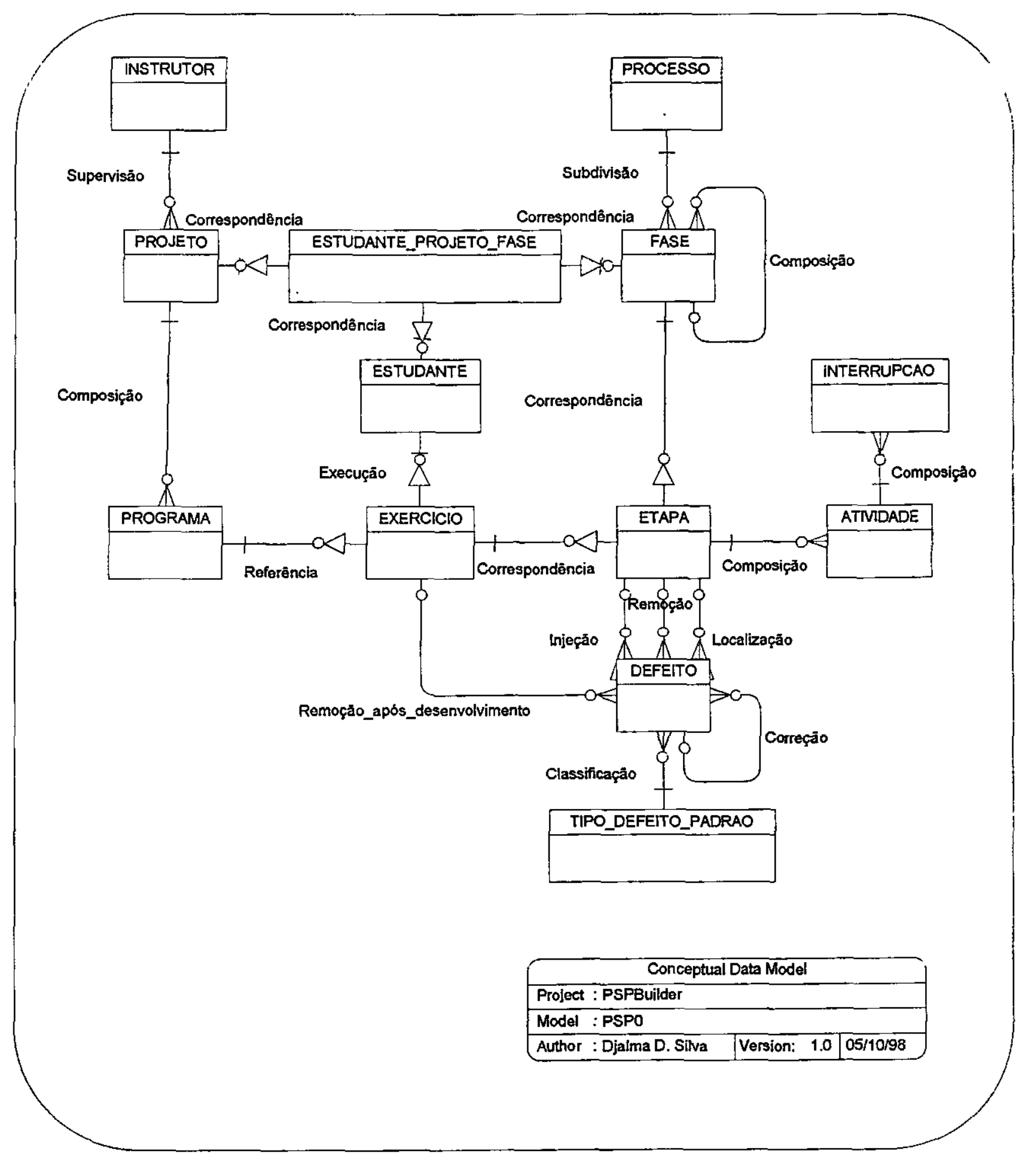

Figura 13. Modelo Conceitual de Dados da etapa PSP0 para o PSPBuilder

- Estudante: participante aprendiz do treinamento PSP ou componente da equipe de desenvolvimento de um sistema, tal como um programador. Como principais atributos, além 
do nome completo, possui identificação e senha, e a quantidade total de defeitos removidos após o desenvolvimento;

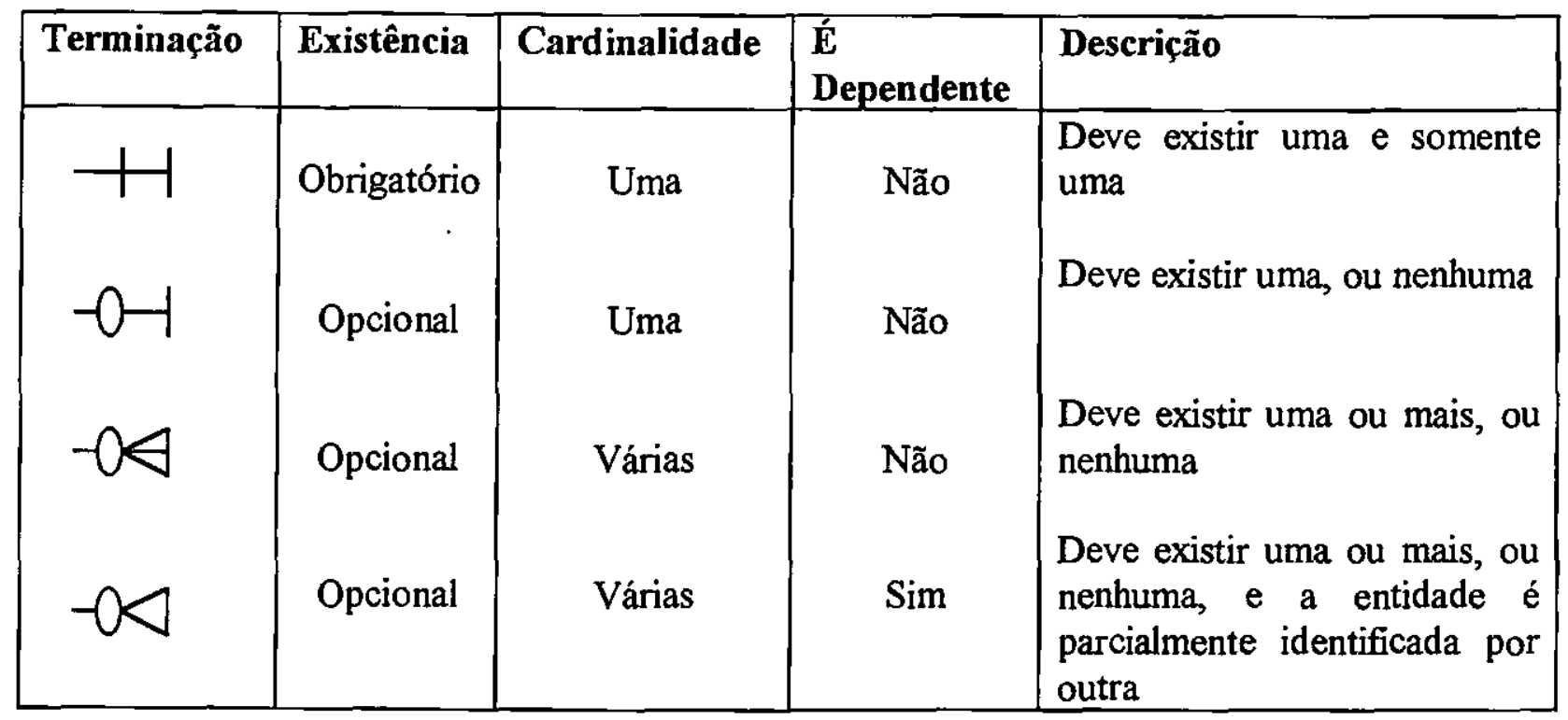

Figura 14. Notação do Modelo Conceitual de Dados

- Exercício: É o produto produzido a um cliente interno, ao empregador, a um cliente externo ou si mesmo, tal como no caso de um treinamento. Seus atributos principais são: a linguagem de programação escolhida para implementar o programa, o tempo total estimado e a quantidade total de defeitos removidos após o desenvolvimento desta implementação;

- Processo: define a forma de conduzir projetos. Processos geralmente possuem várias fases ou etapas, tais como planejamento, desenvolvimento e teste. Seus principais atributos são identificação e descrição;

- Fase: subdivisão de um processo. Pode ser composto por múltiplas tarefas ou atividades, tais como teste de integração, teste de produto e teste de sistema. Descrição da fase, referência à descrição da fase da qual faz parte e indicação de qual nível do processo pertence, se PSP0 ou PSP2.1 por exemplo, são os seus atributos;

- Etapa: apontamentos de atividades e defeitos para uma determinada fase e exercício de um projeto. Seus principais atributos são na verdade derivações de características de outras entidades com quem se relaciona diretamente, tais como quantidade de defeitos injetados, defeitos removidos e tempos realizados; 
- Atividade: elemento definido de trabalho. Também chamada de tarefa. Seus atributos são identificação, instantes de início e término, duração líquida e comentário;

- Interrupção: paralisações durante a execução de uma atividade ou tarefa de um projeto. Seus atributos são semelhantes à da atividade à qual pertence, ou seja, identificação, instantes de inicio e término, duração e descrição da interrupção;

- Defeito: algo que está errado com um programa ou produto, tal como um erro de sintaxe, um erro de pontuação ou um comando de programa incorreto. Um defeito poderá ser a conseqüência da correção de um outro defeito e é recomendável identificar as etapas que originalmente localizou, injetou e removeu o defeito. Por esta razão, na medida do possivel deverão ser informados o número do defeito que provocou o atual defeito ao fazer a devida correção, a etapa na qual o defeito foi.injetado, localizado e removido, o tipo de defeito padrão segundo a classificação de Chillarege [Chi92], a identificação do exercício atual quando se tratar de remover o defeito após o desenvolvimento, descrição do defeito, duração da correção do defeito, instantes de início e término dessa correção e a sua própria identificação;

- Tipo_Defeito_Padrão: classificação padrão de defeitos em categorias originalmente propostas por Chillarege. Seus atributos são: identificação, nome e descrição.

- Estudante_Projeto_Fase: apontamentos de atividades e defeitos para uma determinada fase de um projeto e estudante. Seus principais atributos são: quantidades de defeitos injetados, defeitos removidos e tempos realizados.

No Apêndice 1 é apresentado o Modelo Conceitual de Dados Completo de toda a ferramenta PSPBuilder, relacionando todas as entidades, atributos e relacionamentos, particionado para as etapas PSP0, PSP0.1, PSP1 e PSP1.1.

\subsection{Avaliação da Qualidade das Ferramentas PSP mais Completas}

Dentre as ferramentas que apoiam o PSP apresentadas anteriormente, o PSPBuilder, 0 PSP Studio e o PSPTool0.6 são as mais completas. Apresenta-se a seguir uma avaliação sucinta da qualidade dessas ferramentas, elegendo um conjunto de requisitos mínimos do que o SEI espera do apoio automatizado ao PSP. 
Antes, porém, são listados esses requisitos mínimos e orientações gerais a serem consideradas na construção de uma ferramenta automatizada que apoie o PSP sugeridos pelo SEI [CMU96]:

1. O sistema deve permitir que algumas adaptações do processo original proposto para o usuário final possam ser consideradas, por exemplo, os tipos de defeitos podem ser alterados ou subdivididos, ou os nomes das fases também podem ser alteradas;

2. O sistema deve garantir privacidade de dados, do tipo: o sistema deverá fornecer segurança apropriada, tal que somente os desenvolvedores possam ter acesso aos seus próprios dados pessoais. Entretanto, funcionalidade deverá ser fornecida para que os dados médios de projeto possam ser divulgados publicamente e o desenvolvedor deverá ter acesso público autorizado a selecionar os diversos tipos de formulários de seus dados pessoais;

3. O sistema deve garantir que nenhum dado seja informado mais que uma vez. Os dados são copiados automaticamente e atualizados entre os formulários;

4. O sistema deve garantir que nenhum controle evidente seja imposto, ou seja, usuários podem operar em qualquer fase que eles acharem apropriado. Entretanto, a disponibilidade de formulários completos e dados gerados impõe uma ordenação parcial sobre a seqüência de atividades. Em outras palavras, o sistema não deverá forçar demasiadamente uma seqüência de atividades restritiva e preconcebida sobre os usuários, tal como "desculpe-me, você não pode fazer isto porque você não completou aquilo";

5. O sistema deve permitir que ajuda on-line adequada e sensível ao contexto seja fornecida. No mínimo, o sistema deverá fornecer diretrizes sobre como executar cada uma das atividades, ou seja, desenvolver o cenário operacional, e como completar cada um dos formulários;

6. O sistema deverá automaticamente inserir as informações de cabeçalho quando um gabarito é gerado para qualquer formulário, ou seja, o nome do desenvolvedor, o nome do programa, a identificação do programa, a linguagem utilizada e a data de início. Essas informações serão fornecidas pelo sistema automatizado que apóia o PSP quando o usuário inicia uma nova atividade de desenvolvimento;

\footnotetext{
${ }^{4}$ Humphrey recomenda enfaticamente que tais adaptações, se necessárias, sejam feitas após o curso e também após um longo periodo de uso do PSP original em vários projetos.
} 
7. O sistema deve permitir que os seguintes formulários sejam acessiveis pelos usuários a todo instante durante o processo de desenvolvimento: Diário de Registro de Tempo (C16), Diário de Registro de Defeito (C18), Proposta de Melhoria do Processo (PMP ou C27) e o Diário de Temas para Debate (C85). Como esses formulários são utilizados por todo o PSP, eles geralmente não são explicitamente especificados como entradas ou saídas para a maioria das atividades. O ideal é que o formulário C16 não apenas seja completado automaticamente pelo sistema (utilizando o cronômetro PSP, formulário RFT), mas também editado manualmente;

8. O sistema deve registrar em qual fase o usuário se encontra (os usuários finais fornecem informações da fase ao sistema) e medir os tempos transcorridos correspondentes e gastos na fase (formulário RFT, Registro de Fases e Tempos). Os dados do formulário RFT são automaticamente transferidos para o formulário $\mathrm{C} 16$;

9. O sistema deve ser capaz de funcionar mesmo que alguns registros históricos estejam indisponiveis. Ao executar uma tarefa de desenvolvimento, o PSP necessita que os dados históricos estejam disponíveis para prever produtividade, médias de defeitos injetados e removidos e tamanho do código. Se tais registros históricos estiverem indisponíveis, isto é, se o sistema de apoio ao PSP automatizado não estivesse previamente sendo usado, assim mesmo o sistema deveria ainda ser capaz de funcionar. Isso inicialmente afeta as atividades associadas com os formulários: Estimativa de Tamanho (C39) e Resumo do Plano do Projeto (C80);

10. O sistema deve permitir que o Diário de Temas para Debate (C85) possa ter a sua capacidade melhorada devido à automação. O formulário atual fornece quatro elementos de informação: Número do Tema, Data, Fase e Descrição. Um quinto elemento poderá ser incorporado: a Fase de Solução, que identifica quando o tema foi resolvido. Com a adição desse novo elemento, a Fase proposta inicialmente deverá ser renomeada para Fase de Inserção.

\subsubsection{PSPTOol0.6}

É apresentada na Tabela 10 uma avaliação da ferramenta PSPTool0.6 com relação aos requisitos relacionados acima. 
Tabela 10. Avaliação da ferramenta PSPTool0.6

\begin{tabular}{|c|c|}
\hline Requisitos & PSPTool0.6 \\
\hline $\begin{array}{l}\text { 1. Permite adaptações do } \\
\text { processo original. }\end{array}$ & $\begin{array}{l}\text { Somente personalização de Tipos de Defeito Padrão são } \\
\text { permitidos. Novas fases do processo não são permitidas. }\end{array}$ \\
\hline $\begin{array}{l}\text { 2. Fornece privacidade dos } \\
\text { dados individuais e acesso } \\
\text { irrestrito aos dados médios de } \\
\text { projeto. }\end{array}$ & $\begin{array}{l}\text { O software é monousuário, não permitindo assim divulgação de } \\
\text { dados médios de projeto em um treinamento ou } \\
\text { desenvolvimento em equipe. A privacidade é coberta pela } \\
\text { autoridade de acesso ou não ao diretório de instalação da } \\
\text { ferramenta. Não existe segurança lógica (exigência de se } \\
\text { identificar com nome e assinatura eletrônica). }\end{array}$ \\
\hline $\begin{array}{l}\text { 3. Garante que o dado seja } \\
\text { informado uma única vez. }\end{array}$ & $\begin{array}{l}\text { Satisfaz este requisito e salva a configuração da última utilização } \\
\text { do software, por exemplo, o projeto em andamento. Existe o } \\
\text { risco aqui de sobrepor as informações de um projeto ao se criar } \\
\text { um novo projeto, caso o usuário não tome o cuidado de } \\
\text { escolher um nome diferente. }\end{array}$ \\
\hline $\begin{array}{l}\text { 4. Permite que nenhum } \\
\text { controle evidente seja imposto. }\end{array}$ & $\begin{array}{l}\text { Dificil acesso a dados históricos, provocando riscos ao analisar } \\
\text { programas e projetos anteriores. A ferramenta não permite } \\
\text { consultar projetos anteriores. Analisar sob esta estrutura de } \\
\text { arquivos é muito trabalhoso e suscetível a erros. É necessário } \\
\text { manipular arquivos textos ao ler dados históricos. }\end{array}$ \\
\hline $\begin{array}{l}\text { 5. Fornece ajuda on-line } \\
\text { adequada e sensivel ao } \\
\text { contexto. }\end{array}$ & $\begin{array}{l}\text { Nenhum tipo de ajuda on-line é fornecida, apesar da interface } \\
\text { parecer auto-explicativa. O recurso utilizado para o seu } \\
\text { desenvolvimento (linguagem de programação TCL/TK) não } \\
\text { explora muito os recursos do Sistema Operacional Windows. Ė } \\
\text { um recurso do UNIX adaptado para o Windows. }\end{array}$ \\
\hline $\begin{array}{l}\text { 6. Fornece preenchimento } \\
\text { automatizado do cabeçalho dos } \\
\text { formulários. }\end{array}$ & Somente um projeto pode ser trabalhado de cada vez. \\
\hline $\begin{array}{l}\text { 7. Permite que os formulários } \\
\text { estejam acessíveis a todo } \\
\text { instante. }\end{array}$ & $\begin{array}{l}\text { Não permite a impressão. Deve-se usar o recurso de dump de } \\
\text { telas. }\end{array}$ \\
\hline $\begin{array}{l}\text { 8. Permite o registro da fase } \\
\text { atual e o registro automatizado } \\
\text { e manual de tempos. }\end{array}$ & $\begin{array}{l}\text { Registros de tempos e defeitos são totalmente implementados, } \\
\text { inclusive nas interrupções e correções de defeitos. }\end{array}$ \\
\hline $\begin{array}{l}\text { 9. Garante funcionalidade, } \\
\text { apesar de informações } \\
\text { indisponíveis. }\end{array}$ & $\begin{array}{l}\text { Apresenta fraca estrutura de arquivos, podendo provocar sérios } \\
\text { problemas futuros. }\end{array}$ \\
\hline $\begin{array}{l}\text { 10. Fornece melhoria ao } \\
\text { formulário Diário de Temas } \\
\text { para Debate (C85). }\end{array}$ & $\begin{array}{l}\text { Não implementa a Proposta de Melhoria de Processo e o } \\
\text { Diário de Temas para Debate. }\end{array}$ \\
\hline
\end{tabular}




\subsubsection{PSP Studio}

Na Tabela 11 é apresentada a avaliação da ferramenta PSP Studio com relação também aos requisitos do SEI.

\section{Tabela 11. Avaliação da ferramenta PSP Studio}

\begin{tabular}{|c|c|}
\hline Requisitos & PSP Studio \\
\hline $\begin{array}{l}\text { 1. Permite adaptações do } \\
\text { processo original. }\end{array}$ & $\begin{array}{l}\text { Permite somente personalização de Tipos de Defeito Padrão. } \\
\text { Novas fases do processo não são permitidas. }\end{array}$ \\
\hline $\begin{array}{l}\text { 2. Fornece privacidade dos } \\
\text { dados individuais e acesso } \\
\text { irrestrito aos dados médios de } \\
\text { projeto. }\end{array}$ & $\begin{array}{l}\text { Este software também possui características monousuárias. } \\
\text { Conseqüentemente não permite o compartilhamento de dados } \\
\text { com os demais usuários. A privacidade é atendida também em } \\
\text { nível de autoridade de acesso ao diretório de instalação da } \\
\text { ferramenta. Nota-se também a omissão de se identificar ao } \\
\text { iniciar um novo projeto, ou seja, não possui indicação nenhuma } \\
\text { de quem desenvolve o projeto. }\end{array}$ \\
\hline $\begin{array}{l}\text { 3. Garante que o dado seja } \\
\text { informado uma única vez. }\end{array}$ & $\begin{array}{l}\text { Atende a este requisito. Oferece segurança ao criar um novo } \\
\text { projeto e impede a alteração das informações de projetos já } \\
\text { concluídos, com exceção de falhas durante o uso do software ou } \\
\text { após o seu desenvolvimento. }\end{array}$ \\
\hline $\begin{array}{l}\text { 4. Permite que nenhum } \\
\text { controle evidente seja imposto. }\end{array}$ & $\begin{array}{l}\text { A ferramenta permite fácil acesso a dados históricos de projetos } \\
\text { ou programas anteriores. Quando o número de programas é } \\
\text { inferior a } 3 \text {, não apresenta o formulário de Estimativa de } \\
\text { Tamanho em } L O C \text {, e somente na conclusão ou autópsia de um } \\
\text { programa é permitido informar defeitos durante o uso ou após o } \\
\text { seu desenvolvimento. }\end{array}$ \\
\hline $\begin{array}{l}\text { 5. Fornece ajuda on-line } \\
\text { adequada e sensivel ao } \\
\text { contexto. }\end{array}$ & $\begin{array}{l}\text { Fornece adequada ajuda on-line sensivel ao contexto. É } \\
\text { acompanhado também de um manual de instalação e operação } \\
\text { da ferramenta bastante ilustrativo e com exemplos de uso. } \\
\text { Explora bem os recursos de interface do Sistema Operacional } \\
\text { Windows (Multiple Document Interface, menus suspensos, em } \\
\text { cascata e pop-ups, barra de ícones e OLE). }\end{array}$ \\
\hline $\begin{array}{l}\text { 6. Fornece preenchimento } \\
\text { automatizado do cabeçalho dos } \\
\text { formulários. }\end{array}$ & Vários projetos podem ser trabalhados ao mesmo tempo. \\
\hline $\begin{array}{l}\text { 7. Permite que os formulários } \\
\text { estejam acessíveis a todo } \\
\text { instante. }\end{array}$ & $\begin{array}{l}\text { Permite a impressão dos formulários a qualquer momento, } \\
\text { mesmo de projetos e programas anteriores. }\end{array}$ \\
\hline $\begin{array}{l}\text { 8. Permite o registro da fase } \\
\text { atual e o registro automatizado } \\
\text { e manual de tempos. }\end{array}$ & $\begin{array}{l}\text { Registros de tempos e defeitos são implementados de forma } \\
\text { automatizada e/ou manual. Os tempos de correção de defeitos } \\
\text { são informados manualmente. }\end{array}$ \\
\hline $\begin{array}{l}\text { 9. Garante funcionalidade, } \\
\text { apesar de informações } \\
\text { indisponíveis. }\end{array}$ & $\begin{array}{l}\text { Faz uso de um banco de dados relacional, proporcionando à } \\
\text { ferramenta segurança e confiabilidade. }\end{array}$ \\
\hline
\end{tabular}


Tabela 11. Avaliação da ferramenta PSP Studio (continuação)

\begin{tabular}{|l|l|}
\hline Requisitos & PSP Studio \\
\hline 10. Fornece melhoria ao & Implementa tanto o formulário de Proposta de Melhoria de \\
formulário Diário de Temas & Processo, quanto o formulário Diário de Temas para Debate, \\
para Debate (C85). & mas sem as melhorias sugeridas pelo requisito. \\
\hline
\end{tabular}

\subsubsection{PSPBuilder}

E por último, é apresentada na Tabela 12 a avaliação da ferramenta PSPBuilder com relação aos mesmos requisitos do SEI.

Tabela 12. Avaliação da ferramenta PSPBuilder

\begin{tabular}{|l|l|}
\hline Requisitos & PSPBuilder \\
\hline $\begin{array}{l}\text { I. Permite adaptações do } \\
\text { processo original. }\end{array}$ & $\begin{array}{l}\text { Permite não só a personalização de Tipos de Defeito Padrão, } \\
\text { mas também a inclusão de novas fases e alterações das fases já } \\
\text { existentes no processo. }\end{array}$ \\
\hline $\begin{array}{l}\text { 2. Fornece privacidade dos } \\
\text { dados individuais e acesso } \\
\text { irrestrito aos dados médios de } \\
\text { projeto. }\end{array}$ & $\begin{array}{l}\text { O PSPBuilder foi concebido já com características } \\
\text { multiusuárias, podendo ser utilizado em rede e compartilhado } \\
\text { com vários desenvolvedores. Está preparado para implementar a } \\
\text { divulgação de dados médios de projeto em um treinamento ou } \\
\text { desenvolvimento em equipe e também de ser evoluído para a } \\
\text { Internet/Intranet (WWW), já que foi desenvolvido em camadas } \\
\text { (Three Tiers) e também Orientado a Objetos (OO), permitindo } \\
\text { dessa maneira uma grande reutilização do desenvolvimento. Ao } \\
\text { iniciar a execução do software, é apresentado um diálogo } \\
\text { solicitando a identificação e senha eletrônica do desenvolvedor. }\end{array}$ \\
\hline $\begin{array}{l}\text { 3. Garante que o dado seja } \\
\text { informado uma única vez. }\end{array}$ & $\begin{array}{l}\text { Também atende a este requisito. Segurança também é oferecida } \\
\text { ao se criar um novo projeto. Pode-se trabalhar com vários } \\
\text { projetos em andamento simultaneamente e não existe o } \\
\text { impedimento de se alterar projetos anteriores, inclusive falhas } \\
\text { durante o uso ou após o seu desenvolvimento. Os dados } \\
\text { acumulados são de todo o desenvolvimento de um mesmo } \\
\text { desenvolvedor (anterior e posterior) para um mesmo projeto. }\end{array}$ \\
\hline $\begin{array}{l}\text { 4. Permite que nenhum } \\
\text { controle evidente seja imposto. }\end{array}$ & $\begin{array}{l}\text { O PSPBuilder também permite fácil acesso a dados históricos de } \\
\text { projetos ou programas anteriores. Se o número de programas } \\
\text { for inferior a 3, é apresentada uma mensagem de que não podem } \\
\text { ser aplicados cálculos estatísticos ao estimar tamanhos de um } \\
\text { novo desenvolvimento em LOC. Quanto a informar defeitos } \\
\text { encontrados após o desenvolvimento de um programa, não } \\
\text { existe nenhuma restrição. }\end{array}$ \\
\hline
\end{tabular}


Tabela 12. Avaliação da ferramenta PSPBuilder (continuação)

\begin{tabular}{|l|l|}
\hline Requisitos & PSPBuilder \\
\hline $\begin{array}{l}\text { 5. Fornece ajuda on-line } \\
\text { adequada e sensivel ao } \\
\text { contexto. }\end{array}$ & $\begin{array}{l}\text { Fornece ajuda on-line sensivel ao contexto adequada. Na } \\
\text { primeira versão não é acompanhado de um manual de instalação } \\
\text { e operação da ferramenta. Explora razoavelmente bem os } \\
\text { recursos de interface do Sistema Operacional Windows } \\
\text { (Multiple Document Interface, menus suspensos e em cascata e } \\
\text { barra de ícones). }\end{array}$ \\
\hline $\begin{array}{l}\text { 6. Fornece preenchimento } \\
\text { automatizado do cabeçalho dos } \\
\text { formulários. }\end{array}$ & $\begin{array}{l}\text { Vários projetos também podem ser trabalhados ao mesmo } \\
\text { tempo. }\end{array}$ \\
\hline $\begin{array}{l}\text { 7. Permite que os formulários } \\
\text { estejam acessiveis a todo } \\
\text { instante. }\end{array}$ & $\begin{array}{l}\text { Permite a impressão de todos os formulários a qualquer } \\
\text { momento, mesmo que sejam de projetos e programas anteriores. }\end{array}$ \\
\hline $\begin{array}{l}\text { 8. Permite o registro da fase } \\
\text { atual e o registro automatizado } \\
\text { e manual de tempos. }\end{array}$ & $\begin{array}{l}\text { Os registros de tempos e defeitos são implementados de forma } \\
\text { automatizada e/ou manual. Os tempos de correção de defeitos, } \\
\text { apenas manualmente. }\end{array}$ \\
\hline $\begin{array}{l}\text { 9. Garante funcionalidade, } \\
\text { apesar de informações } \\
\text { indisponiveis. }\end{array}$ & $\begin{array}{l}\text { Faz uso de um banco de dados relacional que permite segurança } \\
\text { e confiabilidade ao ser compartilhado e usado por diversos } \\
\text { usuários. }\end{array}$ \\
\hline $\begin{array}{l}\text { 10. Fornece melhoria ao } \\
\text { formulário Diário de Temas } \\
\text { para Debate (C85). }\end{array}$ & \begin{tabular}{l} 
Implementa ambos os formulários sem as melhorias sugeridas. \\
\hline
\end{tabular}
\end{tabular}

\subsubsection{Análise Comparativa}

É apresentada na Tabela 13 uma análise comparativa das ferramentas avaliadas com relação aos requisitos do SEI relacionados acima. Cada requisito é avaliado para cada uma das ferramentas automatizadas que apoiam o PSP em SIM, se a ferramenta atende totalmente o requisito, NÃO, se a ferramenta não atende o requisito, e PARCIAL, se a ferramenta atende parcialmente o requisito.

Tabela 13. Comparativo entre algumas ferramentas PSP

\begin{tabular}{|l|c|c|c|}
\hline Requisitos & PSPTool0.6 & PSP Studio & PSPBuilder \\
\hline $\begin{array}{l}\text { 1. Permite adaptações } \\
\text { do processo original. }\end{array}$ & PARCIAL & PARCIAL & SIM \\
\hline
\end{tabular}


Tabela 13. Comparativo entre algumas ferramentas PSP (continuação)

\begin{tabular}{|l|c|c|c|}
\hline Requisitos & PSPTool0.6 & PSP Studio & PSPBuilder \\
\hline $\begin{array}{l}\text { 2. Fornece privacidade } \\
\text { dos dados individuais } \\
\text { e acesso irrestrito aos } \\
\text { dados médios de } \\
\text { projeto. }\end{array}$ & PARCIAL & PARCIAL & PARCIAL \\
\hline $\begin{array}{l}\text { 3. Garante que o dado } \\
\text { seja informado uma } \\
\text { única vez. }\end{array}$ & SIM & SIM & SIM \\
\hline $\begin{array}{l}\text { 4. Permite que } \\
\text { nenhum controle } \\
\text { evidente seja imposto. }\end{array}$ & NÃO & PARCIAL & SIM \\
\hline $\begin{array}{l}\text { 5. Fornece ajuda on- } \\
\text { line adequada e } \\
\text { sensível ao contexto. }\end{array}$ & NÃO & SIM & SIM \\
\hline $\begin{array}{l}\text { 6. Fornece } \\
\text { preenchimento } \\
\text { automatizado do } \\
\text { cabeçalho dos } \\
\text { formulários. }\end{array}$ & PARCIAL & PARCIAL & SIM \\
\hline $\begin{array}{l}\text { 7. Permite que os } \\
\text { formulários estejam } \\
\text { acessíveis a todo } \\
\text { instante. }\end{array}$ & PARCIAL & PARCIAL & PARCIAL \\
\hline $\begin{array}{l}\text { 8. Permite o registro } \\
\text { da fase atual e o } \\
\text { registro automatizado } \\
\text { e manual de tempos. }\end{array}$ & SIM & SIM & SIM \\
\hline $\begin{array}{l}\text { 9. Garante } \\
\text { funcionalidade, apesar } \\
\text { de informações } \\
\text { indisponiveis. }\end{array}$ & PARCIAL & SIM & \\
\hline $\begin{array}{l}\text { 10. Fornece melhoria } \\
\text { ao formulário Diário } \\
\text { de Temas para } \\
\text { Debate (C85). }\end{array}$ & NÃO & & \\
\hline
\end{tabular}

Atribuindo pesos 0 (zero) às avaliações que NÃO atendem os requisitos, 0.5 (meio) às avaliações que atendem PARCIALmente os requisitos e 1 (um) aos SIM, ou seja, às avaliações que atendem totalmente os requisitos, chega-se ao seguinte resultado: PSPTool0.6 com 4.5 
(quatro e meio pontos), PSP Studio com 7.5 (sete e meio pontos) e PSPBuilder com 9 (nove pontos) de um total de 10 (dez pontos).

\subsection{Considerações Finais}

O PSPBuilder é mais uma ferramenta que apoia o PSP, mas exclusiva para o ambiente de desenvolvimento de Sistemas de Informação que utiliza o PowerBuilder como linguagem de programação. A avaliação da qualidade das ferramentas PSPTool0.6, PSP Studio e PSPBuilder, consideradas as mais completas ferramentas que apoiam o PSP, seguiu os requisitos e orientações mínimas recomendadas pelo SEI.

O resultado da avaliação apresentada na Tabela 13 não demonstra uma superioridade da ferramenta PSPBuilder em relação às demais ferramentas avaliadas, mas sim uma preocupação inicial na sua concepção em atender os requisitos mínimos estabelecidos pelo SEI no que se refere à automação do PSP. As demais poderão no futuro evoluir para o mesmo nível de funcionalidade.

No próximo capítulo são apresentadas as adaptações do PSP para o Domínio de Sistemas de Informação que faz uso do PowerBuilder como ferramenta de desenvolvimento e os resultados obtidos da aplicação de um programa-exercício utilizando o PSPBuilder como ferramenta automatizada que apóia o PSP, especialmente concebida para apoiar este ambiente de desenvolvimento de Sistemas de Informação. Também é apresentado um comparativo do ganho de produtividade ou eficiência em se utilizar o PSPBuilder em relação ao procedimento manual. $\mathrm{O}$ emprego do procedimento manual serve como uma verificação da confiabilidade do software. 


\section{Adaptações do PSP para o Domínio de Sistemas de Informação e Exemplo de Uso do PSPBuilder}

\subsection{Considerações Gerais.}

O processo PSP proposto originalmente por Humphrey [Hum95a] é genérico o suficiente para ser empregado nos diversos ambientes de programação utilizados atualmente. Apesar desta generalidade, alguns recursos exigidos pelos programas-exercícios do treinamento PSP e alguns dos formulários deste mesmo processo são dependentes dos recursos de desenvolvimento disponiveis nesses ambientes de programação. Se adaptações desses programas-exercícios e formulários não forem feitas, estes se tornariam inapropriados, não permitindo assim atingir os objetivos estabelecidos pelo PSP.

O Domínio de Sistemas de Informação escolhido para este trabalho foi o desenvolvimento Cliente-Servidor que emprega a ferramenta RAD (Rapid Application Development) PowerBuilder e o banco de dados relacional Sybase SQL Anywhere, ambos da Sybase.

Inicialmente, será apresentada a adaptação do PSP para esse Dominio de Sistemas de Informação e em seguida um exemplo de uso da ferramenta tema desta dissertação, o PSPBuilder, ilustrando o desenvolvimento do primeiro programa-exercício proposto no treinamento PSP. No final deste capitulo são apresentadas algumas telas do PSPBuilder que implementam os demais formulários que compõem as etapas posteriores à PSP0 (PSP0.1 a PSP2.1).

\subsection{PSP para PowerBuilder}

O PSP depende da linguagem, do paradigma e dos recursos oferecidos pelo ambiente de programação que se está utilizando para a implementação dos programas. Por esse motivo, é imprescindivel construir uma versão PSP para a linguagem PowerBuilder se o desenvolvedor a 
utiliza para desenvolver os seus sistemas automatizados. Deve-se adaptar alguns dos formulários, tabelas, roteiros e exercícios, tais como: o Padrão de Codificação (C29), o Checklist de Revisão de Código (C58) e o Padrão de Contagem de Linha de Código, todas propostas por Humphrey [Hum95a].

Um padrão de codificação sugerido para a linguagem PowerBuilder é apresentado na Tabela 1 do Anexo A, Tabelas da Versão PSP para PowerBuilder, e deve ser usado como um guia ao se escrever os códigos fontes dos scripts de uma aplicação na linguagem PowerScript. Tal padrão, tipicamente, especifica a maneira de se formatar o código fonte, quais comandos deverão ficar em linhas separadas, como os comandos deverão ficar indentados, como definir comentários e como definir variáveis. $O$ padrão de codificação torna o código mais legível, facilitando a depuração, uso ou modificação do código fonte.

O Padrão de Contagem de LOC apresentado na Tabela 2 desse mesmo anexo especifica a maneira apropriada de contar linhas de código para a linguagem de programação em questão, 0 PowerScript. Dessa maneira, poderá ser medida e comparada a produtividade ao desenvolver um programa e medir o progresso à medida em que se avança nas etapas seguintes do PSP.

O checklist de revisão de código faz parte de um procedimento de revisão que auxilia eficientemente a encontrar defeitos. É uma maneira muito eficaz de garantir qualidade[Pre95a]. $O$ checklist proposto na Tabela 3 do Anexo A é o sugerido ao se codificar em PowerScript. Esse checklist recomenda vários pontos a considerar quando é desenvolvido um método (função ou evento) de uma aplicação. Note-se que este procedimento deverá ser executado momentos antes de finalizar a edição da função ou evento no painter PowerScript, pelo fato de o PowerBuilder compilar automaticamente ao sair do modo de edição ou ao se salvar um script.

Todas essas versões de tabelas são sugestões iniciais, que podem ser personalizadas pelo desenvolvedor, principalmente o Checklist de Revisão de Código (C58). Esse checklist resume os principais e mais freqüentes erros cometidos individualmente.

Os demais formulários, tabelas, roteiros e exercicios são de uso genérico, independente dos recursos disponiveis no ambiente de desenvolvimento. Sua personalização é recomendável após a conclusão do treinamento, uso e maturidade do processo PSP.

A seguir é apresentado um exemplo de uso da ferramenta automatizada PSPBuilder ao desenvolver o primeiro dos programas-exercicios propostos no treinamento PSP sugerido por Humphrey [Hum95a]. 


\subsection{Exemplo de Uso do PSPBuilder}

O uso da ferramenta automatizada PSPBuilder depende se esta já foi utilizada ou se é o primeiro uso após sua instalação e se é para um novo projeto ou para um já em andamento. No exemplo de uso do PSPBuilder descrito a seguir, considerou-se a primeira utilização da ferramenta e o início de um novo projeto, no caso, o projeto de treinamento PSP.

Sendo assim, inicialmente são detalhadas as atividades que antecedem o registro das fases que compõem o processo PSP e em seguida, a resolução do primeiro programa-exercício seguindo a etapa PSP0 de Medição Pessoal.

\subsubsection{Preliminares}

Ao iniciar o PSPBuilder, é apresentado um diálogo de assinatura eletrônica, Figura 15. O usuário deve identificar-se com o seu código, senha e tipo de usuário, se é estudante ou instrutor. Caso o estudante utilize o PSPBuilder pela primeira vez, terá que ser cadastrado pelo seu instrutor. Na execução do PSPBuilder logo após a sua instalação, o instrutor terá de informar a assinatura de usuário inicial cujo código é INSTRUTOR e senha INSTRUTOR, se cadastrar como instrutor e eliminar a assinatura de usuário inicial.

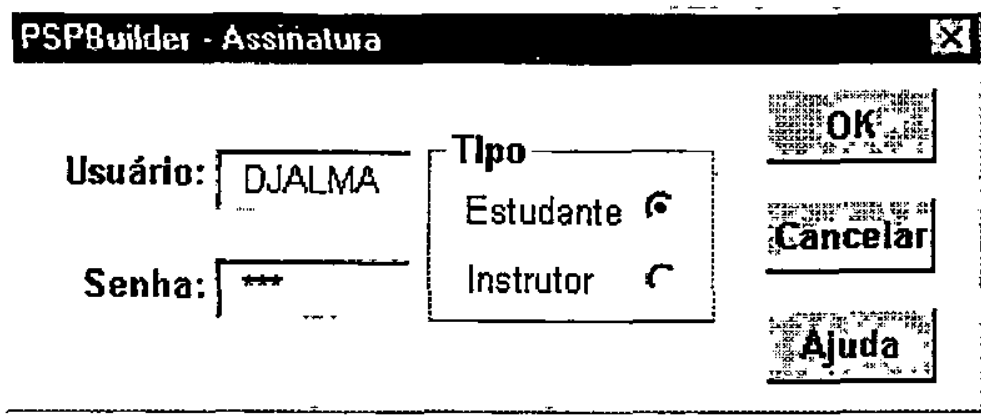

Figura 15. Diálogo de Assinatura Eletrônica. 
Quando se inicia um novo projeto ou treinamento, é necessário cadastrar este projeto, associando-o à identificação do instrutor responsável. Em seguida, são cadastrados os programas que compõem esse projeto. Neste exemplo de uso, o projeto ë "Treinamento PSP", que consiste na elaboração dos programas-exercícios PSP básicos, e o programa cujos dados serão apresentados nesta seção é o Programa_1A que calcula a média e o desvio padrão de um conjunto de dados.

Será empregado pára a elaboração deste programa-exercício o processo PSP0, Medição Pessoal, que consiste basicamente em utilizar o processo de desenvolvimento de software atual e registrar tempos e defeitos, defeitos estes injetados e removidos. As fases que compõem este processo são: Planejamento, Desenvolvimento e Autópsia. A fase de Desenvolvimento por sua vez é composta de Projeto, Codificação, Compilação e Teste.

Já estão previamente cadastrados os Processos PSP, as Fases que compõem cada Processo e os Tipos de Defeito Padrão, todos propostos originalmente por Humphrey em seu livro texto [Hum95a], podendo ser modificados e adaptados ao processo individual de cada desenvolvedor. Quando se faz uso de uma linguagem de desenvolvimento rápido de aplicações (RAD - Rapid Application Development) e orientada a evento e/ou a objetos, o código fonte é segmentado nos diversos eventos e funções que compõem a aplicação. Geralmente o código é compilado ao finalizar a edição de cada segmento. Desta maneira, na maioria das vezes não tem sentido considerar a fase de Compilação quando se emprega uma ferramenta de desenvolvimento $\mathrm{RAD}$, salvo se apresentar erros durante a codificação antes do primeiro teste ou execução parcial. Esses defeitos e seus tempos de correção devem ser registrados nos formulários de Registro Diário de Defeitos e Tempos, respectivamente.

Em seguida é associado o programa ao desenvolvedor (estudante), constituindo assim um exercício, conforme apresentado na Figura 16. Neste momento também é informada a linguagem de programação que será empregada no seu desenvolvimento. A linguagem de desenvolvimento escolhida para construir o programa-exercício Programa_1A é a PowerBuilder.

Está previsto também nesse diálogo de Cadastro de Exercicio o fornecimento da quantidade de defeitos encontrados e removidos após o seu desenvolvimento. Isto significa que se durante o uso, a reutilização de todo o código fonte ou o aproveitamento de parte deste código fonte, surgir ou for descoberto algum defeito, este é corrigido e informado nesse diálogo. 
Já a associação do programa-exercício à etapa PSP que será empregada durante o seu desenvolvimento é realizada no diálogo de Cadastro de Programas que compõem um determinado Projeto.

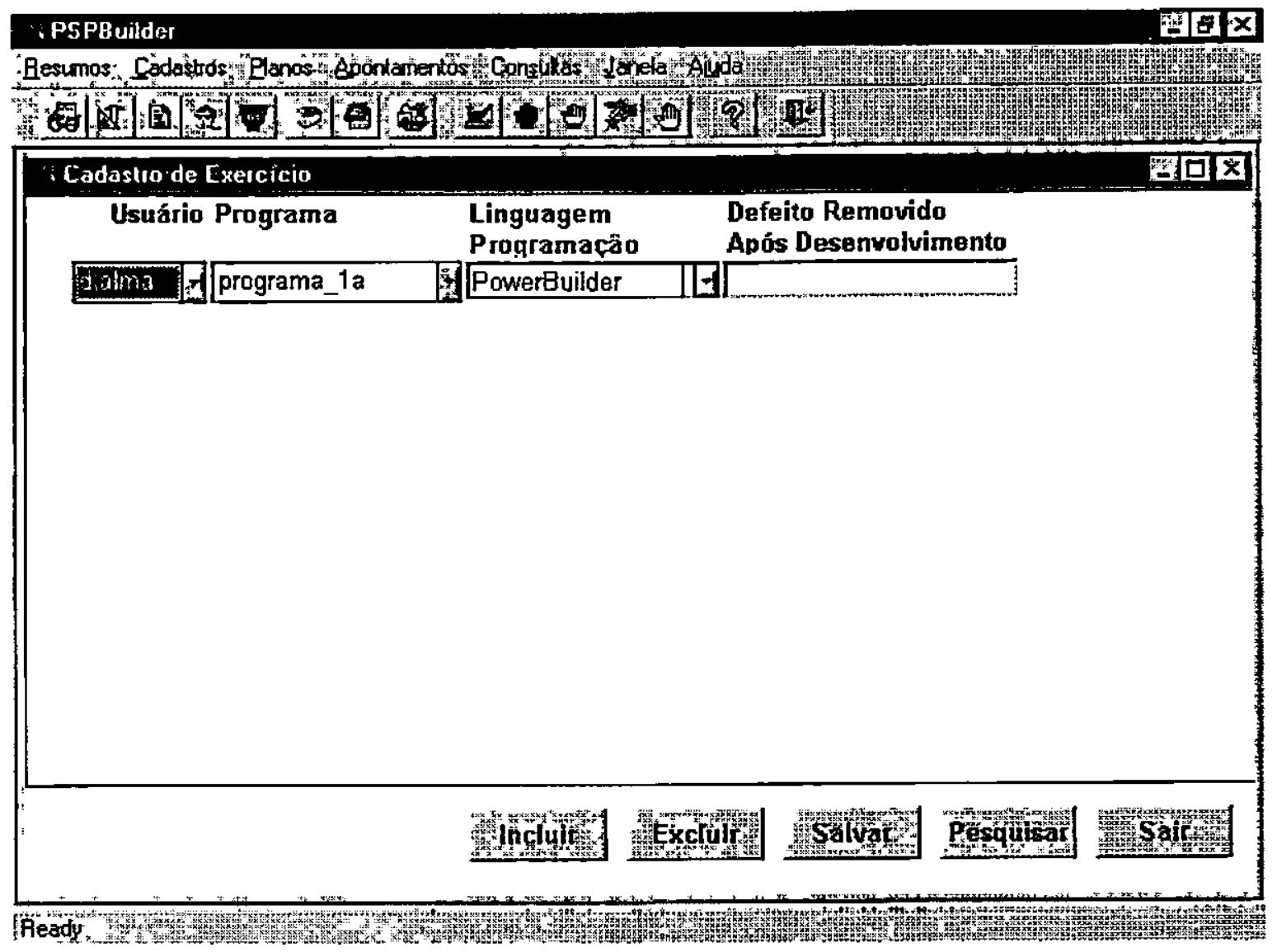

Figura 16. Cadastramento de um Exercício.

Esses são os procedimentos iniciais que antecedem o desenvolvimento dos programasexercícios seguindo o PSP e utilizando a ferramenta de apoio PSPBuilder, A sèguir são apresentadas detalhadamente cada uma das Fases que compõem o PSP0, as Tarefas que fazem parte de cada Fase e alguns resultados de uso durante o desenvolvimento do Programa_1A.

\subsubsection{Planejamento do Programa_1A.}

A Fase de Planejamento inicia-se ao produzir ou obter uma declaração dos requisitos para o Programa_1A, resolver quaisquer indefinições e garantir que esta declaração de requisitos seja 
clara e sem ambigüidades. A seguir, a declaração de requisitos e a estimativa de tempo para o desenvolvimento deste exercício são apresentadas.

Finalidade do Programa_1A: Calcular a média e o desvio padrão de um conjunto de dados.

Requisitos do Programa_1A: Escrever um programa para calcular a média e o desvio padrão de uma amostra dè $n$ números reais. A média é a aritmética dos números e sua fórmula é $x_{\text {arg }}=\frac{1}{n} \sum_{i=1}^{n} x_{i}$. A fórmula para o desvio padrão é $\sigma\left(x_{1}, \ldots, x_{n}\right)=\sqrt{\frac{\sum_{i=1}^{n}\left(x_{1}-x_{a n}\right)^{2}}{n-1}}$ onde $\sigma\left(x_{1}, \ldots, x_{n}\right)$ é o desvio padrão dos valores de $x$ e $x_{o x}$ a média aritmética destes $n$ valores.

Teste do Programa_1A: Testar minuciosamente o programa. Pelo menos três dos testes devem usar os dados de cada uma das três colunas à direita da Tabela 14. Os desvios padrão para as colunas na Tabela são: LOC Objetos, 572.03; LOC Novas e Alteradas, 625.63, e Horas de Desenvolvimento, 62.26 .

Tabela 14. Tamanhos de Objetos Pascal e Horas de Desenvolvimento.

\begin{tabular}{|l|l|l|l|}
\hline $\begin{array}{l}\text { Número do } \\
\text { Programa }\end{array}$ & LOC Objetos & $\begin{array}{l}\text { LOC Novas e } \\
\text { Alteradas }\end{array}$ & $\begin{array}{l}\text { Horas } \\
\text { Desenvolvimento }\end{array}$ \\
\hline 1 & 160 & 186 & 15.0 \\
\hline 2 & 591 & 699 & 69.9 \\
\hline 3 & 114 & 132 & 6.5 \\
\hline 4 & 229 & 272 & 22.4 \\
\hline 5 & 230 & 291 & 28.4 \\
\hline 6 & 270 & 331 & 65.9 \\
\hline 7 & 128 & 199 & 19.4 \\
\hline 8 & 1657 & 1890 & 198.7 \\
\hline 9 & 624 & 788 & 38.8 \\
\hline 10 & 1503 & 1601 & 138.2 \\
\hline
\end{tabular}


Estimativa de Recursos do Programa_1A: A estimativa de tempo necessário para o desenvolvimento deste exercício é de $120 \mathrm{~min}$.

\subsubsection{Projeto do Programa_1A.}

A próxima grande fase é o Desenvolvimento. A sub-fase Projeto é iniciada, consistindo em revisar os requisitos e produzir um projeto para atingir os requisitos anteriormente declarados. $\mathrm{Na}$ Figura 17 é representado o Modelo Estático ou o Modelo de Objetos segundo o Método Fusion de Análise e Projeto Orientados a Objetos [Col96] e na Figura 18, o Modelo Dinâmico ou os Grafos de Interação entre Objetos da operação cálculo_média_deviopadrão(). Durante o Projeto, os tempos das atividades são registrados, assim como todas as interrupções durante esta fase. A Figura 19 ilustra o registro de tempos durante o desenvolvimento deste programa-exercício.

\section{Estático}

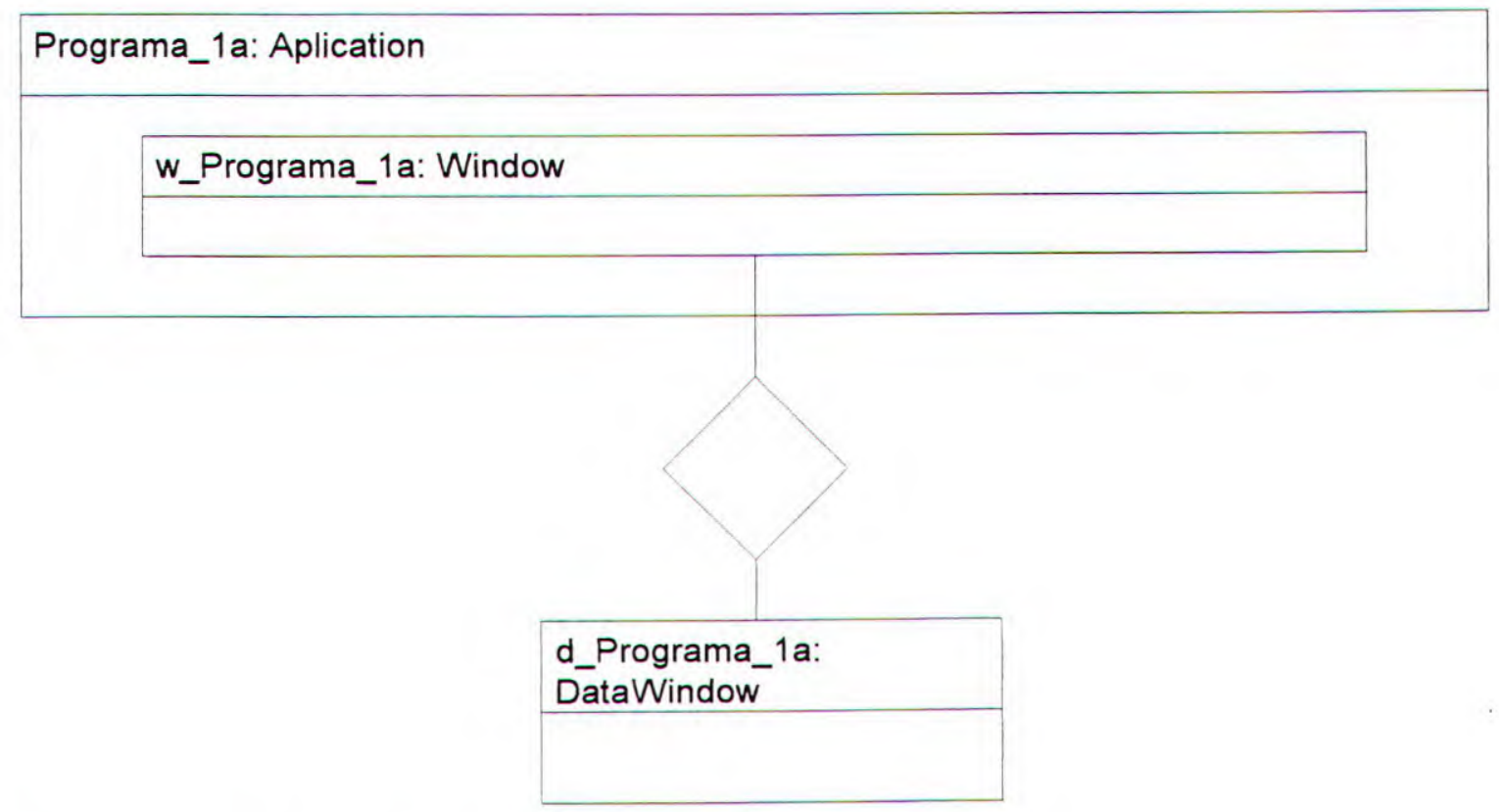

Figura 17. Modelo de Objetos do Sistema.

Dinâmico

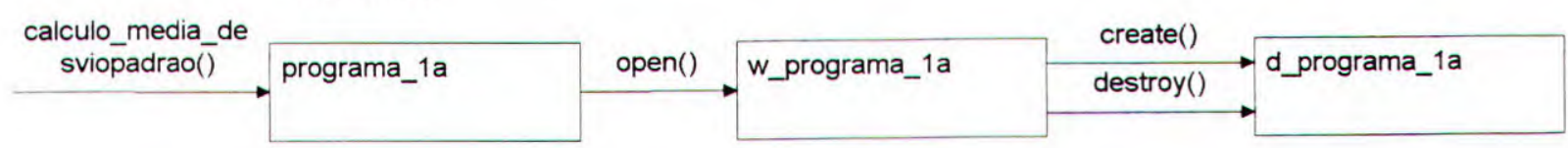

Figura 18. Grafo de Interação entre Objetos da Operação calculo_media_desviopadrao(). 


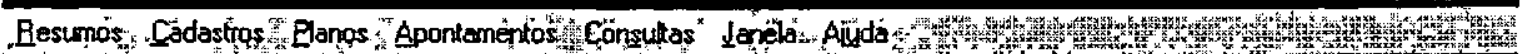

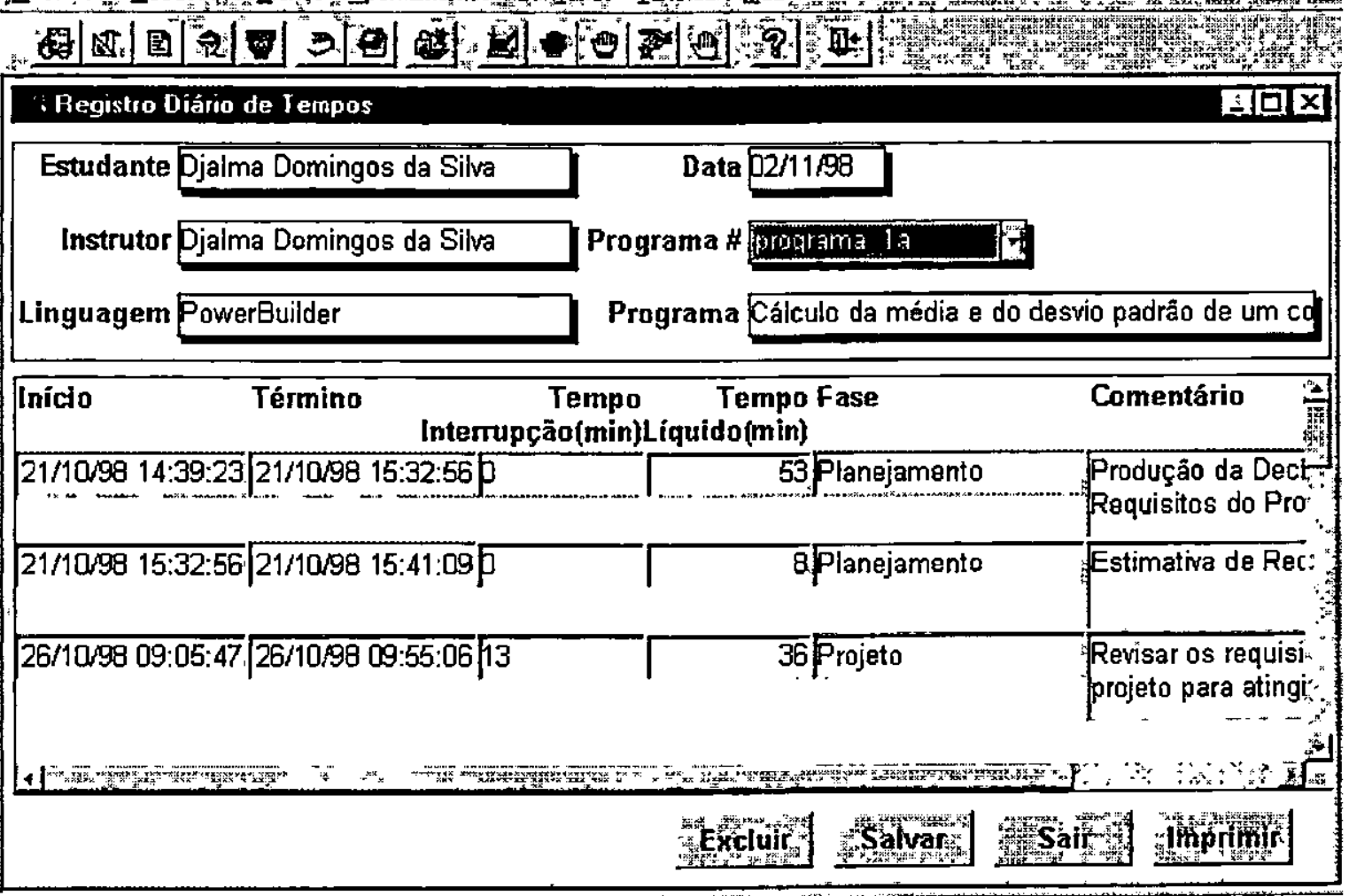

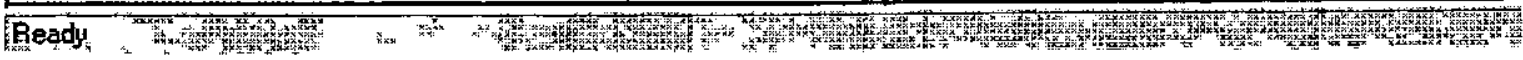

Figura 19. Registro Diário de Tempos.

\subsubsection{Codificação e Compilação do Programa_1A.}

A seguir é implementado o projeto, ou seja, a sub-fase de codificação é iniciada. Quaisquer defeitos encontrados provenientes de Projeto são registrados no Diário de Registro de Defeito e todos os tempos das atividades são registrados no Diário de Registro de Tempo. A Figura 20 apresenta o formulário de Diário de Registro de Defeitos para este programa-exercício.

Como salientado anteriormente, a programação orientada a eventos é segmentada e o PowerBuilder faz a compilação automática ao finalizar a edição de um evento, função ou método. Portanto, é extremamente dificil estabelecer um limite entre a codificação e a compilação, salvo se apresentar defeitos durante a compilação. A duração total da correção destes possíveis defeitos é 
que irá corresponder à duração total da sub-fase de Compilação. Tempos de Defeitos também são registrados nos Diários de Registro de Tempos e Defeitos, respectivamente.

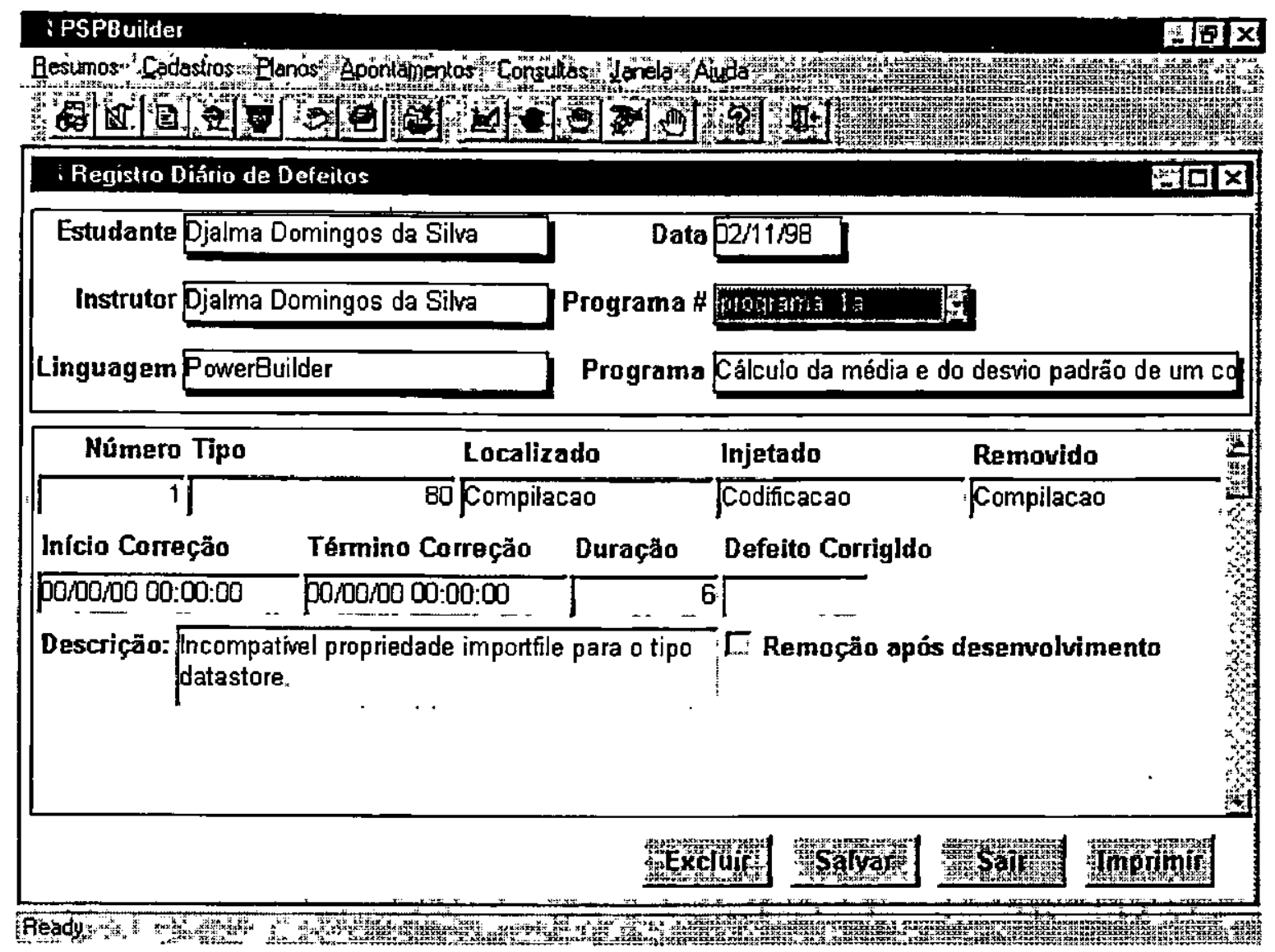

Figura 20. Registro Diário de Defeitos.

\subsubsection{Teste do Programa_1A.}

Após a implementação de um objeto ou um conjunto de objetos, poderá ser iniciada a subfase de Teste. Neste estágio inicial do PSP, o PSP0, não é obrigatório registrar os resultados esperados e obtidos dos casos de teste, mas no mínimo os casos de teste sugeridos na declaração de requisitos precisam ser executados até que não apresentem erros. Os defeitos encontrados precisam ser corrigidos e registrados também no Diário de Registro de Defeitos com os tempos despendidos durante a sua correção. Da mesma maneira, os tempos das atividades de Teste são registrados no Diário de Registro de Tempo. Na Figura 21 é apresentado um dos resultados 
obtidos com o teste do Programa_1A ao informar o arquivo de Horas de Desenvolvimento dos Objetos Pascal, última coluna da Tabela 14 acima.

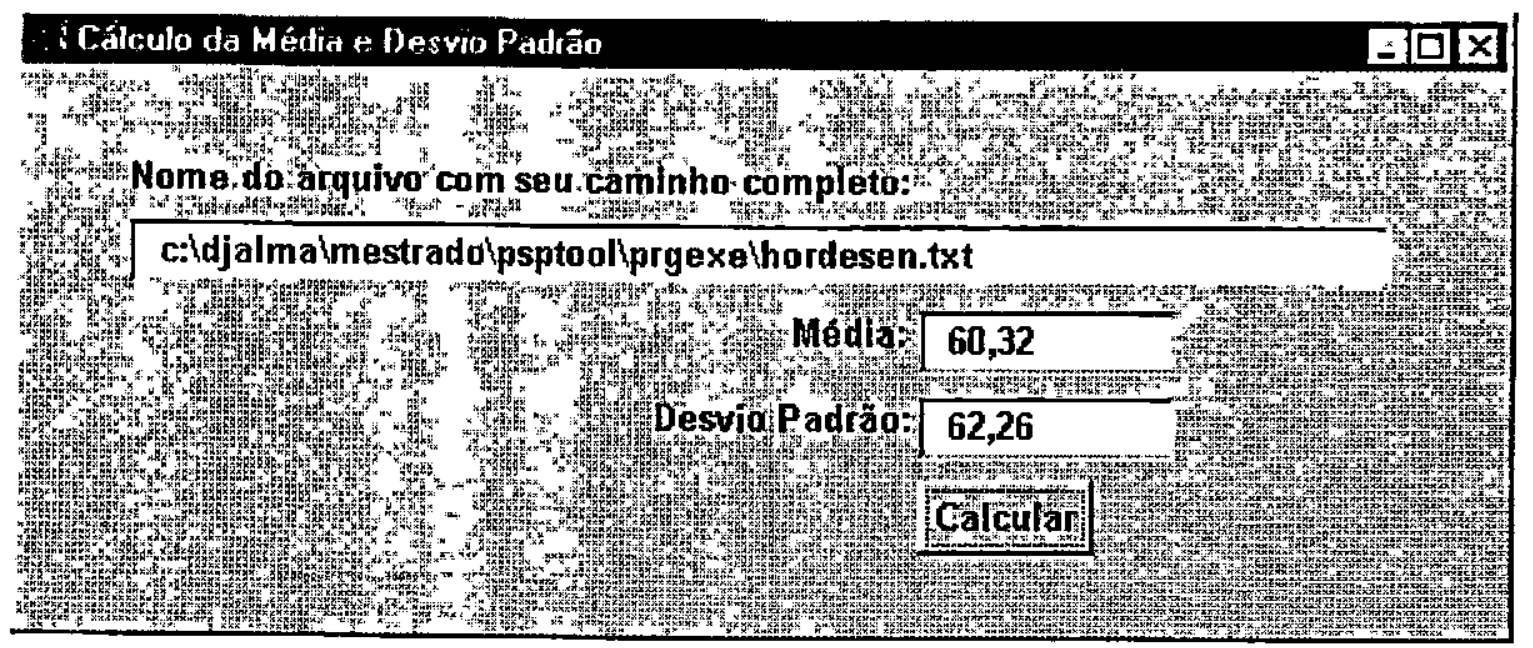

Figura 21. Resultado do Cálculo da Média e do Desvio Padrão do Programa_1A.

\subsubsection{Autópsia do Programa_1A.}

E para finalizar o processo, é executada a fase de Autópsia do Programa_1A É aqui onde existe o maior ganho em se utilizar uma ferramenta automatizada. As informações são automaticamente transferidas e manipuladas para o formulário Resumo do Plano do Projeto, conforme apresentado na Figura 22, ganhando-se em tempo e em precisão. A Figura 22 representa os Tempos nas Fases em minutos.

A Autópsia deste programa-exercício foi executada também de forma manual e a sua duração foi de $20 \mathrm{~min}$, que representa aproximadamente $8 \%$ da duração total da construção do Programa_l A. As atividades da Autópsia foram apenas totalizar e transferir as informações entre os formulários Diário de Registro de Tempos e Defeitos e o formulário Resumo do Plano do Projeto PSP0, desconsiderando o esforço em digitar tais relatórios. Conclui-se que existe um ganho de tempo de no minimo $8 \%$, já que nas etapas posteriores do PSP novas atividades são acrescentadas à fase de Autópsia, requerendo assim um maior trabalho nas suas realizações. 
Programa Cálculo da média a do desvio padrăo de um ca

Tempos nas Fases (mln) [Defeitos Injetados]

\section{Tempos nas Fases (min)}

Faso

Planejamento

Projeto

Codificacao

Compilacao

Teste

Planejado
\begin{tabular}{|r|r|r|} 
Realizado & Acumulado & Acumulado \%/ \\
\hline 61 & 61 & $25,52 \%$ \\
\hline 36 & 36 & $15,06 \%$ \\
\hline 60 & 40 & $16,74 \%$ \\
\hline 96 & 6 & $2,51 \%$ \\
\hline
\end{tabular}

Figura 22. Resumo do Plano do Projeto PSPO.

\subsection{Implementações das demais etapas PSP no PSPBuilder}

No PSP0.1 é feita a estimativa do número total de LOC novas e alteradas necessárias ao desenvolvimento do programa-exercício e a distribuição do tempo de desenvolvimento nas fases planejadas do projeto utilizando o percentual acumulado dos mais recentes programas desenvolvidos como um guia durante a fase de Planejamento (Figura 23). Na fase de Codificação o projeto é implementado seguindo o Padrão de Codificação apresentado na Tabela 1 do Anexo A e na Autópsia são contadas automaticamente as linhas de código do programa finalizado e as linhas básicas, informadas as linhas de código reutilizadas, excluidas, modificadas e as novas reutilizáveis, e calculadas as linhas adicionadas e o total de linhas de código novas e alteradas. Todos esses dados são transferidos automaticamente para o Resumo do Plano do Projeto. Durante o uso do processo são registradas na Proposta de Melhoria do Processo as lições 
aprendidas e a descrição de possiveis problemas e sugestões de melhoria do processo, conforme apresentado na Figura 24.

\section{PSPBuilder}

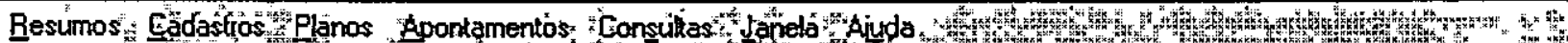

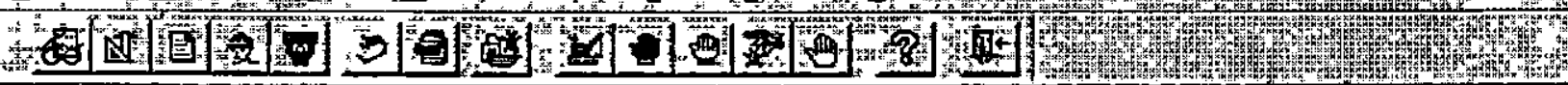

\begin{tabular}{|c|c|c|}
\hline - Plano PSPO. 1 & & $-d D x$ \\
\hline Estudante Djalma Domingos da Silva & Data & $17 / 11 / 98$ \\
\hline Instrutor Djalma Domingos da Silva & Programa \# & programa_za \\
\hline Linguagem $\longdiv { \text { PowerBuilder } }$ & Programa & Cálculo da média e do desvio padrâo de um co \\
\hline
\end{tabular}

\begin{tabular}{rr} 
Tempo Total Estimado: & $178 \mathrm{~min}$ \\
\hline
\end{tabular}

LOC Nova e Modificada Total Estimada: 50

Aplicaçäo Base:

\begin{tabular}{|lc|}
\hline Descriçäo Etapa & Tempo Estimado Etapa \\
\hline Planejamento & 45 \\
Codificacao & 30 \\
Compilacao & 4 \\
Projeto & 27 \\
Teste & 72 \\
\hline
\end{tabular}

\section{Figura 23. Plano PSP0.1}

O processo de contar LOC integra-se ao utilitário PowerBuilder Cross Reference do APU (Advanced PowerBuilder Utilities) que está localizado no item Apontamentos do PSPBuilder. São selecionadas as PBLs que contém os objetos associados ao programa-exercício que se deseja contar LOC e o Cross Reference se encarrega de relacionar e salvar na base de dados todos os seus objetos. Desta maneira, é possivel finalmente contar as linhas de código fonte dos objetos dos programas-exercicios de acordo com as regras estabelecidas na Tabela 2 do Anexo A, Padrão de Contagem de LOC para o PowerScript, por meio da opção Contagem LOC e Métodos do mesmo item Apontamentos. 


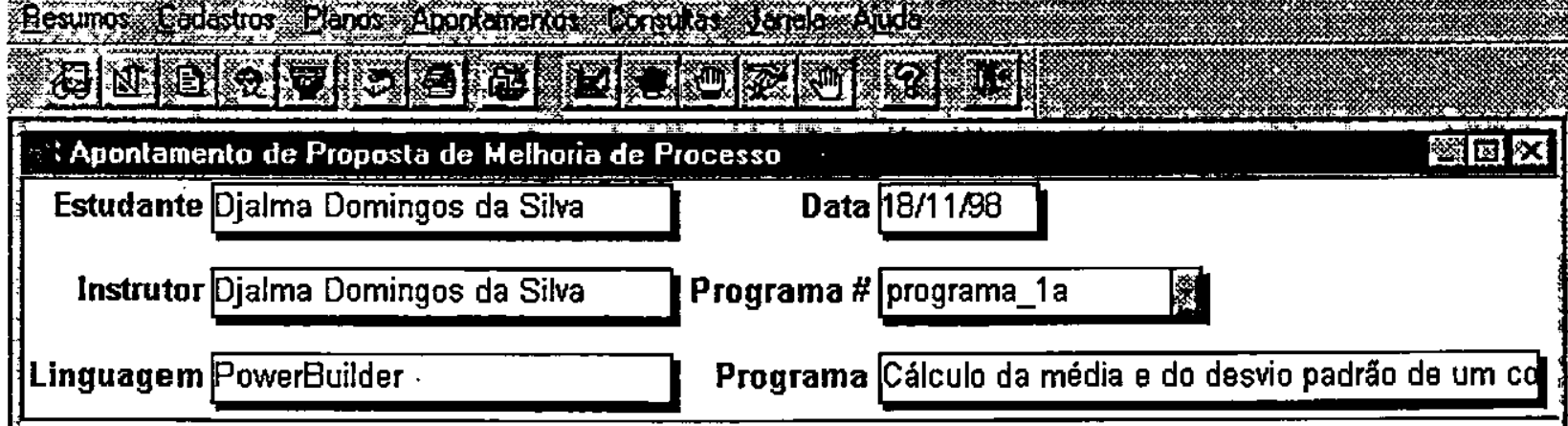

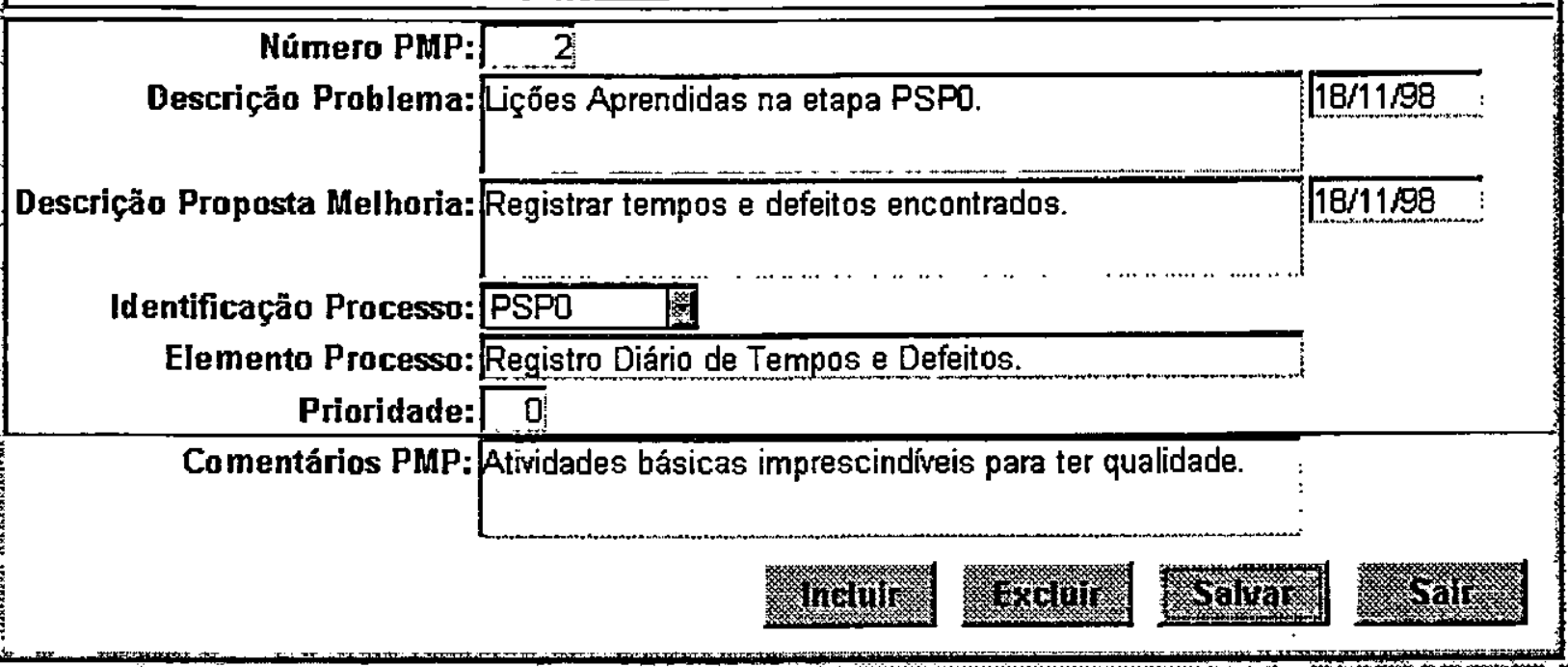

Geadin

\section{Figura 24. Proposta de Melhoria de Processo.}

Na etapa PSP1, antes de estimar o total de LOC novas e alteradas necessárias para desenvolver o programa utilizando o método PROBE, é produzido um projeto conceitual do mesmo programa. Também são estimadas, além do total de LOC novas e alteradas, as LOC excluídas, modificadas e reutilizadas. Essas informações são transferidas automaticamente para o Resumo do Plano do Projeto. A única restrição de se utilizar o método PROBE é que a quantidade mínima de programas com suas quantidades de linhas de código (LOC) fonte novas e alteradas calculadas e armazenadas na base de dados é três.

Em seguida à estimativa de tamanho é feita a estimativa do tempo necessário para o desenvolvimento com base no tempo necessário por LOC nos programas anteriores. Nesta etapa também são registrados os testes conduzidos e resultados obtidos no Gabarito Relatório de Teste, conforme apresentado na Figura 25. 


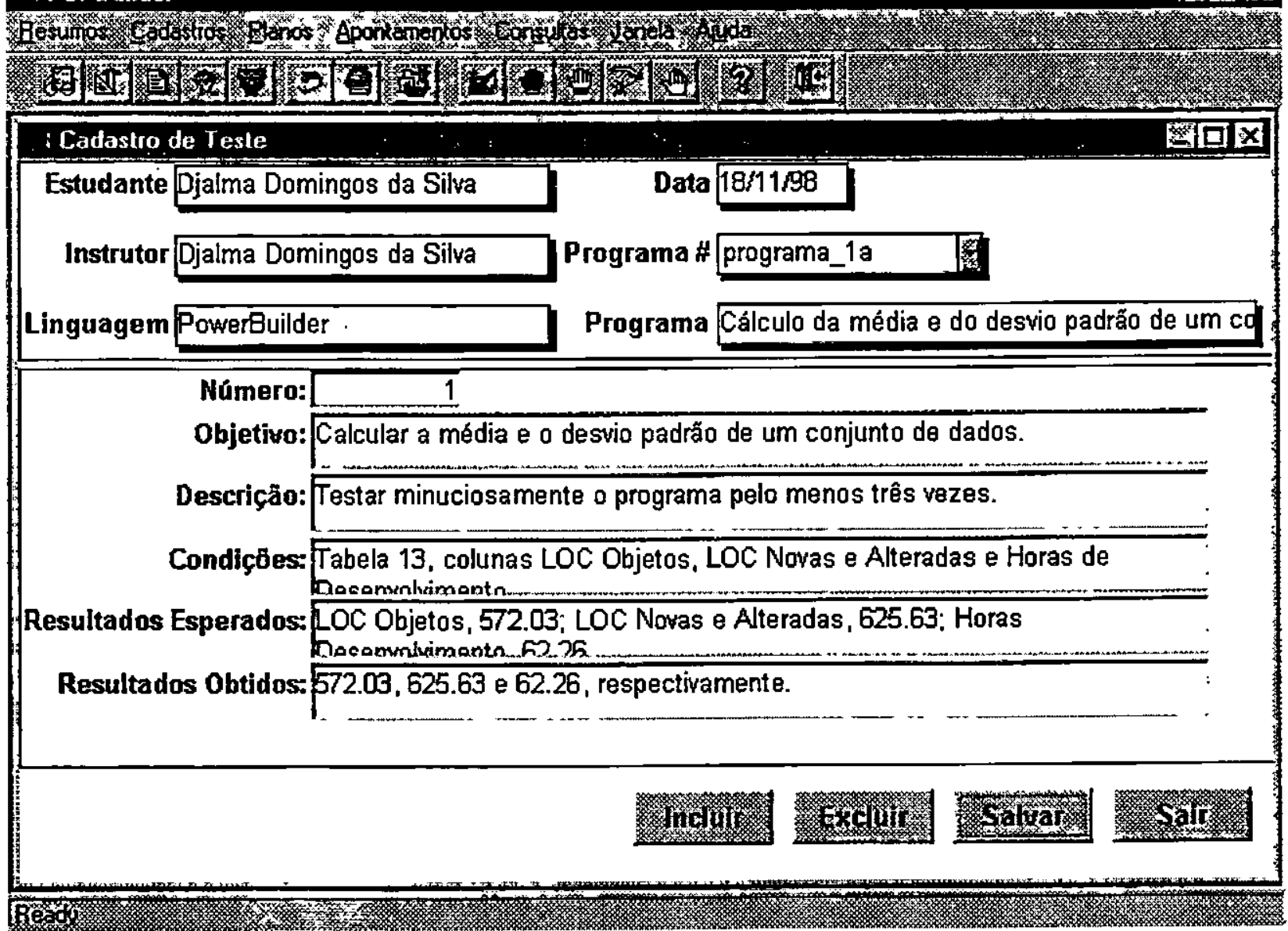

\section{Figura 25. Gabarito Relatório de Teste.}

Na etapa PSP1.1 é utilizado o método PROBE para também estimar o tempo necessário para desenvolver o programa. Nos casos de projetos que requerem muitos dias de trabalho recomenda-se completar os gabaritos de Planejamento de Tarefa e de Escalonamento, conforme apresentados na Figura 26.

E, por último, na etapa PSP2 é calculado o intervalo de confiança de tamanho de LOC e de tempo em $70 \%$ na fase de planejamento, ou seja, o intervalo que possui a probabilidade de $70 \%$ de chance de acerto. A partir desta etapa também são estimados o total de defeitos a serem encontrado no programa em desenvolvimento, com base nos dados acumulados de defeitos por LOC nova e alterada e também os números de defeitos a serem injetados e removidos por fase, com base nos dados de \%Acumulado. A partir desta etapa também são feitas as Revisões de Projeto e Código seguindo o Checklist de Revisão de Projeto e de Código (Tabela 3 do Anexo 
A), respectivamente. Durante essas revisões são corrigidos todos os defeitos encontrados e os defeitos com seus respectivos tempos são registrados nos Diários de Registro de Defeitos e Tempos. Na fase de Autópsia é calculado o esforço de revisão geral do processo realizado e esse valor é transferido automaticamente para o Resumo do Plano do Projeto.

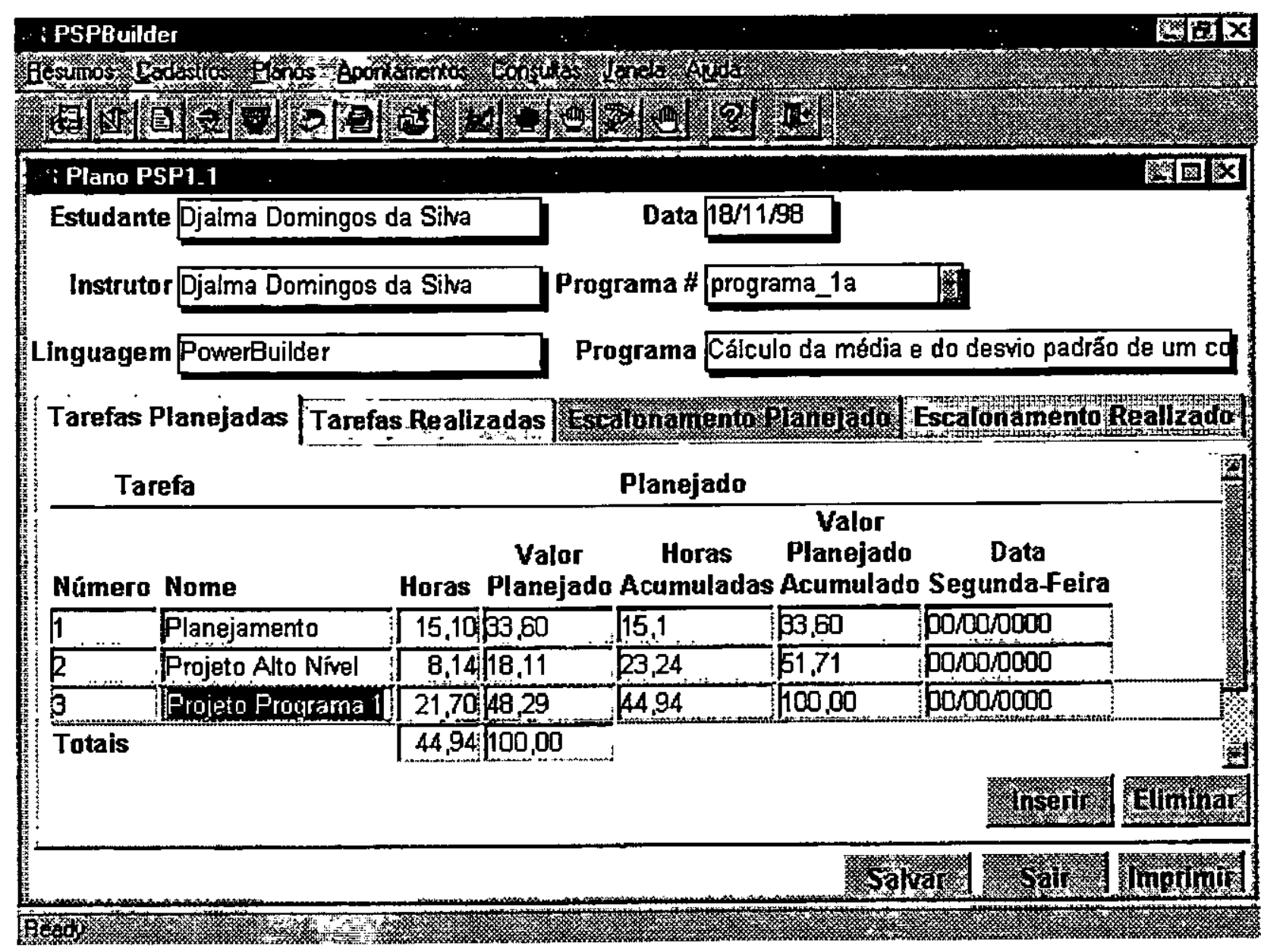

\section{Figura 26. Plano PSP1.1}

\subsection{Considerações Finais.}

O ganho de qualidade e produtividade individual ao aplicar o PSP depende da adaptação deste processo ao ambiente de desenvolvimento utilizado e o apoio de uma ferramenta automatizada agiliza e estimula a aplicação deste processo. Essas são as principais razões de se adaptar o PSP para o Domínio de Sistemas de Informação proposto e desenvolver uma ferramenta que apoie o PSP para este mesmo ambiente, o PSPBuilder. 


\section{Conclusões}

\subsection{Considerações Gerais.}

O processo PSP proposto originalmente por Humphrey [Hum95a] se demonstra eficaz, mesmo considerando apenas parte do ciclo de vida de desenvolvimento de um sistema, ou seja, com maior ênfase as fases de Projeto, Codificação e Teste de Software. Esta maneira seqüencial e progressiva de introduzir fatores de qualidade no processo de desenvolvimento do software em nivel individual, tais como elaboração de relatórios, padronização de código, estimativas de LOC e tempo, planejamento adequado, etc., torna o desenvolvedor disciplinado, seguro e profundo conhecedor de seus pontos fortes e, principalmente de seus pontos fracos, nos quais concentrará esforços para fortalecê-los.

O treinamento PSP proposto no mesmo livro-texto [Hum95a] é de fundamental importância para o aprendizado e bom uso do PSP, mas fazê-lo de uma forma autodidata exige do desenvolvedor uma excelente auto-disciplina para cumprir todas as etapas e prazos exigidos. Também não basta fazer o treinamento PSP, seja de maneira autodidata ou oferecido por uma instituição, e tentar utilizá-lo sem alguma adaptação em um ambiente de desenvolvimento de caracteristicas bem diversas daquelas oferecidas durante o treinamento. Se alguns dos formulários e exercícios PSP não forem adaptados à nova linguagem e ao novo ambiente de desenvolvimento, a avaliação de uso do PSP poderá ficar prejudicada, não alcançando assim os objetivos estabelecidos pelo processo.

Observa-se que existe uma carência em divulgar modelos de qualidades por intermédio de disciplinas nos cursos de graduação e pós-graduação em Computação e áreas afins. $\mathrm{O}$ engenheiro de software que recebe, durante a sua formação profissional, treinamento em modelos de gerência de qualidade no processo de software, possibilitará à empresa que o contratará uma redução nos custos quanto à sua formação e treinamento de pessoal, e conseqüentemente um retorno mais rápido dos beneficios em se utilizar tais modelos. Dentre os modelos de qualidade, o PSP é o que demonstra ser o mais prático e imediato, permitindo ao engenheiro de software possuir um 
histórico com dados sobre sua qualidade e produtividade, auxiliando-o a tomar e planejar melhor as decisões profissionais.

\subsection{Contribuições.}

Como principais contribuições deste trabalho podem ser consideradas as adaptações de alguns formulários PSP para atender especificamente o Domínio de Sistemas de Informação que faz uso da linguagem de desenvolvimento PowerBuilder e a construção e emprego da ferramenta automatizada PSPBuilder para principalmente apoiar o PSP nesse ambiente.

As adaptações dos formulários sugeridas por este trabalho fornecem um maior realismo nos dados coletados durante o uso do PSP em um ambiente de desenvolvimento que utilize o PowerBuilder como linguagem de programação, tornando o processo viável e sem distorções. Os principais formulários adaptados são os apresentados no Anexo A: o Padrão de Codificação PowerScript (C29), o Padrão de Contagem de LOC para o PowerScript e as Diretrizes e Checklist de Revisão de Código para PowerBuilder (C58). Os dois primeiros fundamentam o PSP e o último garante principalmente qualidade ao software durante o seu desenvolvimento ou manutenção.

O emprego de uma ferramenta automatizada que apoie o PSP para o Domínio de Sistemas de Informação que utilize o PowerBuilder, o PSPBuilder, é um outro grande beneficio proporcionado por este trabalho. A coleta automatizada dos dados possibilita grandes ganhos no emprego do PSP, seja durante um treinamento, seja durante o desenvolvimento de um software em um ambiente de trabalho de uma empresa. Alguns dos principais ganhos proporcionados por esta ferramenta são: maior precisão nas tomadas de tempos, agilidade na contagem de LOC, fornecimento das informações uma única vez, transferência automática dos dados entre os diversos formulários, execução de cálculos estatísticos complexos e que envolvem um grande volume de informações, boa apresentação dos resultados na forma de relatórios ou consultas em tela, e, conseqüentemente, extrema agilidade ao fazer a Autópsia do software após seu desenvolvimento. O PSPBuilder, além de permitir ser utilizado de forma genérica para atender a maioria dos ambientes de desenvolvimento, oferece maiores vantagens quando esse ambiente faz uso da linguagem de desenvolvimento PowerBuilder. O PSPBuilder é integrado ao PowerBuilder no 
que diz respeito à contagem de LOC dos programas e dos objetos que compõem esses programas.

Outras vantagens são a grande flexibilidade que o PSPBuilder oferece em adaptar o processo original, permitindo assim a personalização, e o fácil acesso a dados históricos de projetos ou programas anteriores, permitindo assim consultar e informar defeitos encontrados após o desenvolvimento de um programa. Embora o PSP foi concebido para ser aplicado individualmente, o PSPBuilder permite o uso compartilhado entre diversos desenvolvedores. Dessa maneira, a ferramenta facilita a divulgação de dados médios de projeto para um grupo que participa de um treinamento do PSP ou para uma equipe que desenvolve um software em uma empresa de TI.

O principal argumento motivador em se utilizar uma ferramenta automatizada que apoie o PSP é que numa situação real de desenvolvimento de software comercial em que seus desenvolvedores foram treinados e procuram aplicar o PSP, se este ambiente de desenvolvimento não permitir coletar automaticamente os dados e efetuar os cálculos sobre esses dados que o PSP necessita, os desenvolvedores provavelmente não seguirão tal disciplina por razões de urgência nos prazos e/ou estresse do dia a dia de trabalho.

\subsection{Trabalhos Futuros}

São classificados os possiveis trabalhos futuros em três grupos, a saber: primeiro, evolução do processo PSP; segundo, melhoria da ferramenta automatizada PSPBuilder; e por último, divulgação e treinamento do PSP em centros de formação de profissionais de computação.

\subsubsection{Evolução do Processo PSP.}

Como mencionado anteriormente, o PSP enfoca parte do ciclo de vida de desenvolvimento de sistemas, ou seja, as fases de Projeto, Codificação e Teste. Também, por ser derivado do CMM, apenas 12 das 18 Áreas-Chave do Processo do CMM foram adaptadas para o 
PSP (todas dos Niveis 4, Gerenciado, e 5, Otimizado; a maioria do Nível 3, Definido; e algumas do Nível 2, Repetivel). As Áreas-Chave do Processo desconsideradas durante a concepção do PSP foram: do Nivel 2, Repetivel, Gerenciamento dos requisitos, Gerenciamento de subcontratação de software, Controle de qualidade de software e Gerenciamento de configuração de software; e do Nível 3, Definido, Programa de treinamento e Coordenação intergrupo. A maioria dessas Áreas-Chave do Processo são realmente de aplicação em grupo ou equipe de desenvolvedores de softwáre, mas duas dessas são de fundamental importância e poderão ser empregas em nivel individual: Gerenciamento dos requisitos e Gerenciamento de configuração de software.

Considerando essas duas Áreas-Chave do Processo, há uma extensão natural do ciclo de vida de desenvolvimento do sistema, passando a considerar a Análise de Requisitos. E para complementar o ciclo de vida de desenvolvimento entre Análise de Requisitos e Projeto, é sugerido abordar a Análise de Sistemas e um método de Análise e Projeto que poderia ser empregado no PSP e que supre essas necessidades poderia ser o Fusion [Col96] ou a notação UML (Unified Modeling Language).

Há alguns trabalhos que adaptam o PSP para uma linguagem de programação específica. A proposta original do PSP [Hum95a] é voltada para a linguagem $\mathrm{C}++$ e Object Pascal. Albuquerque, em sua dissertação de mestrado, propõe uma abordagem de PSP orientada a Java [Alb97] e este trabalho aborda PSP para PowerBuilder. Outras linguagens de programação são de uso muito freqüente em organizações de TI, tais como, Visual Basic, Delphi, Cobol e linguagens procedimentais para a construção de Triggers e Procedures para os diversos bancos de dados relacionais comerciais empregados atualmente (Oracle, Sybase, DB2, Progress, Informix, etc.), constituindo assim novas opções de trabalho.

\subsubsection{Melhoria da Ferramenta Automatizada PSPBuilder}

Como também mencionado no Capítulo 4, o PSPBuilder atende até a etapa PSP2.1, Qualidade Pessoal, e também não é orientado à Web. Como possibilidade de trabalho futuro, 0 PSPBuilder poderia ser ampliado para atender ao Processo Cíclico PSP3 e ao mesmo tempo construir uma nova versão orientado à Web. Dessa maneira, a ferramenta poderia ser empregada 
no desenvolvimento de grandes sistemas que adotam o modelo de ciclo de vida em espiral de Boehm [Boe88] e permitiria também acessar remotamente por intermédio da Internet/Intranet um site onde estaria instalada e sendo executado o PSPBuilder.

$\mathrm{Na}$ verdade, trata-se de uma manutenção não trabalhosa, já que o PSPBuilder foi construído com caracteristicas Cliente-Servidor, orientado a objetos e também em camadas. Seria necessário remodelar sua base de dados e alguns objetos para atender à etapa PSP3 e substituir a camada de apresentação, ou os objetos do tipo Window, por páginas HTML. O aspecto de usabilidade também poderia ser evoluído, tornando-o mais prático, funcional e atrativo, explorando recursos gráficos. Uma sugestão seria construir na tela principal da ferramenta uma espécie de "Painel do Desenvolvedor", o qual apresentaria as principais informações sobre qualidade e produtividade do desenvolvedor.

\subsubsection{Divulgação e Treinamento do PSP utilizando o PSPBuilder}

Uma terceira possibilidade de trabalho futuro seria a disseminação do PSP em Universidades, Centros de Formação Profissional em Computação e em Organizações de TI, utilizando o PSPBuilder.

Seria uma ótima oportunidade para que os participantes dos treinamentos PSP e os desenvolvedores de software das Organizações de TI assimilassem e praticassem qualidade, e principalmente fossem constantemente estimulados a praticar.

Desta forma, o aluno ou desenvolvedor estaria utilizando um modelo de gerência e processo de desenvolvimento de software para organizar, planejar e otimizar seu modo de trabalho e de elaboração e execução de projetos de sua carreira profissional de uma maneira eficiente.

Seria um excelente começo para o profissional iniciante ou aperfeiçoamento de profissionais experientes, e suas chances seriam muito maiores em conquistar e permanecer no mercado de trabalho na área. As informações de qualidade e produtividade individual que o PSP proporciona e fornecidas pelo PSPBuilder poderiam também compor o curriculo profissional, fornecendo assim valiosos subsídios à empresa contratante. 
Este treinamento teria um kit para aula, contendo transparências, apostilas para o professor e para o aluno, exemplos com aplicações práticas para exercícios e uma cópia do PSPBuilder para ser instalada e usada. 


\section{Anexo A - Tabelas da Versão PSP para PowerBuilder}

Tabela 1 - Padrão de Codificação PowerScript (C29)

\begin{tabular}{|c|c|c|c|}
\hline Propósito & \multicolumn{3}{|c|}{ Guiar o desenvolvimento de aplicações PowerBuilder. } \\
\hline $\begin{array}{l}\text { Cabeçalhos } \\
\text { Scripts }\end{array}$ & \multicolumn{3}{|c|}{$\begin{array}{l}\text { Iniciar o script default de um objeto com a sua descrição funcional } \\
\text { resumida e uma tabela histórica listando datas, autores e resumos das } \\
\text { funções do script quando do desenvolvimento ou das modificações } \\
\text { quando se tratar de alterações. }\end{array}$} \\
\hline $\begin{array}{l}\text { Formato dos } \\
\text { Cabeçalhos }\end{array}$ & \multicolumn{3}{|c|}{ Descrição do Objeto. } \\
\hline $\begin{array}{l}\text { Exemplo } \\
\text { Cabeçalho }\end{array}$ & \multicolumn{3}{|c|}{$\begin{array}{l}\text { Data, Autor, Descrição quando da criação ou alteração. } \\
\text { Aplicação Windows Cliente/Servidor que faz interface com o back- } \\
\text { end de banco de dados SYBASE SQL ANYWHERE. }\end{array}$} \\
\hline $\begin{array}{l}\text { Instruções } \\
\text { Reuso }\end{array}$ & \multicolumn{3}{|c|}{$\begin{array}{l}\text { - Descrever como a aplicação é usada fornecendo o formato da } \\
\text { declaração, valores, tipos e limites dos argumentos. } \\
\text { - Fornecer advertências de valores ilegais, condições de overflow ou } \\
\text { outras condições que poderiam potencialmente resultar em uma } \\
\text { operação imprópria. }\end{array}$} \\
\hline $\begin{array}{l}\text { Exemplo } \\
\text { Reuso }\end{array}$ & \multicolumn{3}{|c|}{$\begin{array}{l}\text { // Instruções de Reuso } \\
\text { dw_impressao.Print() } \\
\text { // Propósito: imprimir uma DataWindow } \\
\text { // Limitações: nenhuma } \\
\text { // Retorna: - 1 se a impressora não estiver pronta para imprimir, senão } \\
\text { // } 1\end{array}$} \\
\hline Identificadores & \multicolumn{3}{|c|}{$\begin{array}{l}\text { Utilizar nomes descritivos para todas variáveis, nomes de funções, } \\
\text { constantes e outros identificadores. Evitar abreviações ou variáveis } \\
\text { com poucas letras. }\end{array}$} \\
\hline $\begin{array}{l}\text { Exemplo } \\
\text { Identificador }\end{array}$ & \multicolumn{3}{|c|}{$\begin{array}{l}\text { int li_número_de_estudantes // Isso é BOM } \\
\text { float } x 4, \mathrm{j}, \text { ftave } \\
\end{array}$} \\
\hline $\begin{array}{l}\text { Objetos } \\
\text { Controles }\end{array}$ & \multicolumn{3}{|c|}{$\begin{array}{l}\text { Nomear os objetos e controles segundo as convenções de } \\
\text { nomenclatura recomendadas a seguir. }\end{array}$} \\
\hline \multirow[t]{2}{*}{ Objetos } & Objeto & Prefixo & Exemplo \\
\hline & $\begin{array}{l}\text { Aplicação } \\
\text { DataWindow } \\
\text { Função } \\
\text { Menu } \\
\text { Estrutura } \\
\text { Query } \\
\text { Objeto do usuário } \\
\text { Janela } \\
\text { Transação }\end{array}$ & $\begin{array}{l}\text { (nenhum) } \\
\mathrm{d}_{-} \\
\mathrm{f}_{-} \\
\mathrm{m}_{-} \\
\mathrm{s}_{-} \\
\mathrm{q}_{-} \\
\mathrm{u}_{-} \\
\mathrm{w}_{-} \\
\mathrm{tr}_{-}\end{array}$ & $\begin{array}{l}\text { address_book, labor_log } \\
\text { d_employee_list } \\
\text { f_salcalc } \\
\text { m_training_schedule_inquiry } \\
\text { s_emp } \\
\text { q_employees_in_department } \\
\text { u_request } \\
\text { w_customer_info } \\
\text { tr_Sybase,tr_Accounts }\end{array}$ \\
\hline
\end{tabular}


Tabela 1 - Padrão de Codificação PowerScript (C29) (continuação)

\begin{tabular}{|c|c|c|c|}
\hline $\begin{array}{ll}\text { Objetos } & \text { do } \\
\text { Usuário } & \end{array}$ & $\begin{array}{l}\text { Class Custom } \\
\text { Class Standard } \\
\text { Visual Custom } \\
\text { Visual Standard } \\
\text { Visual External } \\
\text { Visual VBX }\end{array}$ & 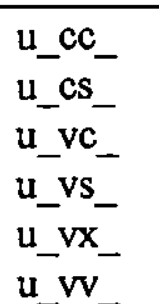 & ? \\
\hline \multirow[t]{2}{*}{ Controles } & Controle & Prefixo & Exemplo \\
\hline & $\begin{array}{l}\text { CheckBox } \\
\text { CommandButton } \\
\text { DataWindow } \\
\text { DropDownListBox } \\
\text { Edit mask } \\
\text { Graph } \\
\text { GroupBox } \\
\text { HScrollBar } \\
\text { Line } \\
\text { ListBox } \\
\text { MultiLineEdit } \\
\text { OLE 2.0 } \\
\text { Oval } \\
\text { Picture } \\
\text { PictureButton } \\
\text { RadioButton } \\
\text { Rectangle } \\
\text { RoundRectangle } \\
\text { SingleLineEdit } \\
\text { StaticText } \\
\text { User object } \\
\text { VScrollBar }\end{array}$ & 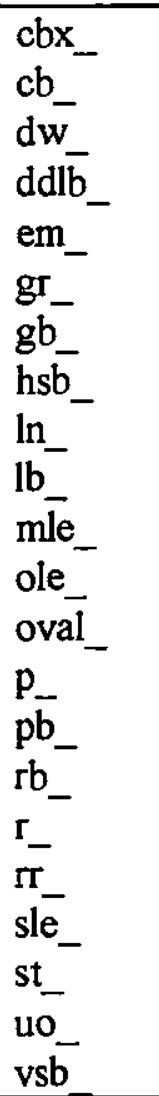 & $\begin{array}{l}\text { cbx_draft } \\
\text { cb_done } \\
\text { dw_part_master } \\
\text { ddlb_color_choice } \\
\text { em_phone } \\
\text { gr_emp_salaries } \\
\text { gb_print_choices } \\
\text { hsb_red } \\
\text { ln_shortline } \\
\text { lb_vendor_number } \\
\text { mle_comments } \\
\text { ole_letter } \\
\text { oval_mid } \\
\text { p_employee } \\
\text { pb_update } \\
\text { rb_include_comments } \\
\text { r_rect } \\
\text { Ir_screen } \\
\text { sle_customer_name } \\
\text { st_main_window_title } \\
\text { uo_saicalc } \\
\text { vsb_percent done }\end{array}$ \\
\hline \multirow[t]{3}{*}{ Variáveis } & \multicolumn{3}{|c|}{$\begin{array}{l}\text { Nomear as variáveis segundo as convenções de nomenclatura } \\
\text { recomendadas a seguir. Os prefixos de variáveis possuem } \\
\text { normalmente o comprimento de dois a três caracteres. O primeiro } \\
\text { indica o escopo, ou seja, determina a acessibilidade e a visibilidade de } \\
\text { uma variável, e o segundo (e algumas vezes o terceiro) indica o tipo } \\
\text { de variável, ou seja, seu tipo fisico de dados. O símbolo "?" } \\
\text { representa o qualificador de prefixo para o tipo de dados da variável. }\end{array}$} \\
\hline & Escopo & \multicolumn{2}{|c|}{ Prefixo } \\
\hline & $\begin{array}{l}\text { Local } \\
\text { Instance } \\
\text { Shared } \\
\text { Global } \\
\text { Argument }\end{array}$ & \multicolumn{2}{|c|}{$\begin{array}{l}\text { l?__opcional) } \\
\text { i? } \\
\text { s? } \\
\text { g? } \\
\text { a? }\end{array}$} \\
\hline
\end{tabular}


Tabela 1 - Padrão de Codificação PowerScript (C29) (continuação)

\begin{tabular}{|c|c|c|}
\hline & Tipos de Dados & Qualificador do Prefixo \\
\hline & $\begin{array}{l}\text { Blob } \\
\text { Boolean } \\
\text { Character } \\
\text { Date } \\
\text { DateTime } \\
\text { Decimal } \\
\text { Double } \\
\text { Integer } \\
\text { Long } \\
\text { Real } \\
\text { String } \\
\text { Time } \\
\text { Unsigned integer } \\
\text { Unsigned long } \\
\text { DataWindow } \\
\text { DataWindowChild } \\
\text { Mail Session } \\
\text { MenuItem } \\
\text { Structure } \\
\text { Transaction Object } \\
\text { User object } \\
\text { Window }\end{array}$ & $\begin{array}{l}\mathrm{bb} \\
\mathrm{b} \\
\mathrm{ch} \\
\mathrm{d} \\
\mathrm{dt} \\
\mathrm{c} \\
\mathrm{db} \\
\mathrm{i} \\
\mathrm{l} \\
\mathrm{r} \\
\mathrm{s} \\
\mathrm{t} \\
\mathrm{ui} \\
\mathrm{ul} \\
\mathrm{dw} \\
\mathrm{dwc} \\
\mathrm{ms} \\
\mathrm{m} \\
\text { str } \\
\text { trans } \\
\text { uo } \\
\text { w }\end{array}$ \\
\hline & Exemplo & Descrição \\
\hline & $\begin{array}{l}\text { gi_num_lines } \\
\text { sstr_data_points[] } \\
\text { iul_pointer } \\
\text { lb_finished } \\
\text { adw_source_rows } \\
\text { gs_line_buffer[ ] } \\
\text { sdt_last_update } \\
\text { idb_last_amount }\end{array}$ & $\begin{array}{l}\text { Inteiro global } \\
\text { Array de estruturas compartilhado } \\
\text { Long sem sinal de instância } \\
\text { Booleano local } \\
\text { DataWindow de argumento } \\
\text { Array de strings global } \\
\text { DateTime (datahora) compartilhado } \\
\text { Double de instância } \\
\end{array}$ \\
\hline Comentários & $\begin{array}{l}\text { Fazer comentários } \\
\text { - Todos os proce } \\
\text { pelo usuário dev } \\
\text { descrevendo-as. } \\
\text { - Faça do comen } \\
\text { seja, diga o que } \\
\text { - Ao criar funçõe } \\
\text { descrevendo ca } \\
\text { contêm. } \\
\end{array}$ & $\begin{array}{l}\text { nsiderando as seguintes recomendações: } \\
\text { mentos de eventos, métodos e funções definidas } \\
\text { m ter pelo menos um breve comentário no início } \\
\text { rio uma descrição funcional e não técnica, ou } \\
\text { e faz, não como faz. } \\
\text { definidas pelo usuário, forneça um comentário } \\
\text { um dos argumentos passados e o que eles }\end{array}$ \\
\hline
\end{tabular}


Tabela 1 - Padrão de Codificação PowerScript (C29) (continuação)

\begin{tabular}{|c|c|}
\hline Comentários & $\begin{array}{l}\text { - Comente declarações de variáveis para indicar seu propósito, } \\
\text { sejam elas de instância, compartilhadas ou globais. Declarações } \\
\text { triviais de variáveis locais para descrever seu uso são } \\
\text { desnecessárias. } \\
\text { - As variáveis, os controles e os objetos devem receber nomes } \\
\text { adequados, de forma que somente o código complexo ou incomum } \\
\text { precise de comentários linha-a-linha. }\end{array}$ \\
\hline Bom Comentário & IF record count $>$ limit // Foram todos os registros processados? \\
\hline Mau Comentário & $\begin{array}{l}\text { IF record_count > limit // Verifique se record_count é maior que } \\
\qquad / / \text { limit }\end{array}$ \\
\hline $\begin{array}{l}\text { Espaços } \\
\text { Branco }\end{array}$ & $\begin{array}{l}\text { - Escrever o código com espaçamento suficiente tal que não apareça } \\
\text { carregado. } \\
\text { - Separar toda construção de código com pelo menos um espaço. }\end{array}$ \\
\hline Indentação & $\begin{array}{l}\text { - Indentar sempre as instruçōes internas às Estruturas de Decisão ou } \\
\text { Condicional (CHOOSE CASE, IF ... THEN) e os Laços (FOR ... } \\
\text { NEXT, DO ... LOOP) com um espaço tabular, que corresponde a } \\
\text { três espaços simples, inclusive os Laços e Estruturas Condicionais } \\
\text { que estiverem aninhados. } \\
\text { - Indentar também com um espaço tabular as linhas de continuação } \\
\text { de uma instrução. }\end{array}$ \\
\hline $\begin{array}{l}\text { Exemplo } \\
\text { Indentação }\end{array}$ & $\begin{array}{l}\text { IF sample > threshold THEN } \\
\text { MessageBox("Advertência", "Perigo! Perigo! Perigo!") } \\
\text { END IF } \\
\text { MessageBox("Erro SQL", String(SQLCA. SQLDBCode) + \& } \\
\text { “. “+ SQLCA.SQLErrText) }\end{array}$ \\
\hline Texto de Código & $\begin{array}{l}\text { - Não permitir que as linhas se estendam além da borda direita da } \\
\text { janela do PowerScript. Usar o operador \& para dividir linhas em } \\
\text { pontos lógicos para que todo código possa ser visto na tela de uma } \\
\text { só vez. } \\
\text { - Evitar a divisão de strings com o operador \&, a menos que seja } \\
\text { necessário, ou seja, não existe outro bom lugar para dividir a linha. } \\
\text { Ao dividir uma string, termine-a com aspas seguidas do sinal de } \\
\text { adição e depois o \&. A próxima linha inicia com aspas. } \\
\text { - Usar aspas para envolver o texto de uma string. Usar apóstrofos } \\
\text { para strings somente se for preciso embutir aspas dentro deles. } \\
\text { - Não colocar mais que um comando numa mesma linha, separados } \\
\text { por ponto e vírgula (;). }\end{array}$ \\
\hline $\begin{array}{l}\text { Exemplo de } \\
\text { Texto de Código }\end{array}$ & $\begin{array}{l}\text { MessageBox("Erro", "Você informou " + \& } \\
\text { "um nome inválido") }\end{array}$ \\
\hline
\end{tabular}


Tabela 1 - Padrão de Codificação PowerScript (C29) (continuação)

\begin{tabular}{|c|c|}
\hline Maiúsculas & $\begin{array}{l}\text { - Escrever com letras maiúsculas todas as instruções PowerBuilder, } \\
\text { inclusive o SQL embutido. } \\
\text { - Escrever com maiúsculas e minúsculas (caso misto) as funções do } \\
\text { usuário, as funções do PowerBuilder e os métodos dos objetos. } \\
\text { - Escrever com minúsculas as variáveis que devem estar na forma } \\
\text { prefixo_corpo como citado acima. Usar o caractere sublinhado } \\
\text { para separar as palavras para distinguir as várias palavras no corpo } \\
\text { de um nome de variável. Não utilizar o caracter hífen numa } \\
\text { variável porque o usuário poderá interpretar como uma subtração. } \\
\text { - Podem ser escritas no caso misto as mensagens enviadas aos } \\
\text { usuários tal que faça uma clara apresentação. }\end{array}$ \\
\hline $\begin{array}{l}\text { Exemplos } \\
\text { Maiúsculas }\end{array}$ & $\begin{array}{l}\text { - IF/THEN/ELSE/ELSEIF/END IF } \\
\text { - } \text { RETURN } \\
\text { - FOR/TO/NEXT } \\
\text { - } \text { CHOOSE/CASE/END CHOOSE } \\
\text { - SELECT/INTO/FROM/WHERE } \\
\text { - INSERT/INTO/WHERE }\end{array}$ \\
\hline $\begin{array}{l}\text { Exemplos do } \\
\text { Caso Misto }\end{array}$ & $\begin{array}{l}\text { - Open }(\text { /Close() } \\
\text { - MessageBox(O } \\
\text { - IsValidO } \\
\text { - Integer(O } \\
\text { - SetFocus() } \\
\end{array}$ \\
\hline $\begin{array}{l}\text { Exemplos de } \\
\text { Minúsculas }\end{array}$ & $\begin{array}{l}\text { - li_conta_linhas } \\
\text { - gs_primeiro_nome } \\
\text { - str_dados_empr } \\
\end{array}$ \\
\hline Cláusula USING & $\begin{array}{l}\text { - Colocar sempre uma cláusula USING em todos os SQLs } \\
\text { embutidos para tornar completamente claro, em qualquer local, } \\
\text { qual objeto de transação está sendo acessado. }\end{array}$ \\
\hline Escopo & $\begin{array}{l}\text { - Sempre mover variáveis para o escopo mais restrito possível. } \\
\text { Evitar variáveis globais usando parâmetros com funções e com } \\
\text { janelas. } \\
\text { - Colocar uma estrutura ou função definida pelo usuário associada a } \\
\text { um objeto. Evitar funções e estruturas globais. } \\
\text { - Usar objetos do usuário não-visuais para encapsular variáveis e } \\
\text { funções associadas a funções comerciais comuns. }\end{array}$ \\
\hline
\end{tabular}


Tabela 2 - Padrão de Contagem de LOC para o PowerScript

\begin{tabular}{|l|l|}
\hline Padrão de Contagem de LOC & Linguagem: PowerBuilder \\
\hline Autor: Djalma Domingos da Silva & Data: $23 / 02 / 98$ \\
\hline
\end{tabular}

\begin{tabular}{|c|c|c|}
\hline Tipo de Contagem & Tipo & Comentários \\
\hline Físico/Lógico & Lógico & \\
\hline Tipo de Instrução & Incluso & Comentários \\
\hline Executável & $\mathrm{Sim}$ & \\
\hline \multicolumn{3}{|l|}{ Não Executável } \\
\hline - Declarações & $\operatorname{Sim}_{1}$ Nota & \\
\hline - Diretivas de Compilação & Não & \\
\hline - Comentários & Não & \\
\hline $\begin{array}{l}\text { - Nas próprias linhas das } \\
\text { instruções }\end{array}$ & Não & \\
\hline $\begin{array}{l}\text { - Em linhas juntamente } \\
\text { com o código fonte }\end{array}$ & Não & \\
\hline - Faixas & Não & \\
\hline - Comentários em branco & Não & \\
\hline - Linhas em branco & Não & \\
\hline Esclarecimentos & & Exemplos/Casos \\
\hline THEN, ELSE & Sim, Nota & \\
\hline ELSEIF & Sim & \\
\hline Keywords & $\mathrm{Sim}$ & \\
\hline Labels & Sim & \\
\hline Nota 1 & & $\begin{array}{l}\text { Conte cada declaração de variável e } \\
\text { parâmetro }\end{array}$ \\
\hline Nota 2 & & $\begin{array}{l}\text { Conte todas as ocorrências das } \\
\text { seguintes palavras-chaves: IF THEN } \\
\text { END IF, ELSE, ELSEIF, FOR NEXT, } \\
\text { STEP, DO UNTIL LOOP, DO WHILE } \\
\text { LOOP, DO LOOP UNTIL, DO LOOP } \\
\text { WHILE, CHOOSE CASE END } \\
\text { CHOOSE, CASE, CASE ELSE }\end{array}$ \\
\hline
\end{tabular}


Tabela 3 - Diretrizes e Checklist de Revisão de Código para PowerBuilder (C58)

\begin{tabular}{|c|c|c|c|c|c|c|c|}
\hline \multicolumn{2}{|c|}{ Nome da Aplicação: } & \multicolumn{6}{|c|}{ Nome do Objeto: } \\
\hline \multirow[b]{2}{*}{ Propósito } & \multirow[b]{2}{*}{$\begin{array}{l}\text { Guiar ao conduzir uma revisão de } \\
\text { código eficaz }\end{array}$} & \multicolumn{4}{|c|}{ Nome do Método } & \multirow[b]{2}{*}{$\begin{array}{l}\text { Acumu- } \\
\text { lado }\end{array}$} & \multirow[b]{2}{*}{$\begin{array}{l}\text { Acurnu- } \\
\text { lado \% }\end{array}$} \\
\hline & & $\#$ & \# & $\#$ & $\#$ & & \\
\hline Geral & $\begin{array}{l}\text { A medida que completar cada etapa } \\
\text { de revisão, anotar o número de } \\
\text { defeitos de cada tipo encontrado nas } \\
\text { colunas à direita. Se nenhum, inserir } \\
\text { um " } x \text { " na ou nas colunas. } \\
\text { Completar o checklist para cada } \\
\text { método antes de iniciar a revisão do } \\
\text { próximo. }\end{array}$ & & & & & & \\
\hline Completinde & $\begin{array}{l}\text { Verificar se todas as funções no } \\
\text { projeto foram codificadas. }\end{array}$ & & & & & & \\
\hline Inicialização & $\begin{array}{l}\text { Verificar variáveis e parâmetros de } \\
\text { início: } \\
\text { - no início da aplicação } \\
\text { - no início de todo laço } \\
\text { - na entrada de função/sub-rotina }\end{array}$ & & & & & & \\
\hline Chamadas & $\begin{array}{l}\text { Verificar os formatos de parâmetros } \\
\text { das funções de chamada }\end{array}$ & & & & & & \\
\hline Nomes & $\begin{array}{l}\text { Verificar a correta escrita dos nomes } \\
\text { e uso: } \\
\text { - É consistente? } \\
\text { - Está dentro do escopo declarado? } \\
\text { - Todas as estruturas/classes } \\
\text { utilizam a notação de ponto? }\end{array}$ & & & & & & \\
\hline $\begin{array}{l}\text { Declaração de } \\
\text { Variáveis }\end{array}$ & $\begin{array}{l}\text { Verificar se todos os tipos de dados } \\
\text { estão corretamente declarados e } \\
\text { utilizados; } \\
\text { Garantir que todas as varáveis foram } \\
\text { apropriadamente inicializadas; } \\
\text { Verificar por problemas de overflow, } \\
\text { underflow ou out-of-range (fora do } \\
\text { domínio) }\end{array}$ & & & & & & \\
\hline $\begin{array}{l}\text { Formato de } \\
\text { Saída }\end{array}$ & $\begin{array}{l}\text { Verificar o formato de saída: } \\
\text { - O salto de linha é apropriado? } \\
\text { - O espaçamento é apropriado? }\end{array}$ & & & & & & \\
\hline Pares () & $\begin{array}{l}\text { Garantir que o () são apropriados e } \\
\text { casados }\end{array}$ & & & & & & \\
\hline $\begin{array}{l}\text { Operadores } \\
\text { Lógicos }\end{array}$ & $\begin{array}{l}\text { Verificar o uso apropriado de todos } \\
\text { os operadores lógicos; } \\
\text { Verificar toda função lógica por } \\
\text { apropriados (). }\end{array}$ & & & & & & \\
\hline
\end{tabular}


Tabela 3 - Diretrizes e Checklist de Revisão de Código para PowerBuilder (C58) (cont.)

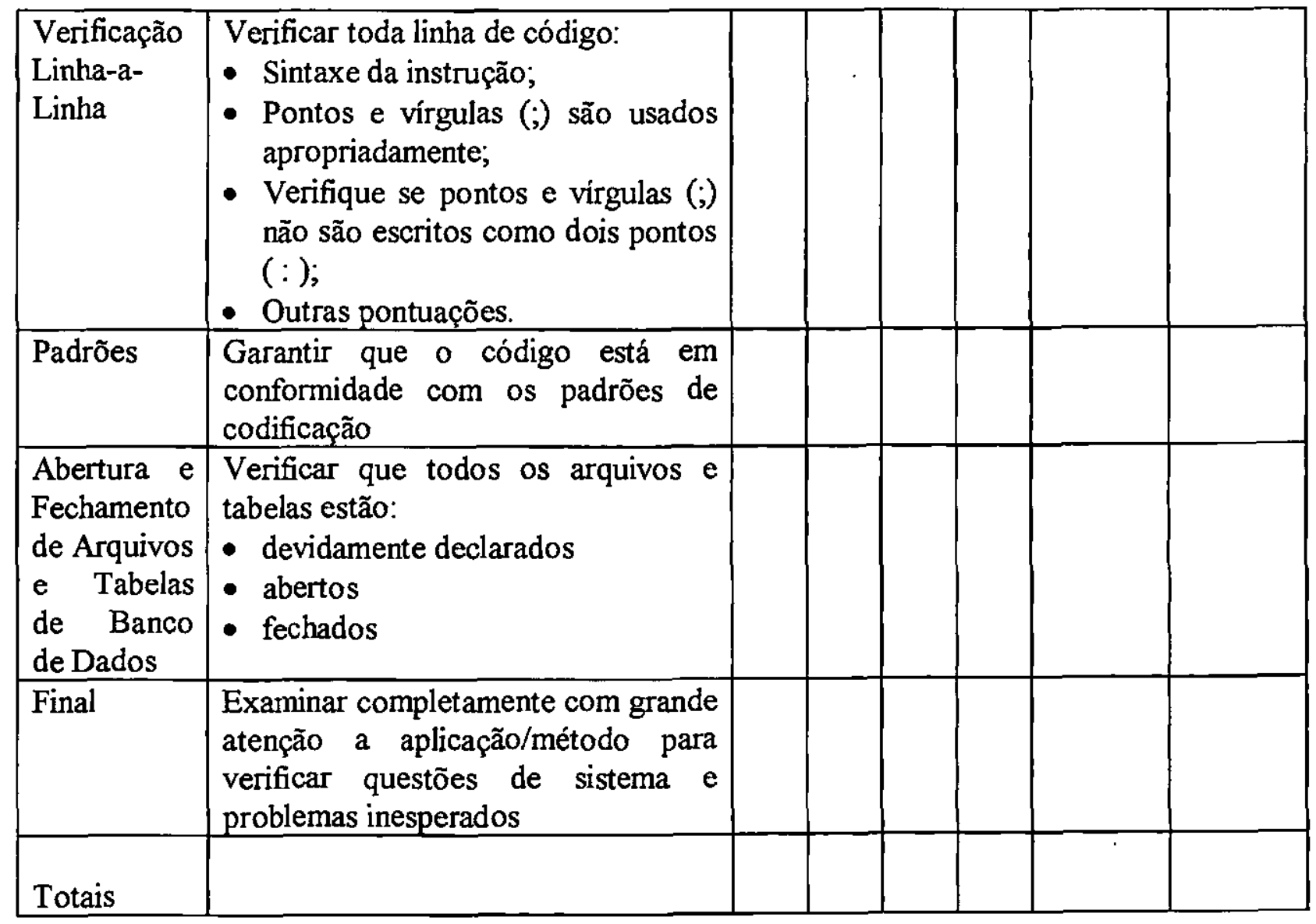


Tabela 4 - Processo PSP

Pré-Requisito: Descrição do problema.

\begin{tabular}{|c|c|c|c|c|c|c|c|}
\hline Fases & Atividades & \begin{tabular}{|l|l|}
0 & 0 \\
1
\end{tabular} & \begin{tabular}{l|l}
$\mathbf{0}$ & $\mathbf{1}$ \\
$\mathbf{1}$ & \\
\end{tabular} & $\begin{array}{l}1 \\
1\end{array}$ & 2 & $\begin{array}{l}2 \\
1\end{array}$ & 3 \\
\hline \multicolumn{8}{|l|}{ 1. Planejamento } \\
\hline \multirow[t]{3}{*}{ 1.1. Requisitos do Programa } & $\begin{array}{l}\text { - } \begin{array}{l}\text { Produzir ou obter uma declaração dos } \\
\text { requisitos para o programa. }\end{array} \\
\end{array}$ & \begin{tabular}{|l|l}
$\mathbf{X}$ & $\mathbf{2}$ \\
\end{tabular} & \begin{tabular}{l|l}
$\mathbf{X}$ & $\mathbf{X}$
\end{tabular} & $\mathbf{x}$ & $\mathbf{X}$ & $\mathbf{X}$ & $\mathbf{X}$ \\
\hline & $\begin{array}{l}\text { - Garantir que a declaração de requisitos } \\
\text { esteja clara e sem ambigüidades. }\end{array}$ & $\mathbf{x} \mid \mathbf{2}$ & $\mathbf{X} \mathbf{X}$ & $\mathbf{x}$ & $\mathbf{x}$ & $\mathbf{X}$ & $\mathbf{X}$ \\
\hline & - Resolver quaisquer questões. & $\mathbf{X} \mid \mathbf{Y}$ & \begin{tabular}{l|l|}
$\mathbf{X}$ & $\mathbf{X}$ \\
\end{tabular} & $\mathbf{X}$ & $\mathbf{X}$ & $\mathbf{X}$ & $\mathbf{X}$ \\
\hline \multirow[t]{6}{*}{ 1.2. Estimativa de Tamanho } & $\begin{array}{ll}\text { - } & \begin{array}{l}\text { Estimar o total de LOC novas e alteradas } \\
\text { necessárias. }\end{array} \\
\end{array}$ & & $\mathbf{X}$ & & & & \\
\hline & $\begin{array}{l}\text { Produzir um projeto conceitual do } \\
\text { programa. }\end{array}$ & & $\mathbf{X}$ & $\mathbf{x}$ & $\mathbf{X}$ & $\mathbf{X}$ & $\mathbf{X}$ \\
\hline & $\begin{array}{l}\text { - Usar o método PROBE para estimar as } \\
\text { LOC novas e alteradas necessárias para } \\
\text { desenvolver este programa. }\end{array}$ & & $\mathbf{X}$ & $\mathbf{X}$ & $\mathbf{X}$ & $\mathbf{X}$ & $\mathbf{X}$ \\
\hline & $\begin{array}{l}\text { Estimar as LOC básicas, adicionadas, } \\
\text { excluídas, modificadas e reutilizadas. }\end{array}$ & & $\mathbf{X}$ & $\mathbf{x}$ & $\mathbf{X}$ & $\mathbf{X}$ & $\mathbf{X}$ \\
\hline & $\begin{array}{l}\text { - Completar o Gabarito de Estimativa de } \\
\text { Tamanho e o Resumo do Plano do } \\
\text { Projeto. }\end{array}$ & & $\mathbf{X}$ & $\mathbf{x}$ & $\mathbf{X}$ & $\mathbf{X}$ & $\mathbf{X}$ \\
\hline & $\begin{array}{l}\text { - Calcular o intervalo de confiança de } \\
\text { tamanho em } 70 \% \text {. }\end{array}$ & & & & $\mathbf{X}$ & $\mathbf{X}$ & $\mathbf{X}$ \\
\hline \multirow[t]{3}{*}{$\begin{array}{l}\text { 1.3. Estratégia de } \\
\text { Desenvolvimento Cíclico }\end{array}$} & $\begin{array}{l}\text { - Subdividir o desenvolvimento do programa } \\
\text { em módulos de aproximadamente } 100 \mathrm{e} \\
\text { não mais que } 250 \text { LOC novas e alteradas. }\end{array}$ & & & & & & $\mathbf{X}$ \\
\hline & $\begin{array}{l}\text { - Alocar o LOC a ser desenvolvido entre os } \\
\text { ciclos. }\end{array}$ & & & & & & $\mathbf{X}$ \\
\hline & $\begin{array}{l}\text { Informar os dados de tamanho no } \\
\text { Planejamento do Resumo Cíclico. }\end{array}$ & & & & & & $\mathbf{X}$ \\
\hline \multirow[t]{4}{*}{ 1.4. Estimativa de Recursos } & $\begin{array}{l}\text { - Estimar o tempo necessário para o } \\
\text { desenvolvimento. }\end{array}$ & \begin{tabular}{|l|l|l}
$\mathbf{X}$ & $\mathbf{I}$ \\
\end{tabular} & $\mathbf{X}$ & & & & \\
\hline & $\begin{array}{l}\text { Estimar o tempo necessário para o } \\
\text { desenvolvimento com base no tempo } \\
\text { necessário por LOC nos programas } \\
\text { anteriores. } \\
\end{array}$ & & $\mathbf{X}$ & & & & \\
\hline & $\begin{array}{l}\text { Usar o método PROBE para estimar o } \\
\text { tempo necessário para desenvolver este } \\
\text { programa. }\end{array}$ & & & $\mathbf{X}$ & $\mathbf{X}$ & $\mathbf{X}$ & $\mathbf{X}$ \\
\hline & $\begin{array}{l}\text { - Calcular o intervalo de confiança de tempo } \\
\text { em } 70 \% \text {. }\end{array}$ & & & & $\mathbf{X}$ & $\mathbf{X}$ & $\mathbf{X}$ \\
\hline
\end{tabular}


Tabela 4 - Processo PSP (continuação)

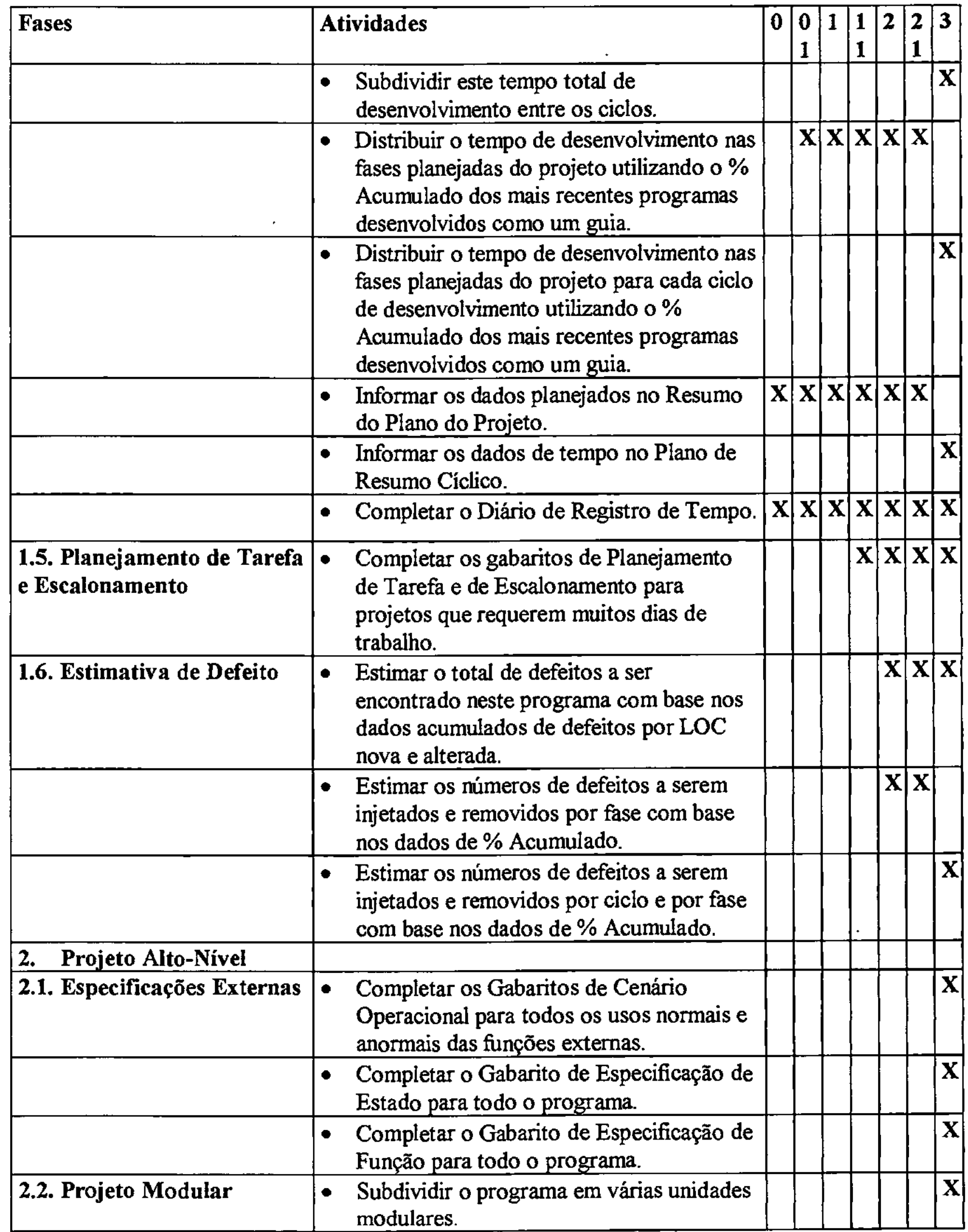


Tabela 4 - Processo PSP (continuação)

\begin{tabular}{|c|c|c|c|c|c|c|}
\hline Fases & Atividades & \begin{tabular}{|l|l|l}
0 & 0 \\
1 \\
\end{tabular} & \begin{tabular}{|l|l|} 
& 1 \\
\end{tabular} & \begin{tabular}{|l|l|}
1 & 2 \\
1 & \\
\end{tabular} & $\begin{array}{l}2 \\
1\end{array}$ & 3 \\
\hline & $\begin{array}{l}\text { - Especificar as características externas para } \\
\text { cada um destes módulos com os Gabaritos } \\
\text { de Cenário Operacional e Especificação } \\
\text { Funcional. }\end{array}$ & & & & & $\mathbf{X}$ \\
\hline & $\begin{array}{l}\text { - Completar os Gabaritos de Especificação } \\
\text { Lógica e de Estado para a rotina principal } \\
\text { ou de controle de mais alto nivel. }\end{array}$ & & & & & $\mathbf{X}$ \\
\hline & $\begin{array}{l}\text { - Registrar as questões chaves ou problemas } \\
\text { do projeto no Registro de } \\
\text { Acompanhamento de Questões. } \\
\end{array}$ & & & & & $\mathbf{X}$ \\
\hline 2.3. Protótipos & $\begin{array}{l}\text { - Identificar, planejar e executar protótipos } \\
\text { necessários. }\end{array}$ & & & & & $\mathbf{x}$ \\
\hline $\begin{array}{l}\text { 2.4. Estratégia de } \\
\text { Desenvolvimento }\end{array}$ & $\begin{array}{l}\text { Decidir uma estratégia para } \\
\text { desenvolvimento e teste do programa em } \\
\text { ciclos. Onde possível manter cada ciclo } \\
\text { com aproximadamente } 100 \text { LOC novas e } \\
\text { alteradas, desenvolver módulos completos } \\
\text { em um ciclo, minimizar a quantidade de } \\
\text { testes necessários e expor à maioria dos } \\
\text { riscos de desenvolvimento o quanto antes. }\end{array}$ & & & & & $\mathbf{x}$ \\
\hline $\begin{array}{l}\text { 2.5. Documentação da } \\
\text { Estratégia de } \\
\text { Desenvolvimento }\end{array}$ & $\begin{array}{l}\text { - Definir as funções de programa e/ou } \\
\text { módulos a serem produzidos em cada ciclo } \\
\text { de desenvolvimento. }\end{array}$ & & & & & $\mathbf{X}$ \\
\hline & $\begin{array}{l}\text { - Especificar a abordagem de teste para } \\
\text { progressivamente integrar os módulos em } \\
\text { cada ciclo. }\end{array}$ & & & & & $\mathbf{X}$ \\
\hline $\begin{array}{l}\text { 2.6. Registro de } \\
\text { Acompanhamento de } \\
\text { Questões }\end{array}$ & $\begin{array}{l}\text { - Revisar o Registro de Acompanhamento } \\
\text { de Questões durante o projeto e fazer } \\
\text { apropriadas adições ou mudanças. }\end{array}$ & & & & & $\mathbf{x}$ \\
\hline $\begin{array}{l}\text { 3. Revisão Projeto de } \\
\text { Alto-Nível }\end{array}$ & & & & & & \\
\hline 3.1. Cobertura de Projeto & $\begin{array}{l}\text { Verificar se os requisitos foram cobertos } \\
\text { pelo projeto, ou seja, se todos os } \\
\text { requisitos funcionais foram especificados, } \\
\text { se os tópicos de projeto de alto-nível no } \\
\text { Registro de Acompanhamento de } \\
\text { Questões foram atingidos e se os materiais } \\
\text { de projeto requeridos foram produzidos. }\end{array}$ & & & & & $\mathbf{x}$ \\
\hline
\end{tabular}


Tabela 4 - Processo PSP (continuação)

\begin{tabular}{|c|c|c|c|c|c|c|c|}
\hline Fases & Atividades & 0 & \begin{tabular}{l|}
0 \\
1 \\
\end{tabular} & \begin{tabular}{|l|l|l}
1 & 1 \\
1
\end{tabular} & \begin{tabular}{l|l}
1 & 2 \\
1 & \\
\end{tabular} & & 3 \\
\hline $\begin{array}{l}\text { 3.2. Verificação da } \\
\text { Máquina de Estado }\end{array}$ & $\begin{array}{l}\text { Verificar os projetos da máquina de } \\
\text { estado, ou seja, se os estados estão } \\
\text { completos e ortogonais, se as condições } \\
\text { de transição de cada estado estão } \\
\text { completas e ortogonais. } \\
\end{array}$ & & & & & & $\mathbf{X}$ \\
\hline 3.3. Verificação Lógica & $\begin{array}{l}\text { Verificar a lógica do projeto de alto-nível. } \\
\text { Usar um método definido, tais quais: } \\
\text { Tabelas de Execução, Tabelas de } \\
\text { Rastreamento e Provas de Verificação. } \\
\end{array}$ & & & & & & $\mathbf{X}$ \\
\hline $\begin{array}{l}\text { 3.4. Verificação de } \\
\text { Consistência de Projeto }\end{array}$ & $\begin{array}{l}\text { Verificar se todos nomes e tipos especiais } \\
\text { estão claros, consistentes e de acordo com } \\
\text { os padrões estabelecidos. }\end{array}$ & & & & & & 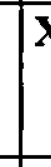 \\
\hline 3.5. Verificação de Reuso & $\begin{array}{l}\text { Verificar se as funções reusáveis estão } \\
\text { disponíveis e seus usos planejados estão } \\
\text { corretos. }\end{array}$ & & & & & & 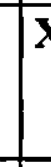 \\
\hline $\begin{array}{l}\text { 3.6. Verificação de } \\
\text { Estratégia de } \\
\text { Desenvolvimento }\end{array}$ & $\begin{array}{l}\text { Revisar a estratégia de desenvolvimento } \\
\text { para garantir que todas as funções } \\
\text { requeridas foram fornecidas, as funções } \\
\text { necessárias estão disponíveis e consistente } \\
\text { com a estratégia de teste e a estratégia de } \\
\text { teste cobre todas as funções requeridas e } \\
\text { os estados-chave do programa. } \\
\end{array}$ & & & & & & 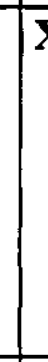 \\
\hline \multirow[t]{2}{*}{ 3.7. Correções de Defeito } & - Corrigir todos defeitos encontrados. & & & & & & $\underline{1}$ \\
\hline & $\begin{array}{l}\text { - Registrar os defeitos no Diário de Registro } \\
\text { de Defeito. }\end{array}$ & & & & & & 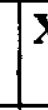 \\
\hline \multicolumn{8}{|l|}{ 4. Desenvolvimento } \\
\hline \multirow[t]{6}{*}{ 4.1. Projeto } & - Revisar os requisitos. & $\mathbf{X}$ & $\mathbf{X}$ & $\mathbf{x} \mid \mathbf{Z}$ & $\mathbf{x} / \mathbf{Z}$ & $\mathbf{x}$ & $\mathbf{X}$ \\
\hline & - Revisar os requisitos do módulo. & & & & & & $y$ \\
\hline & $\begin{array}{l}\text { Produzir um projeto para atingir os } \\
\text { requisitos. }\end{array}$ & $\mathbf{X}$ & $\mathbf{x}$ & $\mathbf{x}$ ? & $\mathbf{x} \mid \mathbf{Z}$ & $\mathbf{x}$ & \\
\hline & $\begin{array}{l}\text { - Produzir uma especificação externa para } \\
\text { atingir os requisitos. }\end{array}$ & & & & & 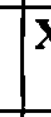 & 2 \\
\hline & $\begin{array}{l}\text { - Completar os Gabaritos de Especificação } \\
\text { de Função e Cenário Operacional para } \\
\text { registrar a especificação. }\end{array}$ & & & & & 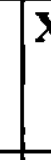 & 3 \\
\hline & $\begin{array}{l}\text { - Produzir um projeto para atingir a } \\
\text { especificação. }\end{array}$ & & & & & 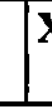 & 2 \\
\hline
\end{tabular}


Tabela 4 - Processo PSP (continuação)

\begin{tabular}{|c|c|c|c|c|c|c|c|}
\hline Fases & Atividades & 0 & & & & & \\
\hline & \begin{tabular}{|l|} 
- Registrar o projeto nos Gabaritos de \\
Especificação Funcional, Cenário \\
Operacional, Especificação de Estado e \\
Especificação Lógica tal como requerido.
\end{tabular} & & & & & & $x$ \\
\hline & $\begin{array}{l}\text { Completar o projeto para o módulo com } \\
\text { os materiais e facilidades de teste. }\end{array}$ & & & & & & $\mathbf{X}$ \\
\hline - & $\begin{array}{l}\text { - Registrar no Diário de Registro de Defeito } \\
\text { quaisquer defeitos encontrados. }\end{array}$ & & & & & $\mathbf{X}$ & $\mathbf{x}$ \\
\hline & 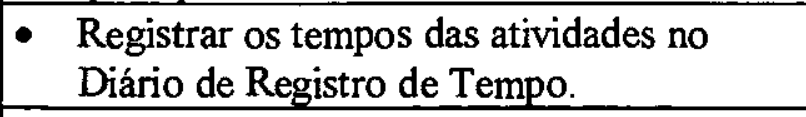 & $\mathbf{x} \mid \mathbf{z}$ & 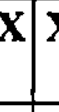 & & & & $x$ \\
\hline 4.2. Revisão de Projeto & $\begin{array}{l}\text { - Seguir o Checklist de Revisão de Projeto e } \\
\text { revisar o projeto. }\end{array}$ & & & & $\bar{X}$ & $x$ & \\
\hline & $\begin{array}{l}\text { - Seguir o Checklist de Revisão de Projeto e } \\
\text { revisar o módulo e os materiais de teste } \\
\text { dos projetos. }\end{array}$ & & & & & & $\mathbf{X}$ \\
\hline & - Corrigir todos os defeitos encontrados. & & & & $\underline{\bar{X}}$ & $x$ & $x$ \\
\hline & $\begin{array}{l}\text { - Registrar os defeitos no Diário de Registro } \\
\text { de Defeito. }\end{array}$ & & & & $\mathbf{x}$ & a. & $x$ \\
\hline & $\begin{array}{l}\text { - Registrar o tempo no Diário de Registro } \\
\text { de Tempo. }\end{array}$ & & & & $\mathrm{x}$ & & $\mathbf{x}$ \\
\hline 4.3. Codificação & - Implementar o projeto. & $\mathbf{x}$ & & & & & \\
\hline & $\begin{array}{l}\text { - Implementar o projeto seguindo o Padrão } \\
\text { de Codificação. }\end{array}$ & & & & & $x$ & $\mathbf{x}$ \\
\hline & $\begin{array}{l}\text { - Registrar no Diário de Registro de Defeito } \\
\text { quaisquer defeitos encontrados. }\end{array}$ & $\mathbf{x} \mid \mathbf{Y}$ & & & & & $x$ \\
\hline & $\begin{array}{l}\text { Registrar os tempos das atividades no } \\
\text { Diário de Registro de Tempo. }\end{array}$ & $\left.\mathbf{x}\right|^{2}$ & $\bar{x} \mid 2$ & & $\mathrm{x}$ & & $x$ \\
\hline 4.4. Revisão de Código & $\begin{array}{l}\text { - Seguir o Checklist de Revisão de Código e } \\
\text { revisar o código. }\end{array}$ & & & & & $x$ & \\
\hline & $\begin{array}{l}\text { - Seguir o Checklist de Revisão de Código e } \\
\text { revisar o código do módulo e teste. }\end{array}$ & & & & & & $\mathbf{x}$ \\
\hline & - Corrigir todos os defeitos encontrados. & & & & & & $x$ \\
\hline & $\begin{array}{l}\text { - Registrar os defeitos no Diário de Registro } \\
\text { de Defeito. }\end{array}$ & & & & & & $\mathbf{x}$ \\
\hline & $\begin{array}{l}\text { - Registrar o tempo no Diário de Registro } \\
\text { de Tempo. }\end{array}$ & & & & & & $\mathbf{x}$ \\
\hline 4.5. Compilação & $\begin{array}{l}\text { - Compilar o programa até que esteja isento } \\
\text { de erro. }\end{array}$ & $\mathbf{x}$ & & & & & $\mathbf{x}$ \\
\hline & $\begin{array}{l}\text { Compilar o programa e os materiais de } \\
\text { teste até que esteja isento de erro. }\end{array}$ & & & & & & $\mathbf{x}$ \\
\hline & - Corrigir todos os defeitos encontrados. & & & & & & $\mathrm{x}$ \\
\hline
\end{tabular}


Tabela 4 - Processo PSP (continuação)

\begin{tabular}{|c|c|c|c|c|c|c|c|}
\hline Fases & Atividades & \begin{tabular}{l|l}
0 & 0 \\
1
\end{tabular} & \begin{tabular}{l|l}
$\mathbf{0}$ & 1 \\
1 &
\end{tabular} & & & & 3 \\
\hline & $\begin{array}{l}\text { - Registrar os defeitos no Diário de Registro } \\
\text { de Defeito. }\end{array}$ & $\left.\mathbf{x}\right|^{2}$ & \begin{tabular}{l|l}
$\mathbf{x}$ & 1
\end{tabular} & $\overline{\mathbf{x}} \mid \mathbf{x}$ & & & $x$ \\
\hline & $\begin{array}{l}\text { Registrar os tempos das atividades no } \\
\text { Diário de Registro de Tempo. } \\
\end{array}$ & $\mathbf{x}$ & $\left.\mathbf{x}\right|_{2} ^{2}$ & $\mathbf{x} \mid \mathbf{x}$ & & & $\mathbf{x}$ \\
\hline 4.6. Teste & $\begin{array}{l}\text { Testar até que todos os testes não } \\
\text { apresentem erros. }\end{array}$ & \begin{tabular}{l|l}
$\mathbf{x}$ & 2 \\
\end{tabular} & $\mathbf{x} \mid \mathbf{z}$ & $\begin{array}{l}\mathbf{X} \\
\mathbf{x}\end{array}$ & $\mathbf{x}$ & $x$ & ) \\
\hline & $\begin{array}{l}\text { - Testar os módulos até que todos os testes } \\
\text { não apresentem erros. }\end{array}$ & & & & & & $\mathbf{x}$ \\
\hline & Corrigir todos os defeitos encontrados. & $\mathbf{x}$ & $\left.\mathbf{x}\right|^{2}$ & $\mathbf{x} \mid \mathbf{X}$ & $\mathbf{x}$ & & $\mathbf{x}$ \\
\hline & $\begin{array}{l}\text { - Registrar os defeitos no Diário de Registro } \\
\text { de Defeito. }\end{array}$ & $\mathbf{x}$ & $\mathbf{X} \mid \mathbf{2}$ & $\mathbf{x}$ & $\mathbf{x}$ & $\mathbf{x}$ & $x$ \\
\hline & $\begin{array}{l}\text { Registrar os tempos das atividades no } \\
\text { Diário de Registro de Tempo. }\end{array}$ & $\left.\mathbf{x}\right|^{2}$ & $\mathbf{x} \mid z$ & \begin{tabular}{l|l}
$\mathbf{X}$ & $\mathbf{X}$
\end{tabular} & $\mathbf{x}$ & $\mathbf{X}$ & $x$ \\
\hline & $\begin{array}{l}\text { - Completar o Gabarito Relatório de Teste } \\
\text { para os testes conduzidos e resultados } \\
\text { obtidos. }\end{array}$ & & & $\mathbf{x} \mid \mathbf{x}$ & & $\mathrm{x} \cdot \mathrm{x}$ & $x$ \\
\hline $\begin{array}{l}\text { 4.7. Reavaliação e } \\
\text { Reciclagem }\end{array}$ & $\begin{array}{l}\text { - Registrar os dados sobre o ciclo de } \\
\text { desenvolvimento. }\end{array}$ & & & & & & $\mathbf{X}$ \\
\hline & $\begin{array}{l}\text { - Reavaliar a situação em comparação com } \\
\text { o planejado e decidir continuar como } \\
\text { planejado ou fazer mudanças. }\end{array}$ & & & & & & $\mathbf{X}$ \\
\hline 5. Autópsia & & & & & & & \\
\hline 5.1. Defeitos Injetados & $\begin{array}{l}\text { - Determinar do Diário de Registro de } \\
\text { Defeito o número de defeitos injetados em } \\
\text { cada fase PSP. }\end{array}$ & $\left.\mathbf{x}\right|^{2}$ & $\mathbf{x}$ & $\mathbf{X}$ & & & $\mathbf{x}$ \\
\hline & $\begin{array}{l}\text { - Registrar este número sob Defeitos } \\
\text { Injetados - Realizados no Resumo do } \\
\text { Plano do Projeto. }\end{array}$ & $\left.\mathbf{x}\right|^{2}$ & $\mathbf{x} \mid \mathbf{2}$ & $\mathbf{x} \mid \mathbf{I}$ & & & $\mathbf{x}$ \\
\hline 5.2. Defeitos Removidos & $\begin{array}{l}\text { Determinar do Diário de Registro de } \\
\text { Defeito o número de defeitos removidos } \\
\text { em cada fase PSP. }\end{array}$ & $\left.\mathbf{x}\right|^{2}$ & $\mathbf{x} \mid \mathbf{2}$ & & & & $\mathbf{x}$ \\
\hline & $\begin{array}{l}\text { - Registrar este número sob Defeitos } \\
\text { Removidos - Realizados no Resumo do } \\
\text { Plano do Projeto. }\end{array}$ & $\mathbf{x}$ & $\mathbf{x} \mathbf{y}^{2}$ & & & & $\mathbf{x}$ \\
\hline & $\begin{array}{l}\text { - Calcular o esforço de revisão geral do } \\
\text { processo realizado e informar no Resumo } \\
\text { do Plano do Projeto. }\end{array}$ & & & & & & $x$ \\
\hline 5.3. Tamanho & - Contar LOC no programa finalizado. & & $\mathbf{x}[3$ & & & & $\mathrm{x}$ \\
\hline
\end{tabular}


Tabela 4 - Processo PSP (continuação)

\begin{tabular}{|c|c|c|c|c|c|c|c|c|}
\hline Fases & Atividades & \begin{tabular}{|l|}
0 \\
\end{tabular} & \begin{tabular}{l|}
0 \\
1
\end{tabular} & 1 & $\begin{array}{l}1 \\
1\end{array}$ & 2 & \begin{tabular}{|l|}
2 \\
1 \\
\end{tabular} & 3 \\
\hline & $\begin{array}{l}\text { Determinar os LOC básicos, reutilizados, } \\
\text { excluídos, modificados, adicionados, total, } \\
\text { total de novos e alterados e novos } \\
\text { reutilizáveis. }\end{array}$ & & $\mathbf{x}$ & $\mathbf{x}$ & $\mathbf{X}$ & $\mathbf{X}$ & $\mathbf{X}$ & $\mathbf{X}$ \\
\hline & $\begin{array}{l}\text { - Registrar estes dados no Resumo do Plano } \\
\text { do Projeto. }\end{array}$ & & $\mathbf{x}$ & $\mathbf{X}$ & $\mathbf{X}$ & $\mathbf{X}$ & $\mathbf{X}$ & $\mathbf{x}$ \\
\hline 5.4. Tempo & $\begin{array}{l}\text { - Revisar o Diário de Registro de Tempo } \\
\text { finalizado. }\end{array}$ & $\mathbf{X}$ & $\mathbf{X}$ & $\mathbf{X}$ & $\mathbf{X}$ & $\mathbf{X}$ & $\mathbf{X}$ & $\mathbf{X}$ \\
\hline & $\begin{array}{l}\text { - Registrar o tempo total gasto em cada fase } \\
\text { PSP na coluna Realizado do Resumo do } \\
\text { Plano do Projeto. }\end{array}$ & $\mathbf{X}$ & $\mathbf{x}$ & $\mathbf{x}$ & $\mathbf{X}$ & $\mathbf{X}$ & $\mathbf{X}$ & $\mathbf{X}$ \\
\hline 5.5. Melhoria & $\begin{array}{l}\text { Completar a Proposta de Melhoria do } \\
\text { Processo descrevendo problemas do } \\
\text { processo, sugestões de melhoria e lições } \\
\text { aprendidas. }\end{array}$ & & $\mathbf{X}$ & $\mathbf{X}$ & $\mathbf{x}$ & $\mathbf{X}$ & $\mathbf{X}$ & $\mathbf{X}$ \\
\hline
\end{tabular}




\section{Referências Bibliográficas}

\section{Bibliografia}

[Alb97] AlbUQUERQUe, J.O. Processo Pessoal de Software: Uma Abordagem Orientada a Java. Recife, 1997. 141p. Dissertação (Mestrado) Centro de Ciências Exatas e da Natureza, Universidade Federal de Pernambuco.

[And96] ANDRADE, A.L.P. et al. Aplicação da Norma ISO/IEC 12119 na Avaliação da Qualidade de Produtos de Software. Curitiba, VII CITS:QS, p.7589, 1996.

[Boe88] BOEHM, B. “A Spiral Model for Software Development and Enhancement". Computer, v.21, n.5, p.61-72, 1988.

[Bro87] BROOKS Jr., F. P. No Silver Bullet: Essence and Accidents of Software Engineering. IEEE Computer, v.20, n.4, p.10-9, 1987.

[Chi92] CHILLAREGE, R. et al. Orthogonal Defect Classification - A Concept for InProcess Measurements. IEEE Transactions on Software Engineering, v. 18, n.11, p.943-56, 1992.

[CHM95a] CURTIS, B.; HeFLeY, W. E.; MILLER, S. Overview of the People Capability Maturity Model. Pittsburgh, Software Engineering Institute, 1995. (Technical Report CMU/SEI-95-MM-01)

[CHM95b] CURTIS, B.; HeFleY, W. E.; MILleR, S. People Capability Maturity Model. Pittsburgh, Software Engineering Institute, 1995. (Technical Report CMU/SEI-95-MM-02)

[Col96] Coleman, D. et al. Desenvolvimento orientado a objetos: o método fusion. Rio de Janeiro, Campus, 1996.

[DoD87] DEPARTMENT Of DEFENSE. Report of the Defense Science Board Task Force on Military Software. Washington, D. C., Office of the Under Secretary of Defense for Acquisition, 1987.

[dTdS96] CEntro Internacional DE TeCNOLOGia DE Software. Gestão da Qualidade no Desenvolvimento de Software: O Modelo SEI/CMM. /Curso oferecido ao X Simpósio Brasileiro de Engenharia de Software, São Carlos, 1996/ 
[dTdS97] CENTRO INTERNACIONAL DE TECNOLOGIA DE SOFTWARE. PSP/SEI Personal Software Process. /Tutorial oferecido à VIII Conferência Internacional de Tecnologia de Software: Qualidade de Software, Curitiba, 1997/

[Fer97] FERGUSON, P. et al. Results of Applying the Personal Software Process. IEEE Computer, v.30, n.5, p.24-31, 1997.

[Har92] HAREL, D. Biting the Silver Bullet. IEEE Computer, p.8-20, January 1992.

[HCR+94] HERBSLEB, J.; CARLETON, A.; ROZUM, J.; SIEGEL, J.; ZUBROW, D. Benefits of cmm-based software process improvement: Initial results. Pittsburgh, Software Engineering Institute, 1994. (Technical Report CMU/SEI-94-TR-13)

[Hen94] HENRY, J. et al. Improving Software Maintenance at Martin Marietta. IEEE Software, p.67-75, July 1994.

[Hum89] HuMPHRE, W. S. Managing the Software Process. Reading, AddisonWesley, 1989.

[Hum94] HUMPHREY, W. S. The Personal Software Process. IEEE Computer Society, v.13, n.1, p.1-3, 1994.

[Hum95a] HUMPHREY, W. S. A Discipline for Software Engineering. Reading, Addison-Wesley, 1995.

[Hum95b] HuMPHREY, W. S. Why Should You Use A Personal Sofware Process? ACM SIGSOFT, Software Engineering Notes, v.20, n.3, p.33-6, 1995.

[Hum95c] HUMPHREY, W. S. Interview with Watts Humphrey: Pushing Process with a Personal Approach. IEEE Software, p.102-3, July 1995.

[Hum96] HuMPHREY, W. S. Using a Defined and Measured Personal Software Process. IEEE Software, p.77-88, May 1996.

[Hum97] HUMPHREY, W. S. Introduction to the Personal Software Process. Reading, Addison-Wesley, 1997.

[ISO94] ISO/IEC 12119. International Standard. Information Technology Software Packages - Quality Requirements and Testing. October, 1994.

[NBR94] NBR ISO/IEC 9126. Tecnologia de Informação - Avaliação de Produto de Software - Caracteristicas de Qualidade e Diretrizes para o seu Uso. Agosto, 1994. 
[Pau95] PAULK, M. C. How ISO 9001 compares with the CMM. IEEE Software, p.74-83, January 1995.

[PCCW93] PaulK, M. C.; Curtis, B.; Chrissis, M. B.; Weber, C. V. Capability Maturity Model for Software Version 1.1. Pittsburgh, Software Engineering Institute, 1993. (Technical Report CMU/SEI-93-TR24)

[Pre95a] PRESSMAN, R S. Engenharia de Software. São Paulo, Makron Books, 1995.

[Pre95b] PRESSMAN, R. S. Making Process Improvement Personal. IEEE Software, p. 82-3, September 1995.

[Sie90] SIEGEL, J. A. L. et al. National Software Capacity: Near-Term Study. Pittsburgh, Software Engineering Institute, 1990. (Technical Report CMU/SEI-90-TR-12)

[Si198] SLVA, D.D.; MASIERO, P.C. Uma Proposta de Versấo e Ferramenta do PSP para o Domínio de Aplicações Comerciais. Curitiba, IX CITS:QS, p.157-68, 1998.

[You95] YouRDon, E. Declínio e Queda dos Analistas e dos Programadores. São Paulo, Makron Books, 1995.

[You97] YouRDON, E. Ressurreição e Ascensão dos Analistas e dos Programadores. São Paulo, Makron Books, 1997. 


\section{Bibliografia da Web}

[Boo95] ETNOTEAM S.P.A. (1995). The Bootstrap Service [Online]. Available: http://www.etnoteam.it/bootstrap/brochure.html [1997, June 18].

[CMU96] CARNEGIE MELLON UNIVERSITy (1996). A Specification for Automated Support. for the PSP [Online]. Available: http://www.sei.cmu.edu/technology/pspAuto/ [1997, March 27].

[CMU97] CARNEGE MELLON UNIVERSITy (1997). Personal Software Process [Online]. Available: http://www.sei.cmu.edu/technology/psp [1997, April 29].

[ETS97] East TenNessee State UnIVERsity (1997). Personal Software Process Studio Home page [Online]. Available: http://www-cs.etsutn.edu/softeng/PSP/index.htm [1998, July 30].

[Hum95d] HUMPHREY, W. S. (1995). A Personal Commitment to Software Quality [Online]. Available: http:/www.sei.cmu.edu/products/publications/ 95.reports/95.ar.psp.qual.html [1996, December 27].

[IPD97] INSTITUTE FOR PROGRAM STRUCTURES AND DATA ORGANIZATION (1997). PSP Resources Page at the University of Karlsruhe [Online]. Available: http://wwwipd.ira.uka.de/ gramberg/PSP/ [1998, July 30].

[ISO96a] INTERNATIONAL ORGANIZATION FOR STANDARDIZATION (1996). Introduction to ISO [Online]. Available: http://www.iso.ch/ [1997, June 16].

[ISO96b] INTERNATIONAL ORGANIZATION FOR STANDARDIZATION (1996). Welcome to iso easy! [Online]. Available: http://www.exit109.com:80/ leebee [1997, June 16].

[Lah97] LAHME, C.C. (1997). Timelog for the Personal Software Process [Online]. Available: http://mats.gmd.de:8080/clemens/java/timelog/ [1998, July 30].

[Lig96] LighTFOOD, T. (1996). Spice - Welcome Page [Online]. Available: http://www-sqi.cit.gu.edu.au/spice/ [1997, June 17].

[QIP96] FRAUNHOFER INSTITUTE FOR EXPERIMENTAL SOFTWARE ENGINEERING (IESE) (1996). Quality Improvement Paradigm (QIP) [Online]. Available: http://www.iese.thg.de/services/projects/Public-Projects/Perfect/ QIP/QIP.html [1997, June 18]. 
[QTt96] LEITE (1996). Qualidade Total - Glossário [Online]. Available: http://qualidade.com [1997, June 18].

[Tri95] UnIVERSTTY of HOUSTON ClEAR LAKE (1995). The Trillium Model [Online]. Available: http://www2.umassd.edu:80/swpi/bellcanada/ trillium-html/trillium.html [1997, June 18].

[Wor97] WORSLEY, A. (1997). PSPTOOL Description, Release 0.6 [Online]. Available: http://www.virtual.net.au/ tqc/description.html [1998, September 07]. 


\section{Apêndice 1 - Relatórios Finais dos Programas-Exercícios e Modelo Conceitual de Dados Completo do PSPBuilder}

São apresentados neste apêndice alguns dos relatórios finais do programa-exercício $1 \mathrm{~A}$ emitidos pelo PSPBuilder e os Modelos Conceituais de Dados complementares ao PSP0 do PSPBuilder. 
PSPO Resumo do Plano do Projeto

Estudante Djalma Domingos da Silva

Instrutor Djalma Domingos da Silva

Linguagem PowerBuilder
Data $12 / 11 / 98$

Programa \# programa_1a

Tempos nas Fases (min)

\section{- Fase}

Planejamento

Projeto

Codificacao

Compilacao

Teste

Total

Defeitos Injetados

\section{Fase}

Planejamento

Projeto

Codificacao

Compilacao

Teste

Total

\section{Defeitos Removidos}

\section{Fase}

Total

Após Desenvolvimento

\begin{tabular}{|c|c|c|c|}
\hline \multirow[t]{6}{*}{ Planejado } & Realizado & Acumulado & Acumulado \% \\
\hline & $\begin{array}{r}61 \\
\end{array}$ & 61 & $25,52 \%$ \\
\hline & 36 & 36 & $15,06 \%$ \\
\hline & 40 & 40 & $16,74 \%$ \\
\hline & 6 & & $2,51 \%$ \\
\hline & 96 & 96 & $40,17 \%$ \\
\hline 120 & 239 & 239 & \\
\hline
\end{tabular}
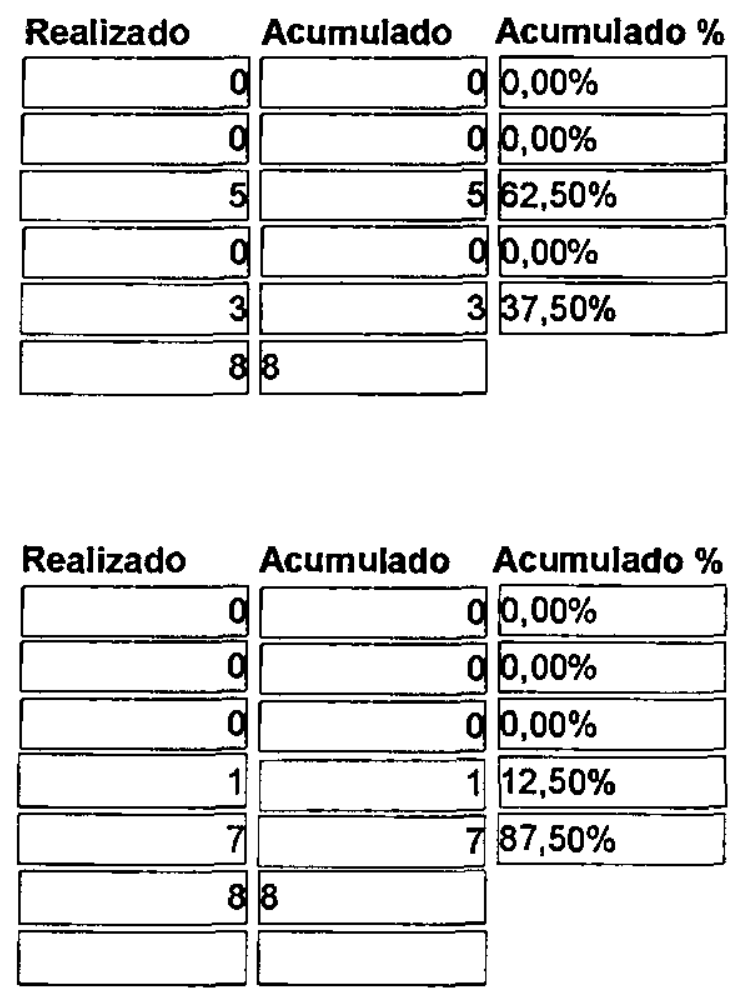


\section{Registro Diário de Tempos}

Estudante Djalma Domingos da Silva

Instrutor Djalma Domingos da Silva

Linguagem PowerBuilder
Término

Tempo

Interrupção(min Líquido(min)
Data $12 / 11 / 98$

Programa \# programa_1a

Programa Cálculo da média e do desvio padrão de um
Inicio

21/10/98 14:39:23 21/10/98 15:32:56 0

21/10/98 15:32:56 $21 / 10 / 98$ 15:41:09 0

$26 / 10 / 98$ 09:05:47 $66 / 10 / 98$ 09:55:06 13

$26 / 10 / 98$ 09:55:06 26/10/98 10:33:21 10

$26 / 10 / 98$ 10:33:21 26/10/98 10:39:20 0

$26 / 10 / 9810: 39: 2026 / 10 / 98$ 10:49:47

$26 / 10 / 98$ 10:49:47 26/10/98 10:54:340

6/10/98 10:54:34 $26 / 10 / 98$ 10:56:51 0

:6/10/98 10:56:51 26/10/98 11:28:50 0

6/10/98 13:41:40 26/10/98 14:19:570

12/11/98 12:08:54 2/11/98 12:11:150

12/11/98 12:11:15 $2 / 11 / 98$ 12:16:59

1/11/98 13:20:38 2/11/98 13:30:03 0

12/11/98 13:48:05 2/11/98 13:55:28 0

2/11/98 13:58:11 2/11/98 13:59:450
53 Planejamento

8 Planejamento

36 Projeto

28 Codificacao

5 Teste

10 Codificacao

4 Compilacao

2 Codificacao

31 Teste

38 Teste

2 Compilacao

5 Teste

$9 \longdiv { \text { Teste } }$

$7 \longdiv { \text { Teste } }$

1 Teste
Comentário

Produção da Declaração de Requisitos do Programa Estimativa de Recursos (Tempo).

Revisar os requisitos e produzir um projeto para atingir os requisitos.

Implementar o projeto.

Testar o programa.

Codificar w_programa_1a

Objeto w_programa_1a.

Aplicação programa_1a.

Teste geral.

Teste geral, continuação.

Para lançar o defeito número 1.

Para lançar os defeitos de números 2 a 8.

Para registrar os defeitos de húmeros 4 a 8.

Registrar defeitos.

Registro de Defeitos. 
Registro Diário de Defeitos

Estudante Djalma Domingos da Silva

Data $12 / 11 / 98$

Instrutor Djalma Domingos da Silva

Programa \# programa_1a

Linguagem PowerBuilder

Programa Cálculo da média e do desvio padrăo de um

\begin{tabular}{|c|c|c|c|}
\hline Número Tipo & Localizado & Injetado & Removidı \\
\hline 1 & 80 Compilacao & Codificacao & Compilaci \\
\hline
\end{tabular}

Início Correção Término Correção Duração Defeito Corrigido

00/00/00 00:00:00

00/00/00 00:00:00

6

Descrição: Incompativel propriedade importfile para o tipo datastore.

6

Início Correção Término Correção Duração Defeito Corrigido

00/00/00 00:00:00

00/00/00 00:00:00

Descrição: Descuido com o Taborder.

Remoção após desenvolv

\begin{tabular}{cc} 
Número Tipo & Localizado \\
\hline nício Correçāo & Término Correçāo Duração \\
\hline $00 / 00 / 0000: 00: 00$ & $00 / 00 / 00$ 00:00:00
\end{tabular}

Descrição: Tamanho insuficiente de sle para digitação.

Injetado

Removidı

Codificacao

Teste

\section{Defeito Corrigido}

2

Remoção após desenvolv

Número Tipo$$
5
$$

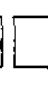

nicio Correção

Término Correçāo

Localizado

Injetado

Removidı

$$
\begin{aligned}
& \text { De } \\
& \hline \\
& \text { In } \\
& 00
\end{aligned}
$$

Descrição: Apresentação do número de casas decimais.

\section{Codificacao \\ Defeito Corrigldo}

Teste

Número Tipo

6

Localizado

50 Teste

Término Correção 00/00/00 00:00:00

Duração

$0 / 00 / 0000 \cdot 00: 00$

escrição: Erro ao acessar objeto extemo propriedade média na linha 8 no evento clicked do objeto

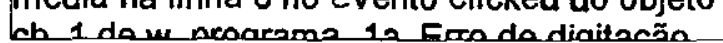

Número Tipo

Localizado

80 Teste

7

7

\begin{tabular}{|l|l|} 
Número Tipo & Localizado \\
\hline nício correção & Término Correção Duração \\
\hline $00 / 00 / 00$ 00:00:00 & $00 / 00 / 00$ 00:00:00 \\
\hline seste
\end{tabular}

Término Correção Duração

\begin{tabular}{|l|l|} 
Número Tipo & Localizado \\
\hline nício correção & Término Correção Duração \\
\hline $00 / 00 / 00$ 00:00:00 & $00 / 00 / 00$ 00:00:00 \\
\hline seste
\end{tabular}$$
\text { lol }
$$

Injetado Removidi

Remoção após desenvolv

Teste —Teste

\section{Defeito Corrigido}

Removid،

Teste Teste

Defeito Corrigido

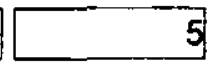

Remoção após desenvolv 


\begin{tabular}{|c|c|c|c|c|}
\hline Número Tipo & \multicolumn{2}{|c|}{ Localizado } & \multirow{2}{*}{$\begin{array}{l}\text { Injetado } \\
\text { Teste }\end{array}$} & \multirow{2}{*}{ Removidi } \\
\hline 8 & 50 Teste & & & \\
\hline nicio Correção & Término Correçăo & Duração & Defeito Corrigido & \\
\hline 00/00/00 00:00:00 & $00 / 00 / 0000: 00: 00$ & 4 & 6 & \\
\hline \multicolumn{3}{|c|}{$\begin{array}{l}\text { escriçăo: Ausência do SetFocus após o tratamento do } \\
\text { erro. }\end{array}$} & \multicolumn{2}{|c|}{ Remoção após desenvolv } \\
\hline Número Tipo & \multicolumn{2}{|c|}{ Localizado } & Injetado & Removidi \\
\hline 9 & \multicolumn{2}{|l|}{50 Teste } & Codificacao & Teste \\
\hline nicio Correçăo & Término Correção & Duração & \multicolumn{2}{|l|}{ Defeito Corrigido } \\
\hline $0 / 00 / 0000: 00: 00$ & $00 / 00 / 0000: 00: 00$ & 6 & 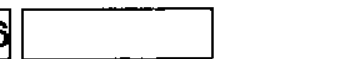 & \\
\hline
\end{tabular}




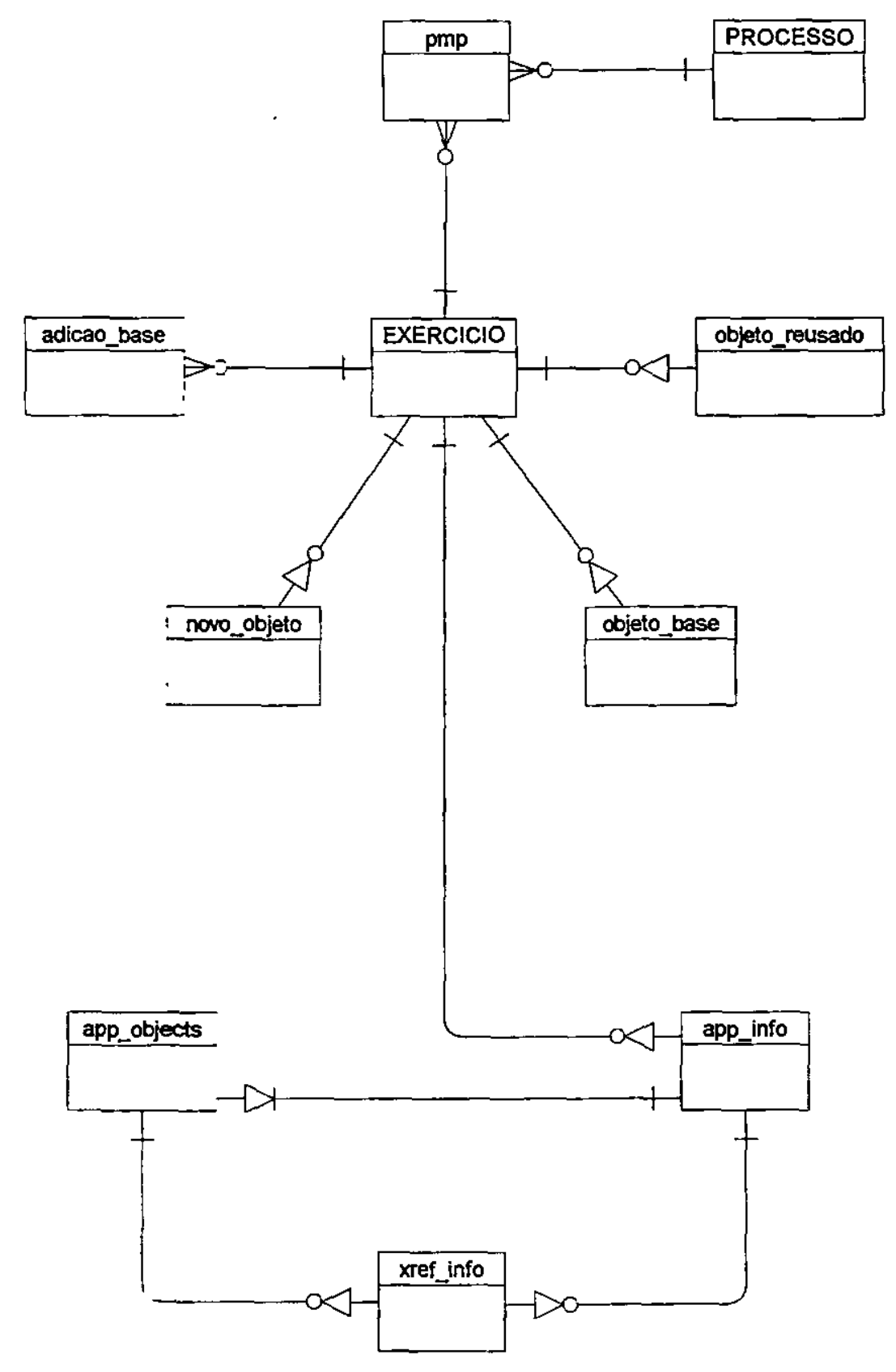

Conceptual Data Model

Project: PSPBuilder

Model : PSPO1

Author: Djalma D. Silva Version: 1.0 $06 / 10 / 98$ 


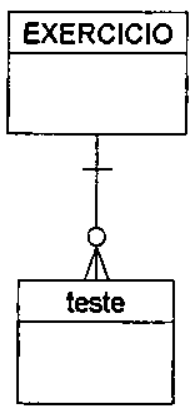

tamanho_relativo

Conceptual Data Model

Project: PSPBuilder

Model : PSP1

\begin{tabular}{|l|l|l|}
\hline Author: Djalma D. Silva & Version: 1.0 & $06 / 10 / 98$ \\
\hline
\end{tabular} 


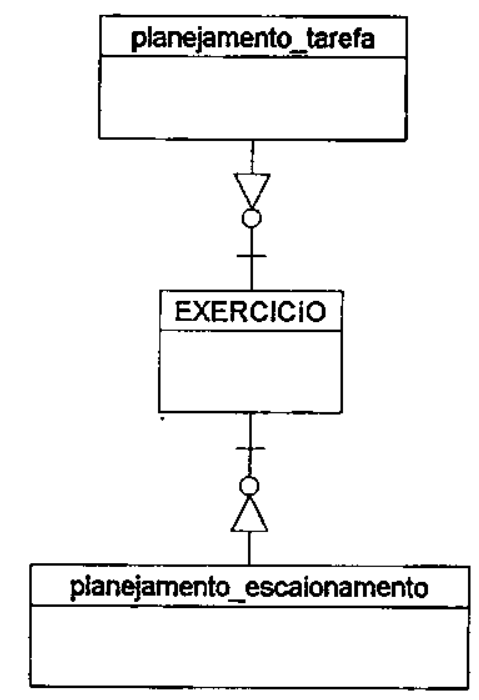

Conceptual Data Modei Project: PSPBuilder

Model : PSP11

\begin{tabular}{|l|l|l|}
\hline Author: Djalma D. Silva & Version: $1.0106 / 1098$ \\
\hline
\end{tabular} 


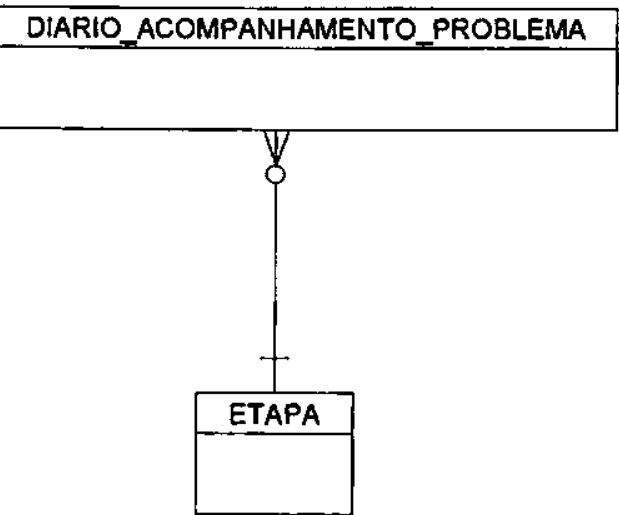

Conceptual Data Mode!

Project: PSPBuilder

Model : PSP3

\begin{tabular}{ll|l|l}
\hline Author: Djalma D. Silva & Version: 1.0 & $15 / 1098$ \\
\hline
\end{tabular} 